\subsection{5 (1) \\ LA-11813-MS}

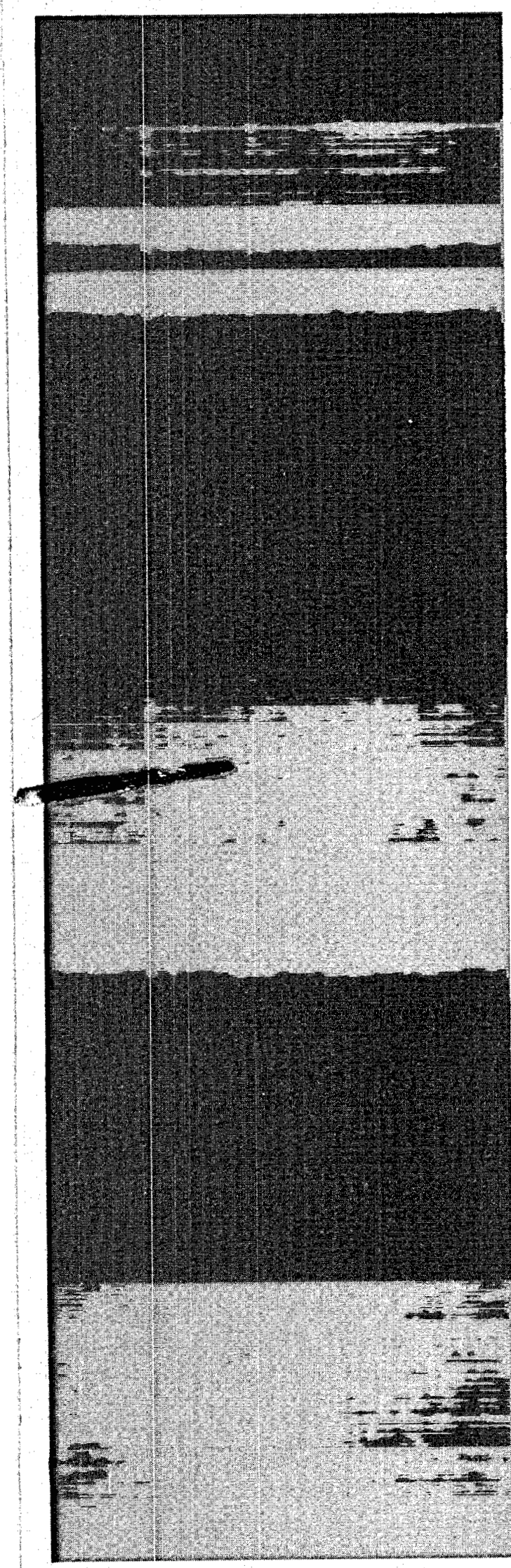

Transient Natural Convection in Heated Inclined Tubes

I NOI SEROFILBS colviti

\section{Los Allamos}

Los Alamos National Laboratory is operated by the University of California for the United States Department of Energy under contract W-7405-ENG-36. 


\section{DISCLAIMER}

Portions of this document may be illegible in electronic image products. Images are produced from the best available original document. 
Prepared by Regina A. Johnson, SST Division

This work was supported by the U.S. Department of Energy, Office of Renewable Energy.
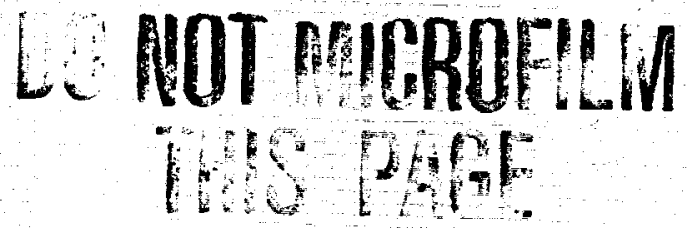

An Affirmative Action/Equal Opportunity Employer

This report was prepared as an account of work sponsored by an agency of the

United States Covernment. Neither the United States Government nor any agency thereof. nor any of their employees, makes any warranty, express or implied, or assumes any legal liability or responsibility for the accuracy, completeness, or usefulness of any information, apparatus, product, or process disclosed, or represents that its use would not infringe privately owned rights. Reference herein to any specific commercial product, process, or seroice by trade name, trademark, manufacturer, or otherwise, does not necessarily constitute or imply its endorsement, recommendation, or favoring by the United States Government or any agency thereof. The views and opinions of authors expressed herein do not necessarily state or reflect those of the United States Gooernment or any agency thereof. 
Transient Natural Convection in Heated Inclined Tubes

Donald M. McEligot*

David A. Denbow**

Hugh D. Murphy

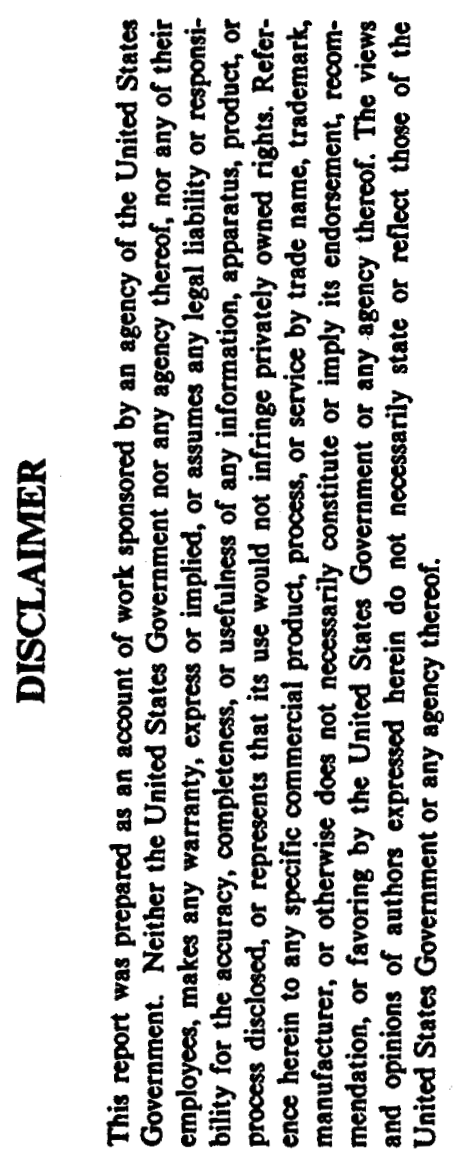

Collaborator at Los Alamos. Westinghouse Electric Corporation, Oceanic Division, Middletown, RI 02840.

* Graduate Research Assistant at Los Alamos. Software AG of North America, Inc., 300 Union Bivd., Lakewood, CO 80228. 



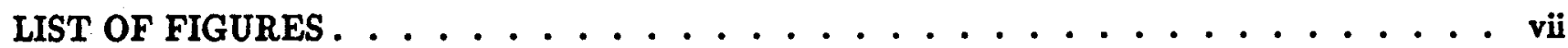

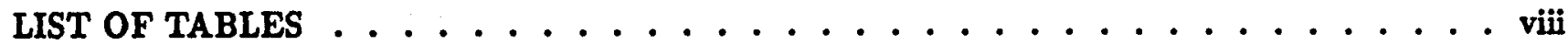
NOMENCLATURE ...................... . ix

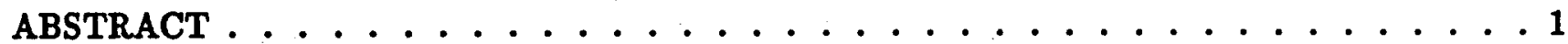

1. INTRODUCTION ......................

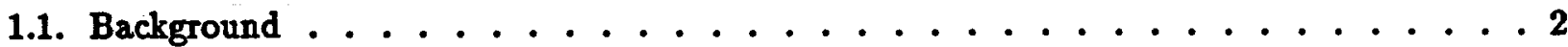

1.2. Goal and Objectives ..................... . . 4

1.3. Previous Work ....................... . . 5

1.3.1. Stability - Vertical Tubes ... . . . . . . . . . . . 5

1.3.2. Flow and Heat Transfer - Vertical Tubes. . . . . . . . . . . . 7

1.3.3. Inclined Tubes . . . . . . . . . . . . . . . . 9

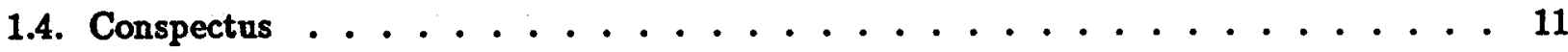

2. ANALYSIS .......................... 11

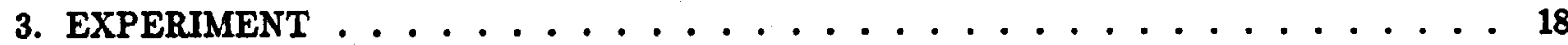

3.1. Apparatus . . . . . . . . . . . . . . . . 18

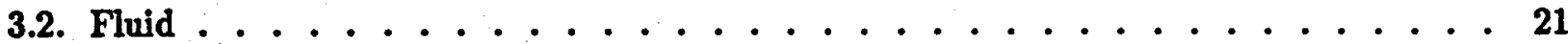

3.3. Thermocouple Calibration . . . . . . . . . . . . . . 22

3.4. Experimental Results . . . . . . . . . . . . . . . . 24

4. NUMERICAL PREDICTIONS . . . . . . . . . . . . . . . . . 30

4.1. Preliminary Survey . . . . . . . . . . . . . . . . . 30

4.2. Code Description . . . . . . . . . . . . . . . . . . 34

4.3. Idealized Geometry . . . . . . . . . . . . . . . . . 38

4.4. Test Cases . . . . . . . . . . . . . . . . . . . . 38

4.4.1. Steady, One-Dimensional Conduction . . . . . . . . . . . 39

4.4.2. Transient Approach to Steady-State, Pure Conduction . . . . . . . . . . . 40

5. COMPARISON BETWEEN EXPERIMENTS AND PREDICTIONS . . . . . . . . . 45

5.1. Numerical Prediction Technique - Time Scales . . . . . . . . . . . . 45

5.2. Numerical Prediction Technique - Steady-State Estimate . . . . . . . . . 4 47

5.3. Effects of Heating Rate and Inclination . . . . . . . . . . . . 48

6. CONCLUDING REMARKS . . . . . . . . . . . . . . 52

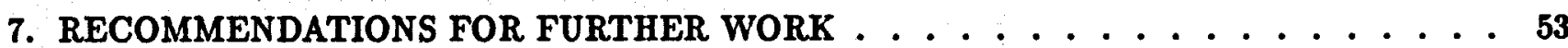
ACKNOWLEDGMENTS .................... 53

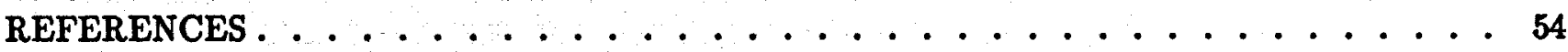
APPENDIX: MEASURED STEADY-STATE TEMPERATURE DISTRIBUTIONS . . . . . 57 



\section{LIST OF FIGURES}

1.1. Schematic diagram of hot dry rock geothermal energy reservoir. . . . . . . . . . . . 3

1.2. Illustration of expected patterns in inclined tube heated from below. . . . . . . . . . 4

2.1. Nomenclature and schematic representation of adiabatic inclined duct. . . . . . . . . 12

2.2. Elemental control volumes for thermal analysis. . . . . . . . . . . . . . . . 13

2.3. Elemental control volumes for flow analysis. . . . . . . . . . . . . . . . . . 14

2.4. Comparison of geometries and nomenclature for end effects. . . . . . . . . . . . . 17

3.1. Schematic diagram of apparatus. . . . . . . . . . . . . . . . . . . 19

3.2. Overall view of test section. . . . . . . . . . . . . . . . . . . . . 20

3.3. Velocity profile with low heating rate in inclined tube, $\phi=31^{\circ}, q_{G}=10 \mathrm{~W}$.

3.4. Indication of flow disturbance by thermocouple during weak convection $\phi=31^{\circ}, q_{G}=10 \mathrm{~W}$. . . . . . . . . . . . . . . . . . . 26

3.5. Evidence of small convective cell typical of multicellular convection. . . . . . . . . . . 27

3.6. Typical temperature distribution as plotted by data acquisition system (a) during transient and (b) steady state. . . . . . . . . . . . . . . . . . . . 28

3.7. Transient response during heating run. . . . . . . . . . . . . . . . . . . 29

4.1. Sketch of isotherms predicted by FLUENT code with vertical, axisymmetric constraints. . . . . . . . . . . . . . . . . . . . 33

4.2. Typical configurations of computational cells (sizes in $\mathrm{cm}$ ). See text for explanation of symbols. . . . . . . . . . . . . . . . . . . . 39

4.3. Transient, approximately one-dimensional conduction in axial direction. . . . . . . . . 41

4.4. Transient, approximately one-dimensional conduction in the radial direction. . . . . . . 43

4.5. Test of TEMPEST predictions versus extended surface (fin) theory. . . . . . . . . . . . 44

5.1. Steady-state predictions compared with measurements. . . . . . . . . . . . . . . . . 49

5.2. Convective heat transfer at cooled end. Measurements compared with numerical predictions. . . . . . . . . . . . . . . . . . 51 


\section{LIST OF TABLES}

3.1. ESTMMATED FLUID PROPERTIES . . . . . . . . . . . . . . . . . . 23

3.2. LOG OF "BEST" DATA . . . . . . . . . . . . . . . . . . . . . . . 27

4.1. SUMMARY OF GENERAL PURPOSE FLUID CODES ca SUMMER 1985 . . . . . . . 31

4.2. FEATURES OF CODES RELATED TO NATURAL CONVECTION IN INCLINED

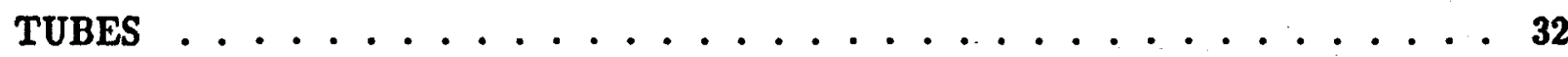

5.1. PROPERTIES EMPLOYED IN THE NUMERICAL SIMULATIONS . . . . . . . . . . 45

A.1. STEADY-STATE TEMPERATURES, LOW POWER, INCLINED . . . . . . . . . . 58

A.2. STEADY-STATE TEMPERATURES, MODERATE POWER, INCLINED . . . . . . . 59

A.3. STEADY-STATE TEMPERATURES, MODERATE POWER, VERTICAL . . . . . . . 60 


\section{NOMENCLATURE}

A area; $A_{c}, A_{c s}$ cross-sectional area

a,b coefficients

Bi Biot number, $h \cdot($ length $) / k_{\text {solid }}$

$\mathrm{C}_{1}$ coefficient, constant

$c_{p} \quad$ specific heat at constant pressure

D diameter; $D_{h}$, hydraulic diameter, $4 A_{c s} / P$

$\dot{E} \quad$ energy flow rate

F force

f friction factor, $2 g_{c} \tau_{w} /\left(\rho V^{2}\right)$

Fo Fourier number, $\alpha \theta / L^{2}$ or $\alpha \theta / r_{w}^{2}$

$g$ acceleration of gravity

$g_{c}$ units conversion factor, e.g., $32.174 \mathrm{lbm} \mathrm{ft} /\left(\mathrm{lbf} \mathrm{sec}^{2}\right)$

Gr Grashof number, defined variously

h convective heat-transfer coefficient

$\mathrm{j}$ index in radial direction

k thermal conductivity; kinetic energy of turbulence; index in axial direction

L length

$\dot{m}$ mass flow rate

$\mathrm{n}$ number of time steps in numerical solution

$\mathrm{Nu}$ Nusselt number, $\mathrm{hD} / \mathrm{k}$

P perimeter

p pressure

Pr Prandtl number, $c_{p} \mu / k$

$Q$ volume flow rate

q heat-transfer rate; $q_{G}$, electrical energy generation rate

$q^{\prime \prime}$ heat flux, $q / A$

$R$ tube radius

r radius (pointwise)

$\mathrm{Ra}$ Rayleigh number, Gr$\cdot \mathrm{Pr}$

Re Reynolds number, $\rho V D_{h} / \nu$

$\mathrm{Ri}$ Richardson number, $\omega_{B V}^{2} /\left(\frac{\partial U}{\partial z}\right)^{2}$

s distance between two fluid parcels (Hines, 1971)

$S_{p} \quad$ spacing

T temperature, absolute

$t$ temperature, relative (e.g., ${ }^{\circ} \mathrm{C}$ )

$\mathrm{U}$ overall heat-transfer coefficient; mean velocity component in streamwise direction

V velocity; volume

W width; mean square of vorticity fluctuations

$\mathrm{x}$ axial distance

y distance from wall

z axial distance (computer code); vertical distance (Hines, 1971)

\section{GREEK LETTERS}

$\alpha \quad$ thermal diffusivity, $k / \rho c_{p} ;$ angle with vertical (Hines, 1971) 
$\beta \quad$ volumetric coefficient of thermal expansion

$\gamma \quad$ specific gravity

$\epsilon$ dissipation of turbulent kinetic energy

$\theta$ time; potential temperature (Hess, 1959)

$\mu \quad$ absolute viscosity

$\nu \quad$ kinetic viscosity, $\mu / \rho$

$\rho$ density

$\tau$ shear stress

$\phi \quad$ angle referred to vertical; azimuthal coordinate

$\omega_{B V}$ Brunt-Väisäla frequency

\section{SUBSCRIPTS}

$\begin{array}{ll}\text { a } & \text { ambient } \\ \text { b } & \text { bottom } \\ \text { c } & \text { cooler } \\ \text { cr } & \text { critical } \\ \text { d } & \text { downflow } \\ \text { E } & \text { based on energy flow rate }(\dot{E}) \\ \text { f } & \text { fluid } \\ \text { fd } & \text { fully developed } \\ \text { G } & \text { generation } \\ \text { h } & \text { hotter } \\ \text { i } & \text { interface } \\ \text { l } & \text { heat loss } \\ \text { m } & \text { modified } \\ \text { N } & \text { last node for region } \\ \text { p } & \text { pressure } \\ \text { s } & \text { surface } \\ \text { t } & \text { top } \\ \text { u } & \text { upflow } \\ \text { w } & \text { wall, surface } \\ \infty & \text { ambient; freestream }\end{array}$




\title{
TRANSIENT NATURAL CONVECTION IN HEATED INCLINED TUBES
}

\author{
by
}

\author{
Donald M. McEligot, David A. Denbow, and Hugh D. Murphy
}

\begin{abstract}
To simulate natural convection flow patterns in directionally drilled wellbores, experiments and analyses were conducted for a circular tube with length-to-diameter (L/D) ratio of 36 at angles of $0^{\circ}, 20^{\circ}$, and $35^{\circ}$ from the vertical. The tube was heated at the bottom and cooled at the top, and the insulation was adjusted so that approximately one- to twothirds of the power dissipated was transferred through the tube wall to the surroundings. An aqueous solution of polyvinyl alcohol was employed as the working fluid in order to obtain low Rayleigh numbers corresponding to conditions in geothermal wellbores. Results were primarily qualitative but were useful in providing insight into the phenomena occurring.

Steady-state temperature distributions were measured for the three orientations and for several heating rates to demonstrate the effects of tube angle and Rayleigh number. Transient measurements of the temperature distribution were obtained during cooling from a higher temperature without a heat source to calibrate the heat losses. With the electrical heat source, temporal data were taken during heating to examine the approach to steady state. Quasi-steady flow conditions were approached rapidly, but the overall time constant of the apparat us was of the order of one-third of a day.

Predictions with the three-dimensional TEMPEST code were first tested by comparison with simple conduction analyses. Comparison with actual data showed good agreement of the predicted temperature levels for the maximum inclination, $35^{\circ}$, and slightly poorer agreement for the other limit, a vertical tube. Trends of temperature level and Nusselt number with heating rate or Rayleigh number were reasonable, but the predicted variation of the end Nusselt number versus inclination was in the opposite direction from the experiment. Further study is needed to understand this latter observation.
\end{abstract}




\section{INTRODUCTION}

\subsection{Background}

Tubes or pipes containing a heated or cooled fiuid are often inclined. In fact, most tubes meant to be either vertical or horizontal are actually inclined from the vertical or horizontal to some extent. In solar collectors with circular central receivers, natural circulation is the mode of flow during shutdowns and during preheating before operation in the power cycle. Single-phase heat pipes can be circular in cross section, and with low flow conditions in a central station power plant or process plant, natural convection can be the dominant mode. Heat transfer through honeycomb structures for suppression of large-scale flows is another application. Several inclined geometries have been suggested for thermal diode applications in passive solar heating (Jones, 1986).

The occurrence of natural convection in a well can affect geothermal gradient measurements and heat-flow estimates. If particularly strong, natural convection may distort reservoir diagnostic tests. For example, convective dispersion of a tracer occurring in the injection and production wells might be falsely attributed to reservoir flow path heterogeneities. Convection is of particular importance in nonvertical wells, because theoretical results (Combarnous, 1978) indicate that stable states cannot exist, i.e., convection is always present, albeit in very weak form for low Rayleigh numbers. Ostrach (1982) has made a comparable statement concerning inclined geometries.

In general, wellbores are not exactly vertical. Further, in the Hot Dry Rock geothermal concept the wellbores are purposely inclined at angles of the order of $30^{\circ}$ from vertical in the deep regions (Smith et al., 1983) as shown in Fig. 1.1. Even in wells not purposely inclined, unintentional deviations up to $10^{\circ}$ from vertical are not unusual. Due to the geothermal gradient resulting in hot water underlying colder, heavier water, the water can be expected to be in a thermally unstable condition when there is no forced flow. Transport of energy and/or particles introduced as tracers then depends on whether significant natural circulation is induced and, if so, its magnitude.

After drilling a wellbore, the disturbance to the pre-existing geothermal environment gradually readjusts - by conduction in the rock and convection in the wellbore - to near steady state. The wellbore acts as a heat pipe, transporting thermal energy upward. However, to date (1984) no method available for calculating the temperature distribution includes treatment of the convection in the tube (Murphy, 1984). Since natural convection in enclosures such as the wellbore can involve a rich variety of flow phenomena (Catton, 1978), it is not a trivial problem.

Figure 1.2 portrays the single antisymmetric convection cell expected, in which one long circulation

loop extends from bottom to top. A radially symmetric cell, which requires more energy to drive and therefore is less probable to occur, would consist of an inner core of rising (or descending) flow surrounded by an annulus of descending (or rising) flow.

The fluid temperature distribution in the more probable antisymmetric case is fully three-dimensional and depends upon the distance, $x$, from the bottom (in the comparable laboratory situation), the radial position, $r$, and the azimuthal position, $\phi$. However, at any distance $x$, one may evaluate an average hot fluid temperature, $T_{h}$, and an average cold fluid temperature, $T_{c}$, by simply averaging over $r$ and $\phi$ the temperature in the upper and lower halves of the tube, respectively. In this manner the hot side and cold side fiuid temperatures can be conveniently characterized for simple hydraulics and heat-transfer computations (Donaldson, 1961).

The right side of Fig. 1.2 shows the expected variation of $T_{h}$ and $T_{c}$ for a related laboratory experiment. In the absence of heat losses from the test section, the only heat transfer taking place is (1) from the heater to the fluid, (2) by exchange from the hot fluid to the cold fluid, and (3) from the 


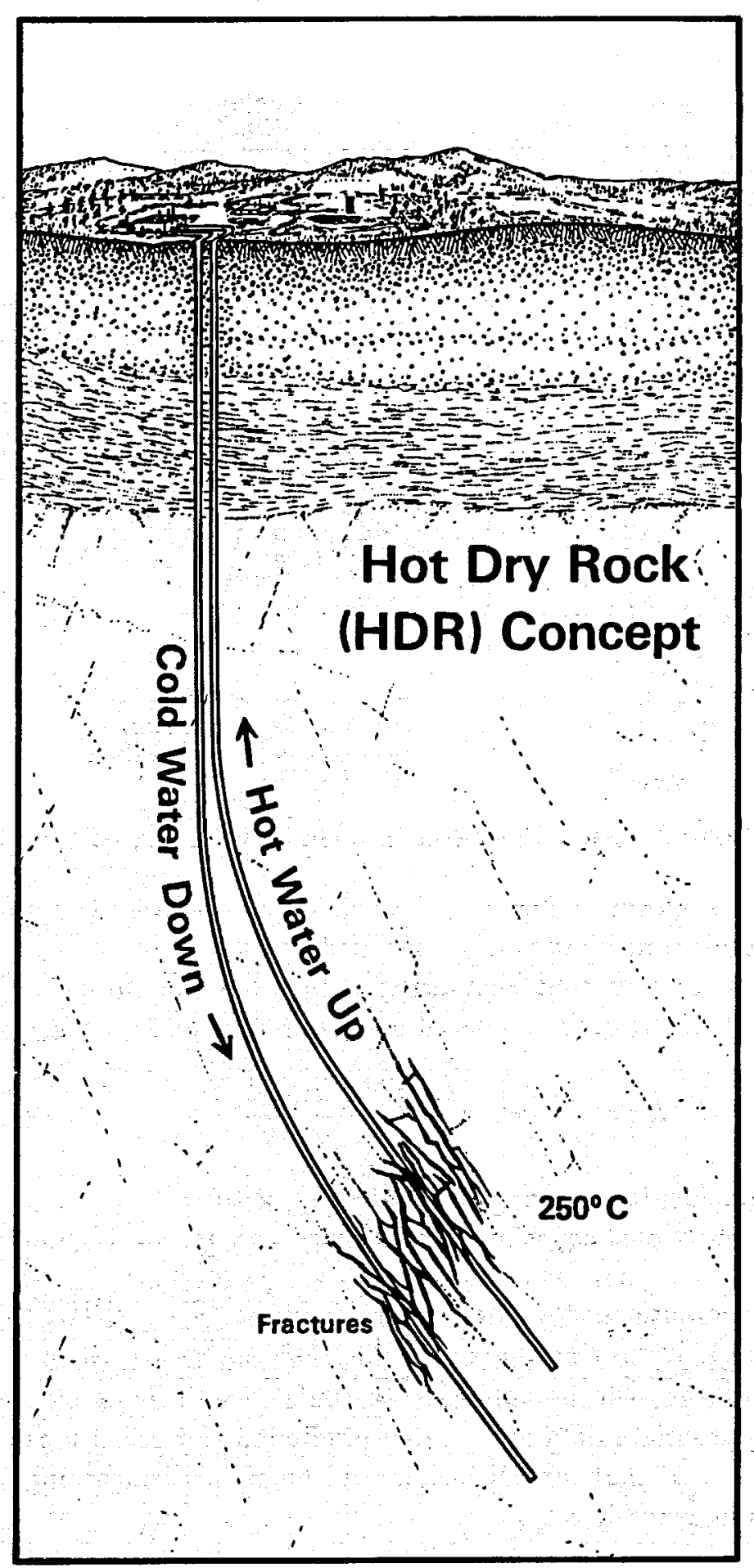

Fig. 1.1. Schematic diagram of hot dry rock geothermal energy reservoir.

fluid to the cooler. The temperature variation is then indicated by the two parallel lines in Fig. 1.2 in which the temperature difference is predicted to be constant, as demonstrated later by the idealized analysis of Section 2.

Typical dimensions in the field experiments of the Hot Dry Rock Project are diameters of 8 in. $(20 \mathrm{~cm})$ and depths of 14,000 ft $(4 \mathrm{~km})$ (Rowley and Carden, 1982). Thus, the aspect ratios of the 


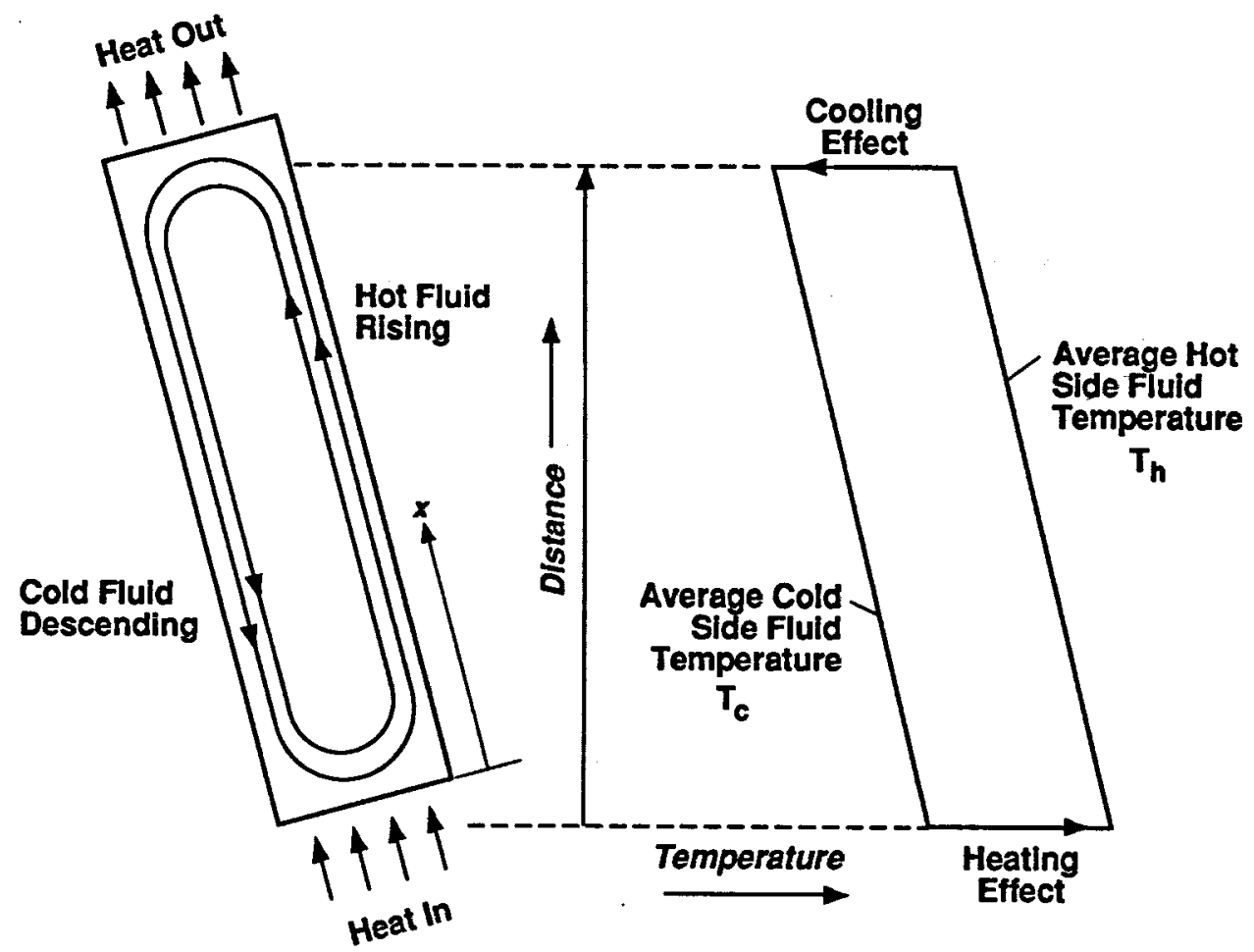

Fig. 1.2. Ilustration of expected patterns in inclined tube heated from below.

holes are effectively infinite. As shown in Fig. 1.1, the axis of the wellbore is approximately vertical near the surface but, by directional drilling, reaches $35^{\circ}$ at depth.

A nondimensional flow parameter that characterizes the thermohydrodynamic problem is the Rayleigh number (or Grashof-Prandtl product) based on bore radius and geothermal gradient.

$$
R a=G r \cdot \operatorname{Pr}=\frac{\rho^{2} g \beta R^{4}}{\mu^{2}} \frac{d t}{d z} \frac{c_{p} \mu}{k} .
$$

For the Hot Dry Rock experiments, it may range from $10^{3}$ to $2 \times 10^{7}$.

Ideally, one would solve the coupled equations of continuity, energy, species, and momentum (probably numerically) with suitable boundary conditions to obtain predictions. It is a three-dimensional transient problem. General computer codes exist for this purpose, e.g., PHOENICS (Rosten et al., 1983), but due to the wide range of flow patterns possible, they must be verified by comparison with appropriate experiments before they can be applied with confidence. One of the implied goals of the present study is to provide appropriate data and related predictions for conditions of practical importance. In the process it is expected that further insight will be gained concerning natural convection in inclined and vertical tubes in general.

\subsection{Goal and Objectives}

Reliable prediction of the transport of tracers in wellbores is the ultimate goal of the overall project. Conceptually, one expects that such predictions can be obtained by numerical solutions of the governing equations if the flow field can be described adequately. With significant buoyancy forces or natural circulation, it would be necessary to solve the thermal energy equation in the process, so prediction of heat transfer to and from the walls of the wellbores would be an intermediate result, important in its own right. 
For the situation without forced flow in the wellbore, a program for the accomplishment of this goal would have the following objectives:

1. Characterize the operational problem in terms of the ranges of governing parameters to be covered.

2. Determine the range of flow regimes to be expected and identify their general features and trends.

3. Derive analyses or adapt existing analyses for the prediction of the velocity and temperature fields for the general problem.

4. Develop an experiment(s) to test the analytical predictions and obtain the appropriate measurements.

5. Apply the analyses to the condition of the experiment and compare the results.

6. Modify the analyses, as necessary, and extend the procedures to solve the species continuity equation to predict the transport of tracers in actual wellbores.

The first objective was partially addressed in the previous section and is further discussed in the following section. In the Hot Dry Rock Geothermal Project, borehole diameters range from 4 in. $(10 \mathrm{~cm})$ to $1 \mathrm{ft}(30 \mathrm{~cm})$, geothermal gradients are in the range $30^{\circ}$ to $100^{\circ} \mathrm{C} / \mathrm{km}\left(0.02^{\circ}\right.$ to $\left.0.05^{\circ} \mathrm{F} / \mathrm{ft}\right)$ with the temperature increasing with depth, wellbore inclination varies from vertical to $35^{\circ}$ depth, and the fiuid is water. Consequently, the Rayleigh number range of interest is about $10^{3}$ to $2 \times 10^{7}$.

As representative experiments are ultimately necessary to accomplish the second objective, this study attacked aspects of the second, third, fourth, and fifth objectives. The general objective of the present work is the development of understanding and predictive methods for flow patterns and temperature and velocity fields inside a long circular tube, heated below and cooled above, for angles from vertical to $35^{\circ}$. This report emphasizes the temperature measurements and predictions. These initial efforts concentrate on the lower end of the Rayleigh number range and on the larger inclination due to the paucity of information avallable in this situation and to obtain preliminary data related to thermal stability in inclined tubes.

\subsection{Previous Work}

For a general background concerning natural convection in enclosures and the related problem of thermosiphons, the reader is referred to the reviews of Ostrach (1982), Buchber et al. (1976), Catton (1978), Japiske (1973), and others. In the following discussion emphasis is on work relating to inclined tubes and long vertical tubes. Studies have concentrated on two general areas: (1) stability and identification of consequent flow patterns and (2) heat-transfer and velocity predictions for specific flow regimes.

1.3.1. Stability - Vertical Tubes. When a long vertical tube is filled with a fluid and subjected to a thermal gradient, such that the temperature increases with depth, the fluid will become unstable (due to density differences arising from thermal expansion) and begin to convect as soon as the gradient reaches a critical value. The fluid instability can be characterized in terms of the Rayleigh number,

$$
R a=\frac{\rho^{2} g \beta R^{4}}{\mu^{2}} \frac{d t}{d z} \frac{c_{p} \mu}{k}=\frac{g \beta R^{4}}{\nu \alpha} \frac{d t}{d z}
$$

As the buoyancy forces are increased, by increasing the thermal gradient, laminar natural circulation will arise at some critical value of the Rayleigh number, $R a_{\mathrm{cr}}$. If the buoyancy driving forces are increased significantly, turbulent convective flow will become the dominant form of heat transport.

With no convection and no heat losses, i.e., subcritical Rayleigh numbers, at steady state a linear . temperature profile occurs along the vertical axis of the tube. As temperature is increased, the enclosed fluid becomes unstable, begins to convect, and a nonlinear profile develops. The onset of fluid motion 
is characterized by a cellular pattern. A single antisymmetric roll cell (fluid motion up on one side of the tube and down the opposite side) is always observed first at the onset of convection since it is the most unstable mode (Heitz and Westwater, 1971). Radial, as well as axial, temperature differences develop in the tube. Different patterns of laminar flow can be produced at elevated Rayleigh numbers up to the transition to turbulent flow. The transition to turbulent flow occurs at high Rayleigh number and is characterized by unstable flow patterns, where random plumes of warm and cold liquid rise and plunge intermittently while intermixing within the bulk fluid.

The problem of characterizing natural convective flow has been studied for a number of differently shaped enclosures (Catton, 1978). Benard (1900) laid the foundations for the theoretical explanation of thermal convection with experiments conducted on a horizontal plate heated from below. He devised the dimensionless grouping of variables, known later as the Rayleigh number, which governed the instability pattern for convective flow and demonstrated that different modes of convective flow correspond to certain ranges of the Rayleigh number.

Hales (1937) analyzed convective patterns within a vertical circular cylindrical tube with a perfectly conducting wall with length much greater than its diameter. Assuming idealized boundary conditions where end effects could be neglected, he derived a modified Rayleigh expression for stability

$$
R a_{c r}=\frac{\rho_{c} g \beta R^{4}}{\rho_{0} \nu \alpha} \frac{d t}{d z}=\text { Constant }
$$

and provided the critical values of $R a_{c r}$ pertaining to the different modes of laminar convection. (In this definition the subscript $o$ denotes the unperturbed state and $c$ represents a reference value [Hales, 1937, Eq. (2.17)\}). Hales aimed his work at characterizing the convective behavior of geysers. Lighthill (1953) later studied natural convection in vertical cylindrical tubes for consideration of cooling turbine blades.

Theoretical evaluations of critical Rayleigh numbers for other situations have been investigated by many authors. Ostroumov (1952) developed a solution as a function of the ratio of the thermal diffusivity of the liquid to the thermal diffusivity of the container material. He applied his solution to the case of antisymmetric flow in a tube with an infinite aspect ratio (L/D) and container material of infinite lateral extent. Catton and Edwards (1967) used relations based on the Malkus-Veronis power integral technique and the concept of an equivalent wave number to estimate critical Rayleigh numbers for convection between parallel horizontal plates heated from below. They found good agreement between theory and experiments.

Diment (1967) measured temperatures as a function of time and depth in a borehole before and after it was filled with water. The hole was $25 \mathrm{~cm}$ in diameter, $340 \mathrm{~m}$ deep, and sealed from influx of groundwater. The measurements revealed that (1) temperature differences between the air-filled hole and the water-filled hole (after dissipation of the water-injected disturbance) did not exceed $0.05^{\circ} \mathrm{C}$ at the same depth; (2) temperatures in the water-filled hole exhibited oscillations at all depths where the temperature increased downward but were stable at the bottom and near the surface where temperature decreased with depth; (3) the temperature oscillations had periods ranging from several minutes to several hours; (4) the amplitudes of the oscillations were several hundredths of a degree, and were roughly proportional to the geothermal gradient near the point of measurement, thus suggesting that the size of cells or eddies was rather constant and that the distance of water movement was no more than several times the inner diameter of the casing; and (5) no oscillations were detected in the air-filled hole, but because the time constants of the instrument were long in an air-filled hole, the possibility of short-period oscillations could not be excluded.

Gretener (1967) presented observational evidence that the fluid in large-diameter wells, such as oil wells, subjected to the normal geothermal gradient is indeed unstable, as predicted by the theory. 
Edwards (1969) presented an analysis showing the effect on the critical Rayleigh number of inserting parallel vertical walls into a fluid heated from below. The walls were rigid (nonslippery) and thermally conducting. Three-dimensional cellular convection between the walls was analyzed to determine the most unstable cell size, and the Rayleigh number for this cell size was calculated. It was shown that the critical Rayleigh number based on either height or spacing could be made as large as desired by decreasing the spacing between vertical wells. At large height-to-spacing ratios with finite conducting walls a new form of Rayleigh number was found to govern the stability. Experimental measurements were reported and compared with the analytical results.

The onset of axisymmetric convection in a cylindrical fluid layer heated from beneath was investigated by Charlson and Sani (1970) for inverse aspect ratios (radius-to-height ratios) from 10 to 80 and for selected smaller aspect ratios. A later communication (Charlson and Sani, 1971) extended that analysis to include the possibility of nonaxisymmetric flows and completed the linear stability analysis of the system.

Convective flow of mercury in a vertical tube was investigated by Verhoeven (1969). He was unable to detect steady antisymmetric flow in his experiment but did measure temperature oscillations laterally along the tube. He concluded that just before the onset of oscillations, an undetected, steady, antisymmetric flow could have been present in the system and that the temperature oscillations were the result of a pulsed flow type of convection. Verhoeven also noted that when the pipe was inclined $20^{\circ}$ from vertical, the critical Rayleigh number for convective flow was lowered significantly, and that temperatures of the fiuid along the top surface of the tube were warmer than the underside.

Heitz and Westwater (1971) conducted an experimental study of heat-transfer modes in water heated from below using test cells of square cross section, $13 \times 13 \mathrm{~mm}(0.5 \times 0.5 \mathrm{in}$.), and heights of 30 to $100 \mathrm{~mm}$ ( 1.3 to 4 in.). Heat transfer was unidirectional and parallel to gravity. Ice was present above the water during certain runs. Three modes of heat transfer, conduction and both laminar and turbulent natural convection, were characterized by temperature profiles, fusion-front velocities and positions, and fluid-flow patterns. Transitions between modes occurred at well-defined critical Rayleigh numbers, which were distinct functions of the aspect ratio of the liquid. The critical values were not affected by the presence of ice, motion of the fusion front, or the temperatures of the warm and cold boundaries, if the Rayleigh number was calculated as they described. The L/D ratio was varied from 0.5 to 8 , and the critical Rayleigh numbers varied from about 1700 to $10^{8}$. They found that experimental values for critical Rayleigh numbers for natural convection of water in square cells agreed with the theoretical calculations of Catton and Edwards (1967).

Olson and Rosenberger (1979) investigated convective instabilities for gaseous $\mathrm{Kr}, \mathrm{Xe}$, and $\mathrm{SiCl}_{4}$ in closed vertical cylinders with conductive walls heated from below. Critical Rayleigh numbers $\mathrm{Ra}_{\mathrm{cr}, \mathrm{i}}$ for the onset of various convective modes (including the onset of marginally stable and periodic flow) were determined with a differential temperature sensing method with high resolution. Flow patterns were deduced from a multiple sensor arrangement. For the three lowest modes $(i=1,2,3)$, good quantitative agreement with linear stability theory was found. Stable oscillatory modes (periodic fluctuations of the mean flow) with a period of approximately $5 \mathrm{~s}$ were found for a relatively narrow range of $\mathrm{Ra}$. The critical Rayleigh number for the onset of oscillatory temperature fluctuations was $1348 \pm 50$ for an aspect ratio (height/radius) of 6.

1.3.2. Flow and Heat Transfer - Vertical Tubes. During the late 1930s numerous deep boreholes were drilled in the search for the gold-bearing reefs of the Witwatersrand system beneath thick covers of younger formations in the southern Transval and adjoining parts of the Orange Free State. For conductivity determinations Krige (1939) selected the two deepest boreholes in which the temperatures had been measured, because of their depth and also because of the exceptionally small amount of change 
in the stratigraphic columns. For the sake of comparison three other boreholes were also included in his discussion.

Lighthill (1953) developed methods for predicting the flow and heat transfer due to free convection in heated vertical tubes, closed at the bottom and opening into a reservoir of cool fluid at the top, the so-called open thermosiphon. These include methods of predicting whether the flow is laminar or turbulent, and whether the boundary layer of heated fluid fills or does not fill the tube, or fills it with a stagnant region near the closed end. Six methods of analysis are needed for the various combinations of these cases. In all cases, the flow depends on a certain modified Grashof number $\mathrm{Gr}_{\mathrm{m}}$ and on $\mathrm{L} / \mathrm{D}$. Laminar flow depends only on the quotient of these quantities, but laminar flow becomes hard to achieve for large $\mathbf{G r}_{\mathbf{m}}$. For large entry disturbances, turbulence is expected for $\mathbf{G r}_{\mathrm{m}}$ greater than about $10^{4}$, and then the shape of the heat-transfer curve changes with $\mathrm{L} / \mathrm{D}$. The theory of the turbulent flow, which is based on an assumption relating the exchange coefficient to its value for ordinary pipe flow, indicates that the effect of turbulence is to decrease heat transfer when the boundary layer fills the tube and to increase it otherwise. This result leads to a peculiar minimum in the heat-transfer curves. The modified Grashof number at which the heat transfer becomes most effective rises steeply with L/D. His theory was extended to apply to a tube closed at both ends, part heated and part cooled.

Ostrach and Thornton (1958) presented an analysis of laminar natural-convection flow and heat transfer in a closed-end tube with a linear wall temperature and large but finite length-radius ratio. It was found that for a given relation between the two physical parameters of the problem, the flow will fill the entire tube length. Representative velocity and temperature profiles were presented to show the effects of the parameters on the flow and heat transfer.

Donaldson (1961) apparently was first to construct theoretical models pertaining to the correlation of wellbore fluid temperature with surrounding ground temperature. He conducted experiments with radially symmetric flow (fluid flow down in the center and up along the sides) in a vertical cylindrical tube heated such that a linear temperature gradient was produced along the tube. The temperature and velocity distributions in the pipe were found to be dependent on a modified Rayleigh number $R_{\mathrm{m}}$. Experiments conducted at values of $\mathrm{Ra}_{\mathrm{m}}$ between 90 and 30,000 agreed with theoretical predictions for values of $\mathrm{Ra}_{\mathrm{m}}$ below 300 and above 3000 . Negative temperature gradients occurring along the axis for values of $\mathrm{Ra}_{\mathrm{m}}$ between 700 and 950 indicated that in this range the flow cannot be radially symmetric. This nonsymmetric flow would develop first as $\mathrm{Ra}_{\mathrm{m}}$ was increased from zero, and it was suggested that the agreement between the experimental and theoretical results for $\mathrm{Ra}_{\mathrm{m}}<300$ shows that the critical value of $\mathrm{Ra}_{\mathrm{m}}$ for the nonsymmetric flow does not differ greatly from the value obtained theoretically for the symmetric regime. Presumably, it is at values of $\mathrm{Ra}_{\mathrm{m}}$ of 3000 and above that the flow takes an axially symmetric form. This higher range is appropriate to geothermal boreholes in New Zealand.

Hasegawa et al. (1963) described two sorts of experimental studies of free convection heat transfer in an open thermosiphon tube. One was carried out using an apparatus with a rectangular passage for observation of the flow pattern, and the other gave the exact heat-transfer data, including the turbulent region, using two sets of apparatus with a circular passage. On the basis of such studies, the heat-transfer mechanisms of thermosiphons in both laminar and turbulent regions were explained. In the laminar region experimental data agreed closely with an analytical solution. As for the occurrence of turbulence, they felt it possibly originated at a boundary between upflow and downflow, where only the downflow was disturbed at first, and there the heat-transfer data were little different from those in the laminar region. When turbulence occurred in their impeded flow regime, however, it spread all over the tube at once, affecting heat-transfer data considerably, but the data could be correlated by using the Prandtl number and L/D parameters. Finally, a correlating equation for heat transfer in an open thermosiphon tube was derived. 
Catton and Edwards (1967) presented experiments giving the Rayleigh number at which convection was initiated in a closed cell and the Nusselt number versus Rayleigh number relationship, which prevails afterwards. Over 700 data points were obtained for 2 types of cells heated from below, one a phenolic-fiberglass hexcell of low thermal conductivity and the other an aluminum hexcell of high thermal conductivity. Relations based upon the Malkus-Veronis power integral technique and a concept of an equivalent wave number were shown to give good correlation of the experimental data for both the low and high conductivity side walls.

Verhoeven (1969) made very precise temperature measurements on a vertical circular column of liquid mercury, and also on a mercury-zinc alloy, heated from below. In both pure mercury and the alloy, two types of temperature oscillations, indicating two modes of time-dependent fluid flow, were observed. The first oscillatory mode appeared at a Rayleigh number $10 \%$ higher than the critical Rayleigh number predicted by linear stability theory for the onset of fluid flow. At higher Rayleigh numbers, this mode disappeared and the second oscillatory mode, having a shorter period, began at Rayleigh numbers $39 \%$ above the critical value. Both types of temperature oscillations are consistent with a pulsed mode of fluid flow. Attempts to detect the predicted steady, antisymmetric flow at the onset of fluid motion by means of lateral temperature measurements were unsuccessful.

Edwards and Catton (1969) also used the Malkus-Veronis power integral technique to predict heattransfer rates in fluids contained in vertical right cylinders heated on a horizontal bottom and cooled on a horizontal top end. Results were obtained for cells with either thermally insulating or conducting sidewalls. Closed-form relations were given for Nusselt numbers in terms of Rayleigh number based on cell height and on an "adjusted wave-number," which depends on height-to-diameter ratio for circular cylinders and height-to-side ratios for square cylinders. Comparisons between the predictions and previously reported data were shown.

Donaldson (1970) demonstrated that most physical characteristics of water, steam, and watersteam geothermal systems may be matched in a model consisting of two vertical permeable channels interconnected at the bottom. One of the channels will, in effect, act as the system fluid reservoir while the other is the heated channel that feeds the hot springs and fumaroles that define the geothermal field. The dimensions of the heated channel, its permeability, the temperature at depth (or the heat flux), and the resistance of the connecting strata were found to play an important role in setting the form of the geothermal field. He discussed some typical fields briefiy. with the aid of the model.

1.3.3. Inclined Tubes. Flow stability and heat transfer for natural convection inside inclined tubes have not been studied frequently. Verhoeven (1969) reported observations for a pipe inclined $20^{\circ}$ from the vertical and noted that the critical Rayleigh number for convective flow was lowered significantly, and that temperatures of the fluid along the top surface of the tube were warmer than the underside, as indicated in Fig. 1.2. Emphasis was on stably stratified fluids at large Rayleigh numbers. The experiments reported showed extreme sensitivity to inclination near the horizontal where a change of one degree in angle could cause a tenfold change in axial heat transport.

Trefethen (1970) reported natural convection inside inclined tubes. He also found his Nusselt number to vary severely for slight changes in inclination near horizontal. In related studies Hartnett et al. (1959), Leslie (1959), and Martin (1959) examined the effect of tilting open thermosiphons, simulating to some extent the Coriolis accelerations arising from rotation in cooling cavities inside rotor blades of gas turbines.

Other than flow inside tubes, a number of inclined geometries have been examined, particularly for solar collector applications. Al-Arabi and Salman (1980) investigated laminar natural-convection heat transfer from the outside surface of a uniformly heated cylinder (constant heat flux condition) 
experimentally at different angles of inclination of the cylinder. General equations for the effect of inclination were determined for both the local and the average heat transfer.

Ozoe et al. (1981) experimentally and theoretically studied natural convection in an inclined annular space, heated and cooled on the end plates and thermally insulated on the concentric cylinder walls. As the heated surface was inclined from the lower horizontal position to an upper horizontal position, the mean Nusselt number at first decreased, then increased, and finally decreased to unity as the mode of circulation switched from a symmetrical array of roll cells to distorted and oblique roll cells to a single circulation. The flow pattern was portrayed with streaklines computed numerically with a three-dimensional model and also with photographs.

Takata et al. (1984) described analytical and experimental work on natural convection in an inclined cylindrical annulus formed by heated inner and cooled outer cylinders. Three-dimensional governing equations were transformed into finite-difference equations and were solved numerically using a successive over-relaxation procedure. The three-dimensional structure of the fluid flow and temperature distributions as well as Nusselt numbers were obtained, and the effect of inclination on them was examined. A flow visualization experiment using a tracer technique was conducted, and photographs of streaklines confirmed the three-dimensional flow structure predicted analytically.

Chung and Trefethen (1982) numerically examined natural convection within a vertical stack of long, inclined parallelogrammic cavities. An explicit, finite difference scheme for two-dimensional flow was formulated along with appropriate boundary conditions. Nusselt numbers were computed for several geometries, Prandtl numbers, Grashof numbers, and conductances between cavities. These analytical results provide a basis for comparison with data that have been obtained with 'one-way' heating walls. The procedure also provides a basis for estimating the potential of such asymmetrical insulating structures; one conclusion is that conduction between cavities considerably reduces the asymmetry attainable in overall Nusselt number.

For heat transfer in inclined rectangular enclosures, the extensive experiments of el Sherbiny et al. (1982) and the reviews of Buchberg et al. (1976) and Catton (1978) should be consulted. The noninclined geometry most relevant to the inclined circular tube is probably the horizontal cylinder with the two ends operated at different temperatures. This situation yields flow patterns that show the general features observed in the present work.

Kimura and Bejan (1980a) reported a finite difference solution for the natural counterflow generated in a horizontal adiabatic duct with different end temperatures. Ducts with circular and rectangular cross section were considered. The natural counterflow was modeled as fully developed. The numerical results demonstrated that the flow consists of a strong axial counterflow superimposed on four secondary eddies situated in the four quadrants of the cross section. The numerical results were also used to assess the applicability of analytical predictions for the flow field in ducts with rectangular cross section.

Kimura and Bejan (1980b) experimentally studied the phenomenon of natural convection in a horizontal pipe with different end temperatures in a cylindrical cavity with $L / D \simeq 9$. The Rayleigh number based on diameter was in the range $10^{8}<\mathrm{Ra}<10^{10}$. It was concluded that in this range the natural convection mechanism departs considerably from the pattern known in the limit $\mathrm{Ra} \rightarrow 0$. Specifically, the end-to-end heat transfer is affected via two thin horizontal jets, the upper (warm) jet proceeding along the top of the cylinder toward the cold end and the lower (cold) jet advancing along the bottom in the opposite direction. The region sandwiched between the two jets is filled with nearly stagnant fluid. In this region the temperature varies linearly with depth. In each vertical cross section, the top-bottom temperature difference is of the same order of magnitude as the end-to-end 
temperature difference. The Nusselt number for end-to-end heat transfer was shown to vary weakly with the Rayleigh number.

Mixed convection (i.e., forced flow with significant buoyancy forces induced) has been studied for inclined tubes. Cheng and Hong (1972a, 1972b) applied a boundary vorticity technique to analyze fully developed laminar flow in an inclined tube.

Abdulmeguid and Spalding (1979) tested the $k-\epsilon$ turbulence model in a three-dimensional numerical analysis for mixed convection in horizontal and vertical tubes; they reported reasonable agreement with Russian data for these situations. In addition, they presented predictions for flow in inclined tubes to demonstrate the trends expected.

\subsection{Conspectus}

Although heat transfer within the tube walls must be considered for geothermal applications and is significant in the experiments conducted, it is instructive first to examine the limiting case of adiabatic inclined tubes. This situation is examined in Section 2 by means of simple, approximate analyses. Section 3 then presents the experiment and typical results. The three-dimensional transient numerical analysis is described in Section 4. Since a very coarse grid is used to represent the geometry in this section, several confidence tests are also presented showing surprisingly good agreement with classical analyses. Section 5 examines the numerical prediction technique further and then compares the experimental measurements with predictions calculated for the same conditions. Finally, Sections 6 and 7 provide concluding remarks and recommendations for further work.

\section{ANALYSIS}

The full description of the flow requires the solution of the Navier-Stokes equations for three velocity components plus the continuity and energy equations that are coupled to them (Schlichting, 1968). Although this system can be solved numerically by several existing computer codes (Johnson and Torok, 1985), it is instructive and useful to consider simpler approximations first.

Flow in a long tube without heat loss is comparable to a closed thermosiphon loop where there is heat transfer between a riser and a downcomer, or a regenerative heat exchanger, as sketched in Fig. 2.1. The tube can have any cross-sectional shape that is vertically symmetric. Warm fluid rises on the upper side while the cooler fluid sinks along the lower side. This type of approach is related to "pipe flow" models applied to describe the gross features of entire geothermal areas (Einarsson, 1942; Donaldson, 1968) and solar thermosiphons (Zvirin et al., 1977; Mertol et al., 1981) with the exception that in the present treatment there is direct thermal communication between the riser and downcomer as in a countercurrent heat exchanger (Kays and London, 1964). It could also be considered to be related to the approach of Batchelor (1954) for vertical parallel surfaces at different temperatures in the limiting case, $\frac{L}{D} \rightarrow \infty$.

For the purpose of this part of the analysis, the following idealizations are made:

1. Laminar, steady flow.

2. The duct is sufficiently long that the flow is effectively parallel to the walls, i.e., internal boundary layer approximation.

3. Fluid properties are constant except for density (Boussinesq approximation).

4. Away from the ends, the axial pressure gradient $\frac{d p}{d x}$ is the same in both the hot and the cool leg at a given axial position, $x$. [This idealization is related to No. 2 ; if $\left(\frac{d p}{d x}\right)_{h}$ were significantly 


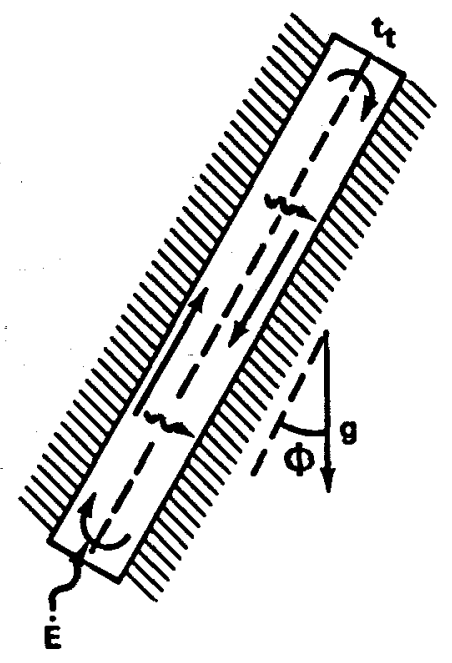

(a)

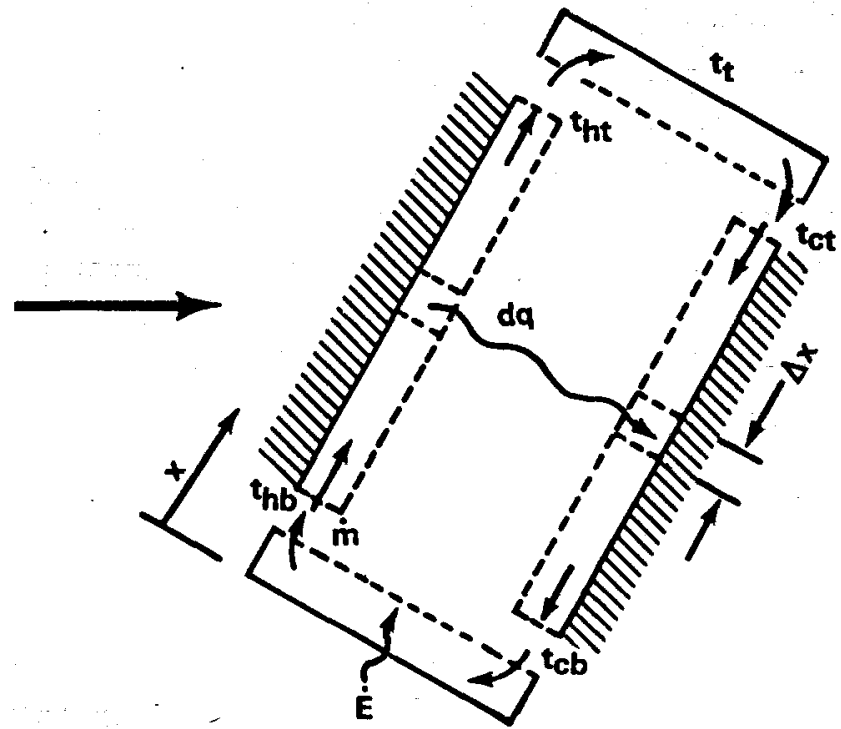

(b)

Fig. 2.1. Nomenclature and schematic representation of adiabatic inclined duct.

different from $\left(\frac{d p}{d x}\right)_{c}$, a nonhydrostatic gradient could form in the transverse direction and induce significant crossflow.]

5. Constant flow cross sections in both directions, up and down.

6. Tube walls are adiabatic.

7. For the approximate momentum equation, the cross-sectional areas occupied by the upflow and downflow streams are equal.

8. In the upflow and downflow regions away from the ends, the flow is considered to be fully established.

9. Negligible streamwise conduction.

Boundary conditions are an imposed heat-transfer rate $\dot{E}$ at the lower end and a specified temperature $t_{t}$ at the upper end.

Continuity requires that the mass flow rate $\dot{m}$ be the same through each sub-control-volume.

An overall energy balance, say on the control volume of Fig. 2.1 (a), demonstrates that the heattransfer rate out the top end would equal the power in, $\dot{E}$. Then an energy balance on the sub-controlvolume at either end yields

$$
\dot{E}=\dot{m} c_{p}\left(t_{h b}-t_{c b}\right)=\dot{m} c_{p}\left(t_{h t}-t_{c t}\right)
$$

or $t_{h b}-t_{c b}=t_{h t}-t_{c t}=\frac{\dot{E}}{\dot{m}_{c p}}$, where the temperatures are treated as local bulk temperatures for the particular streams.

In the region away from the ends, one can take an elemental slice of length $\Delta x$, Fig. 2.2. For the common surface between the two subvolumes formed, the heat-transfer rates must be equal; the related energy balances can then be represented as

$$
-\frac{d \dot{E}_{h}}{d x} \Delta x=d q=-\frac{d \dot{E}_{c}}{d x} \Delta x
$$


or, since the properties are treated as constant, $\left(\frac{d_{\text {th }}}{d x}\right)=\left(\frac{d_{\text {ic }}}{d x}\right)$. Therefore, the temperature difference is predicted to remain constant along the tube as

$$
t_{h}-t_{c}=t_{h b}-t_{c b}=\frac{\dot{E}}{\dot{m} c_{p}}
$$

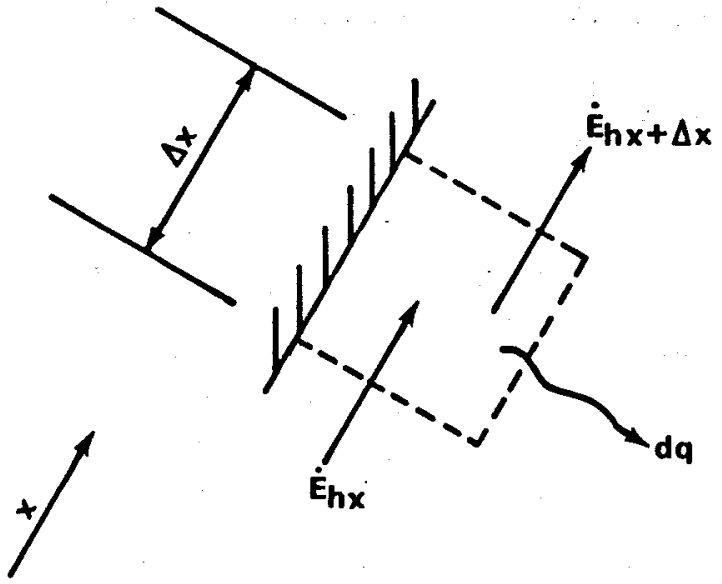

HOT FLUID

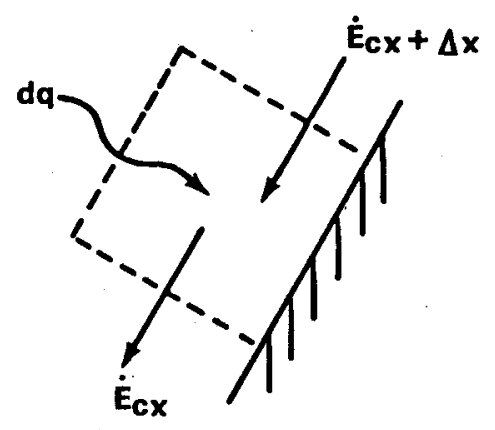

COLD FLUID

Fig. 2.2. Elemental control volumes for thermal analysis.

At any section the heat-transfer rate between the two streams can be represented, as in a countercurrent heat exchanger, as

$$
d q=U P_{i} \Delta x\left(t_{h}-t_{c}\right)
$$

where $P_{i}$ is the perimeter of the interface between the hot and cold fluid. For a circular tube with half the cross section occupied by each portion, $P_{i}$ would be the diameter $D$; or $P_{i}=W$ for a wide duct. The overall heat-transfer coefficient $U$ can be deduced by considering the thermal resistance from the hot fluid to the interface and from the interface to the cooler fluid, i.e., $U=\left(\frac{1}{h_{h}}+\frac{1}{h_{c}}\right)^{-1}$. If the conditions can be considered fully established, $U$ can be taken as constant, giving

$$
\frac{d t}{d x}=-\frac{d q}{(\Delta x) \dot{m} c_{p}}=-\frac{U P_{i}}{\dot{m} c_{p}}\left(t_{h}-t_{c}\right)=\text { constant }
$$

That is, the temperature decrease with $x$ would be linear. Since the flow is considered laminar, the heat-transfer coefficients can often be estimated from results in the compendium by Shah and London (1978).

Since the wall shear stress is a function of the flow rate, the mass flow rate induced by the heating can be determined by applying the momentum equation and idealization No. 7. The elemental control volumes are as sketched in Fig. 2.3. From idealization No. 8, there is no change of momentum in the $x$ direction, i.e., no acceleration, so Newton's Second Law of Motion leads to

$$
F_{\mathrm{p}}-F_{g}-F_{\tau h}-F_{\tau i}-F_{p+\Delta p}=0 \quad \text { Hot fluid (up) }
$$

and

$$
F_{p}+F_{\tau i}+F_{\tau c}-F_{g}-F_{p+\Delta p}=0 \text { Cold fluid (down). }
$$


Since the velocity at the interface is zero by idealization No. 7, for laminar flow each stream can be approximated as flow in a duct where the interface can be taken as one of the walls. Then the shear forces can be evaluated from the friction factor results of Shah and London (1978) as

$$
F_{\tau h}+F_{\tau i}=\tau_{w h} P_{h} \Delta x=f \cdot \frac{\rho V_{h}^{2}}{2 g_{c}} P_{h} \Delta x
$$

and a comparable equation for the cold stream. The average friction factor is of the form $f=\frac{C_{1}}{R e_{h}}$ where

$$
R e_{h}=\frac{\rho V D_{h h}}{\mu}=\frac{4 \dot{m}}{P_{h} \mu}
$$
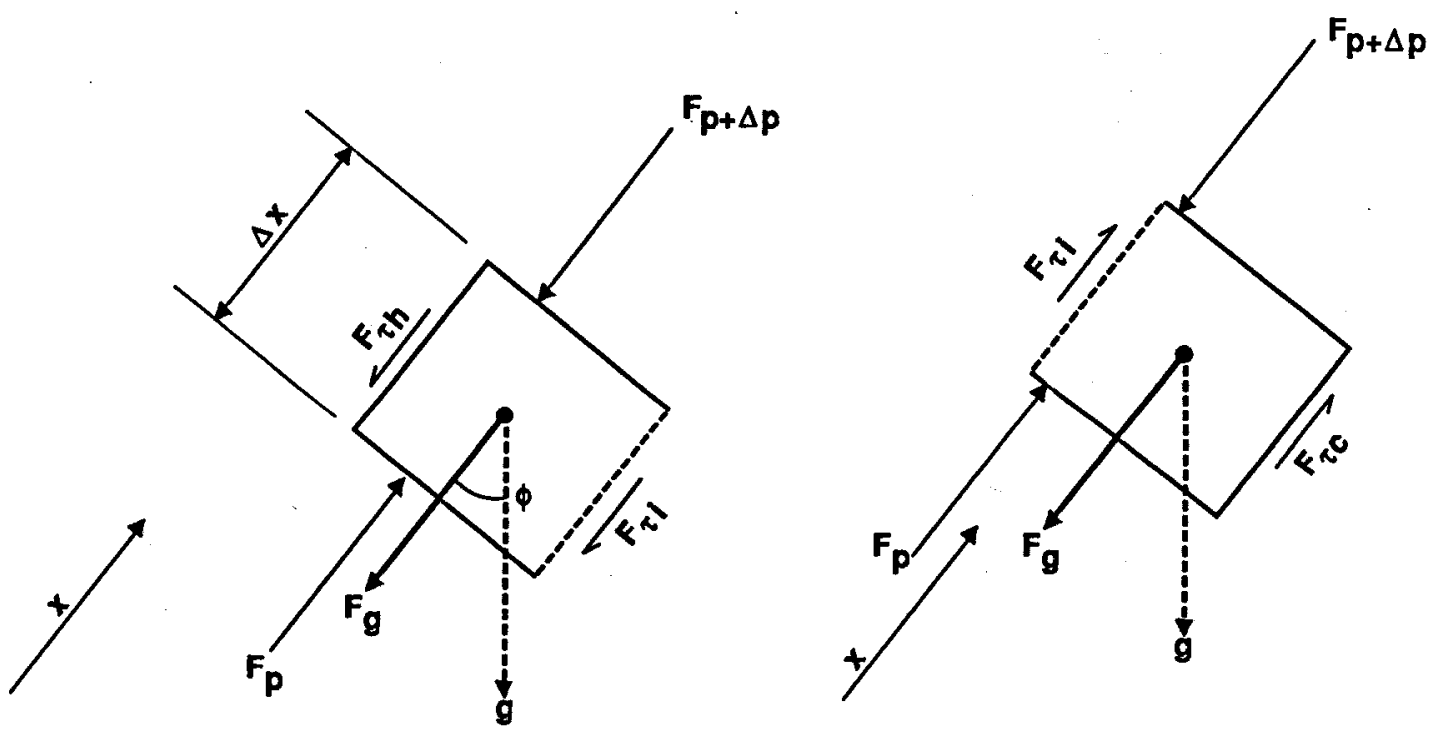

Hot Fluid (upflow)

\section{Cold Fluid (downflow)}

Fig. 2.3. Elemental control volumes for flow analysis.

The two momentum equations can be written as

and

$$
\frac{d p}{d x}=-\rho_{u} \frac{g}{g_{c}} \cos \phi-\frac{\tau_{w h} P_{h}}{A_{c h}} \quad \text { Upflow }
$$

$$
\frac{d p}{d x}=-\rho_{d} \frac{g}{g_{c}} \cos \phi+\frac{\tau_{w c} P_{c}}{A_{c c}} \quad \text { Downflow. }
$$

If one adopts idealization No. 7 , then $A_{c c}=A_{c h}$ and, if it is a symmetric geometry as a tube or duct, $P_{c}=P_{h}$ and $\tau_{w h}=\tau_{w c}$. (If nonsymmetric, choosing $A_{c c}=A_{c h}$ would determine the perimeters and shear stresses, but the assumption might not be good.)

For the symmetric case, equating the pressure gradients gives

$$
\frac{2 \tau_{w} P_{h}}{A_{h}}=\left(\rho_{d}-\rho_{u}\right) \frac{g}{g_{c}} \cos \phi=\rho \beta\left(t_{h}-t_{c}\right) \frac{g}{g_{c}} \cos \phi .
$$


Substituting for $\tau_{w}$ and $\left(t_{h}-t_{c}\right)$ and then rearranging yields

$$
\dot{m}^{2}=\frac{4 \rho^{2} \beta g \dot{E}}{C_{1} c_{p} \mu} \cdot \frac{A_{c h}^{3}}{P_{h}^{2}} \cos \phi
$$

Therefore, for a given situation, the mass flow rate would vary as $\sqrt{\dot{E}}$. If the idealizations or approximations are reasonable, increasing $\dot{E}$ would increase $\dot{m}$ until the interfacial shear induced a KelvinHelmholtz instability and the flow would probably break up into cells and/or turbulence. When the tube is inclined, it is likely that considerable kinetic energy must be in the streams to overcome the stable situation of warmer fluid above cooler in the transverse direction.

Once known, $\dot{m}$ can be substituted in the relation for the temperature difference to obtain

$$
t_{u}-t_{d}=t_{h}-t_{c}=\frac{\dot{E}}{\dot{m} c_{p}}=\frac{P_{h}}{\rho A_{c h}} \sqrt{\frac{C_{1}}{4} \frac{\mu}{g \beta c_{p}} \frac{\dot{E}}{A_{c h} \cos \phi}}
$$

so the temperature difference between the two streams varies as $\sqrt{\dot{E}}$. However, since $\dot{m}$ also varies as $\sqrt{\dot{E}}$, the streamwise temperature gradient

$$
\frac{d t_{c}}{d x}=\frac{d t_{h}}{d x}=-\frac{U P_{i}}{\dot{m} c_{p}}\left(t_{h}-t_{c}\right)=-\frac{U P_{i} \dot{E}}{\dot{m}^{2} c_{p}^{2}} \sim \frac{U P_{i}}{c_{p}}
$$

is predicted, surprisingly, to be independent of the energy transfer rate. It can be represented by

$$
\frac{d t_{c}}{d x}=\frac{d t_{h}}{d x}=-\frac{N u_{f d} C_{1}}{32} \cdot \frac{k \mu}{\rho^{2} c_{p} \beta g} \frac{P_{i} P_{h}^{3}}{A_{c h}^{4}} \frac{1}{\cos \phi}
$$

where $N u_{f d}$, the fully developed Nusselt number for forced convection in a half-duct with one adiabatic wall, is a constant for a specified geometry in laminar flow. The major temperature gradient or thermal resistance in the streamwise direction is expected to be at the ends, which are not treated here.

The above results can be rephrased in terms of nondimensional parameters. The nondimensional temperature gradient can be written as a Rayleigh number,

$$
R a_{d t / d x}=\frac{\rho^{2} g \beta D_{h h}^{4}\left(d t_{u} / d x\right)}{\mu^{2}} \cdot \frac{\mu c_{p}}{k}=-\frac{8 N u_{f d} C_{1}\left(P_{i} / P_{h}\right)}{\cos \phi},
$$

which would be a constant for a fixed geometry and angle. This definition can be seen to be the same as Eq. (1-1) except for a geometric factor. The mass flow rate can be described as a Reynolds number,

$$
R e^{2}=\left(\frac{\dot{m} D_{h h}}{A_{c h} \mu}\right)^{2}=\frac{1}{4 C_{1}}\left(\frac{\rho^{2} g \beta D_{h h}^{4}\left(\dot{E}_{t}^{\prime \prime} / k\right)}{\mu^{2}}\right)\left(\frac{k}{\mu c_{p}}\right)\left(\frac{A_{c t}}{A_{c h}}\right) \cos \phi
$$

or

$$
R e^{2}=\frac{1}{4 C_{1}} \frac{G r_{E}}{\operatorname{Pr}} \frac{A_{c t}}{A_{c h}} \cos \phi
$$

where $\dot{E}_{t}^{\prime \prime}=\dot{E} / A_{c t}$ is based on the total cross-sectional area instead of that of the stream.

Trefethen (1970) defines a Nusselt number as the ratio of the total actual heat-transfer rate to the conduction heat-transfer rate for the same axial temperature gradient. For $\dot{E} \gg-k A_{c t} \frac{d t}{d x}$, it may be written as

$$
\frac{\dot{E}}{-k A_{c t}\left(\frac{d t}{d x}\right)}=\frac{1}{8 N u_{f d} C_{1}}\left(\frac{\rho^{2} g \beta D_{h h}^{4}\left(\dot{E}_{t}^{\prime \prime} / k\right)}{\mu^{2}}\right)\left(\frac{c_{p} \mu}{k}\right)\left(\frac{P_{h}}{P_{i}}\right) \cos \phi
$$


or

$$
\frac{\dot{E}}{-k A_{\text {et }}\left(\frac{d t}{d x}\right)}=\frac{1}{8 N u_{f d} C_{1}} \cdot G r_{E} \cdot \operatorname{Pr} \cdot\left(\frac{P_{h}}{P_{i}}\right) \cos \phi .
$$

It can also be seen that this relation may be written in terms of $\left(R e \cdot P_{r}\right)^{2}$ if desired.

In the context of the present study, the ratio $\frac{E}{\left(-k A_{c t}\left(\frac{d x}{d x}\right)\right)}$ is a measure of the importance of the induced natural convection relative to the pure conduction that would occur otherwise. One might say that natural convection becomes significant when the ratio is greater than about 0.1 , but the analysis itself is not reasonable until the ratio reaches about 10 , if then. (The reader is reminded of the dependence of these results on some of the idealizations, particularly No. 7 - equality of cross-sectional areas, which may not be reasonable.)

In summary, for the idealizations assumed, the effects of increasing the heating rate $\dot{E}$ are

a) to increase $\dot{m}$ as $\sqrt{\dot{E}}$,

b) to increase $\left(t_{h}-t_{c}\right)$ as $\sqrt{\dot{E}}$, and

c) to leave the streamwise temperature gradient constant.

The quantity $G r_{E} \operatorname{Pr}\left(\left(P_{h} \cos \phi\right) / P_{i}\right) /\left(8 N u_{f d} C_{1}\right)$ is a measure of the importance of natural convection relative to pure conduction.

The stability of the circulating flow to disturbances in the central shear layer can be considered in terms of the gradient Richardson number,

$$
R_{i}=\frac{\omega_{B V}^{2}}{\left(\frac{\partial U}{\partial x}\right)^{2}},
$$

which serves as a criterion for the onset of atmospheric turbulence (Hines, 1971). The Brunt-Väisäla frequency is defined as

$$
\omega_{B V}^{2}=\left(\frac{g}{\theta}\right) \cdot\left(\frac{\partial \theta}{\partial z}\right)^{2},
$$

where $\theta$ is the potential temperature (Hess, 1959). Hines (1971) shows that for nonhorizontal shear layers the stabilization criterion can be written as

$$
\frac{\left(\frac{q}{\theta}\right)\left(\frac{\partial \theta}{\partial s}\right) \cos \alpha}{\left(\frac{\partial U}{\partial s}\right)^{2}} \leq \frac{1}{4}
$$

where $s$ is the axis connecting the two parcels of air considered and $\alpha$ is the angle between $s$ and the vertical gravity vector. In our nomenclature $s$ would be perpendicular to $x$ and $\alpha=\left(\frac{\pi}{2}\right)-\phi$ (Fig. 2.1).

Bejan and Rossie (1981) also considered the stability of countercurrent streams in a horizontal duct with heat transfer at the ends in terms of a local Richardson number,

$$
R i=\frac{g \beta \frac{\partial t}{\partial y}}{\left(\frac{\partial U}{\partial y}\right)^{2}}
$$

They point out that with adiabatic walls $R i$ approaches values less than the order of $1 / 4$, but that the walls themselves promote stability (Hazel, 1972).

By approximating the velocity gradient via the difference between the bulk velocities in the two streams and taking the length scale as half the distance between the center plane and the surface, i.e.,

$$
\frac{\partial U}{\partial s} \simeq \frac{2 V_{u}}{r_{w}}=\frac{2 \dot{m}}{\left(\rho A_{c h} r_{w}\right)}
$$


one may rephrase the Richardson number to our configuration as

$$
R i \simeq \frac{g \beta\left(t_{h}-t_{c}\right)}{r_{w}\left(\frac{2 V}{r_{w}}\right)^{2}} \cos \alpha=\frac{C_{1}}{R e_{D_{h h}}} \cdot \frac{r_{w}}{D_{h h}} \frac{\cos \alpha}{\cos \phi}
$$

or

$$
R_{i} \simeq 2 C_{1}^{3 / 2} \sqrt{\frac{P r}{G r_{E}}} \sqrt{\frac{A_{c t}}{A_{c h}}} \frac{r_{w}}{D_{h h}} \frac{\cos \alpha}{\cos ^{3 / 2} \phi}
$$

That is, $R i$ varies as $\frac{1}{\sqrt{E}}$, so increasing the heating rate reduces the stability to disturbances in the shear layer. When $R i$ is reduced to $O(1 / 4)$, multiple cells, temporal waves, or turbulence might be expected. [A better approximation to $\frac{\partial U}{\partial \iota}$ might be deduced from solutions given by Shah and London (1978) for laminar flow in ducts.]

The vertical tube, with $\cos \phi=1$ and $\cos \alpha=0$, would appear to be inherently unstable in this sense.

The predictions above have been developed by assuming a "long" tube, i.e., one sufficiently long that velocity and temperature fields can be considered independent of end effects and, therefore, fully established (idealizations $2,4,7$, and 8). In order to examine the validity of this assumption, we can compare the situation to the entrance of a duct with forced convection and relate the common quantities.

The configurations are shown in Fig. 2.4 with a parallel plate duct representing the forced convection case and an arbitrary but symmetric (circular, rectanglar, elliptical) geometry for the inclined natural convection. It is emphasized that only order-of-magnitude estimates are desired - and these might be improved by applying results from Shah and London (1978). It is seen that the duct spacing $S_{p}$ corresponds to $r_{w}$ in the inclined case. The duct entrance at $x=0$ may be roughly equivalent to a location that is a distance of approximately $r_{w}$ to $D$ from the end of the inclined geometry.
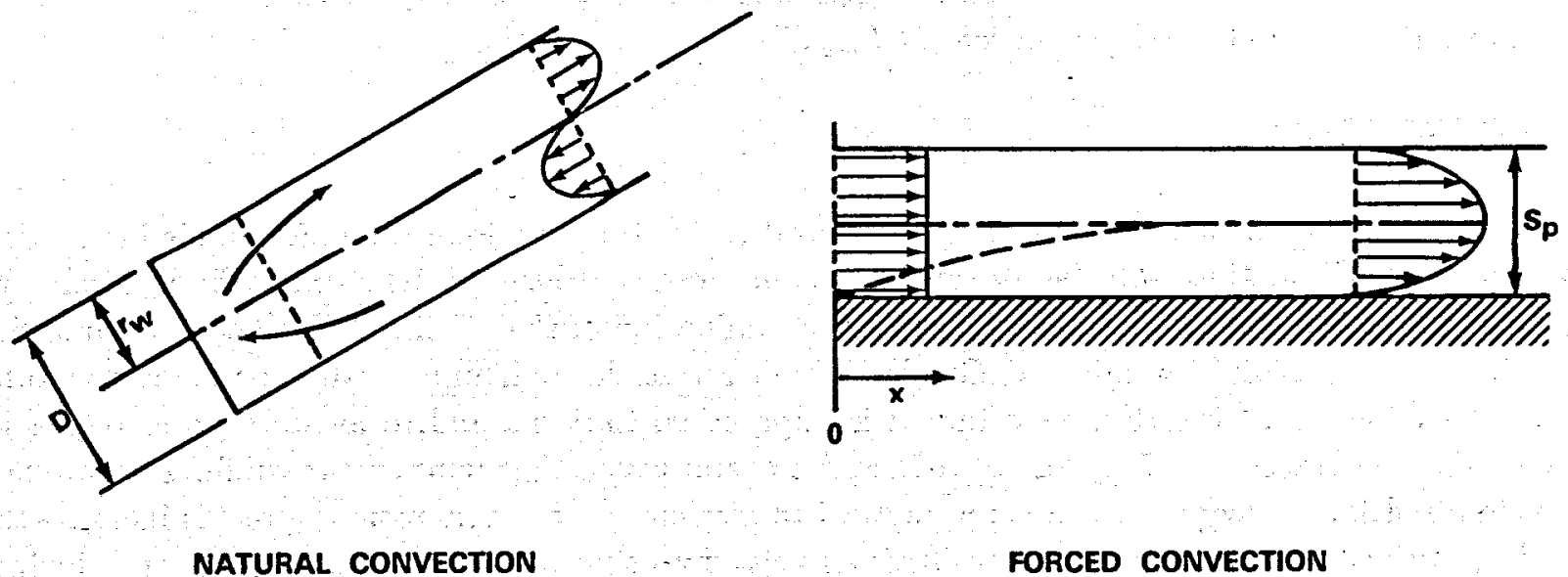

Fig. 2.4. Comparison of geometries and nomenclature for end effects.

For parallel plates, McEligot et al. (1977) showed that the distances for the integral parameters to reach within about $5 \%$ of their fully established values are about

$$
\frac{2 L}{S_{p} \cdot R e_{D_{h}}} \simeq 0.1 \rightarrow 0.2 \quad \text { for friction parameters }
$$

and 


$$
\frac{2 L}{S_{p} \cdot R e_{D_{A}} \cdot \operatorname{Pr}} \simeq 0.1 \rightarrow 0.2 \quad \text { for heat-transfer parameters. }
$$

A comparable approximation was considered by Batchelor (1954) in estimating how tall a narrow cavity must be in order to neglect end effects. Choosing values of 0.1 , we can transform these estimates to our case as

$$
\frac{L_{\text {flow }}}{D} \geq \frac{0.1}{4} \operatorname{Re}_{D_{\mathrm{AL}}}=0.0125 \sqrt{\frac{G r_{E} A_{\text {ct }}}{C_{1} \operatorname{Pr} A_{c h}} \cos \phi}
$$

and

$$
\frac{L_{h t}}{D} \geq \frac{0.1}{4} \operatorname{Re}_{D_{h h}} \operatorname{Pr}=0.0125 \sqrt{\frac{G r_{E} \operatorname{Pr}}{C_{1}} \frac{A_{c t}}{A_{c h}} \cos \phi}
$$

where $D$ represents the diameter of a circular tube, the depth of a duct, an axis of an ellipse, etc.

One sees that the approximate development length $L / D$ varies as $\sqrt{G r_{E}}$ and, therefore, as $\sqrt{\dot{E}}$. The choice of fluid can have a substantial effect since $L_{h t} / D$ varies as $\sqrt{P_{r}}$ also. In order to have a fully established region appear halfway along the tube, the overall length should be of the order

$$
\frac{L}{D}>O\left(2+2 \frac{L_{\max }}{D}\right)
$$

where $L_{\max }$ represents the larger of $L_{\text {flow }}$ and $L_{h t}$. The predicted relation between the two development lengths is seen to be

$$
\frac{L_{h t}}{L_{\text {flow }}}=\operatorname{Pr}
$$

so for a high-viscosity fluid, such as oil or polyvinyl alcohol solution, $L_{h t} \gg L_{\text {flow }}$. However, since the flow depends on the buoyancy forces (which in turn depend on the temperature differences) it is expected that, for $\operatorname{Pr} \gg 1$, in practice $L_{f l o w}$ would be approximately equal to $L_{h t}$, as well as determining the required development length $L_{\max }$.

\section{EXPERIMENT}

The experiment was designed to examine natural circulation in a long tube of variable inclination from vertical, with heating from below, cooling at the top, and heat transfer through side walls, as might occur in a realistic geothermal application. Examination of their definitions shows that in order to obtain low values of Rayleigh and Grashof numbers, as desired, one must (1) reduce the tube diameter to values less than $10 \mathrm{~mm}$ so that it is impractical to insert and to locate thermocouples or flow visualization tracers carefully, or (2) reduce $\dot{E}$ to values such that temperature differences are less than a hundredth of a degree, which is impractical to measure with thermocouples, or (3) increase the fluid viscosity. We chose to increase the fluid viscosity by using a $6 \%$ aqueous solution of polyvinyl alcohol, resulting in viscosity about 60 times that of water.

\subsection{Apparatus}

The heart of the apparatus was a pivoting test section constructed of Plexiglas as shown schematically in Fig. 3.1, and in actuality in Fig. 3.2. Inner diameter was 1.93 in. (4.9 cm) and wall thickness was 0.25 in. $(0.6 \mathrm{~cm})$. A well-type heater of copper and electrical heating tape provided an approximately isothermal heat source at the bottom, and a countercurrent water cooler with an internal impinging 


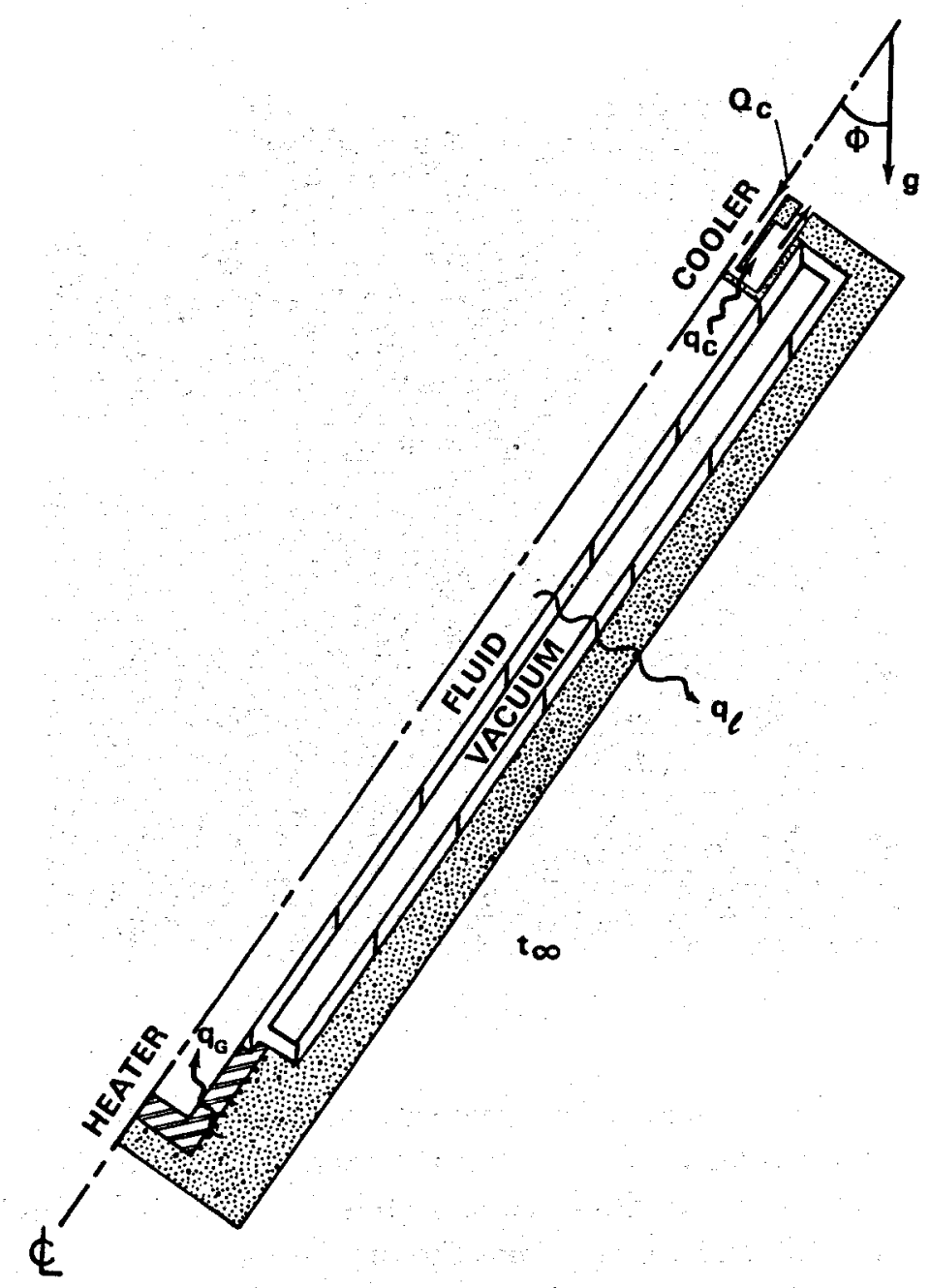

Fig. 3.1. Schematic diagram of apparatus.

jet determined the upper thermal boundary condition. The distance from the top of the well heater to the bottom of the cooler was $70 \mathrm{in}$. $(178 \mathrm{~cm})$, giving an aspect ratio of about 36 .

The angle could be varied from vertical to $\pm 40^{\circ}$ from vertical. It was measured to within $\pm 0.1^{\circ}$ with the inclinometer feature of a Bruton "Pocket Transit."

The cooler and heater were enclosed in fiber glass insulation to reduce heat losses. In order to provide a compromise between having moderate heat losses from the Plexiglas tube and the ability to conduct flow visualization and to measure velocity and temperature profiles, the test section was surrounded by another Plexiglas tube, aluminum foil, and 2 in. $(5 \mathrm{~cm})$ of Fiberglas insulation. Between the two Plexiglas tubes a moderate vacuum was maintained to increase the thermal resistance. Removable viewing ports were constructed in the insulation. Overall, the apparatus had a thermal time constant of about seven hours, so the viewing ports could be opened for the visual measurements for a reasonable time without excessively disturbing the thermal environment.

Calibrated thermocouples were inserted through the Plexiglas walls into the fluid in order to measure the overall temperature field whenever desired. All were constructed from the same spool of wire. These thermocouples provided the evidence for the transient response, heat loss calibration, and comparison of the effects of inclination angle and heating rate (Rayleigh number) presented later. All 


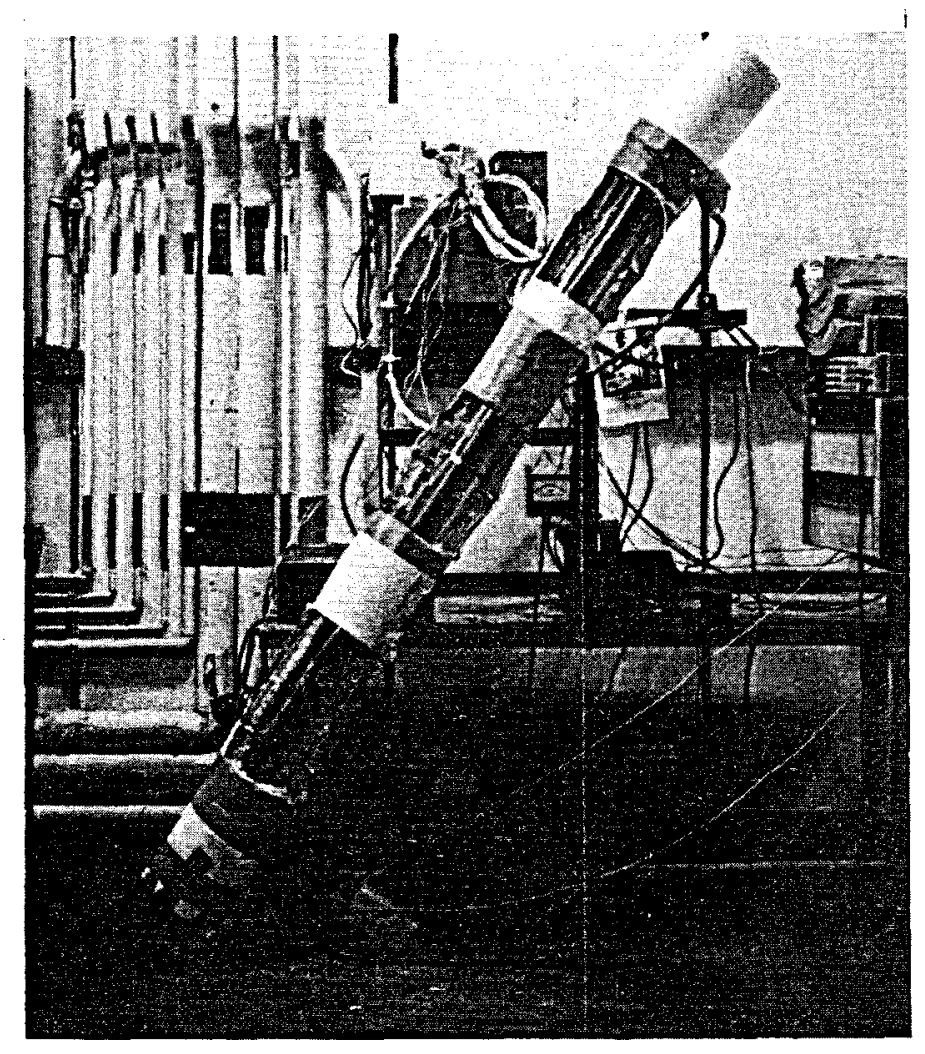

Fig. 3.2. Overall view of test section.

were mounted on the vertical centerplane. One row was located about $0.5 \mathrm{in} .(1.3 \mathrm{~cm})$ from the wall along the lower surface, and a comparable row was the same distance in from the upper surface. In addition, there were five stations where three thermocouples were positioned in line radially at depths of $0.14,0.5$, and $0.8 \mathrm{in}$. $(0.3,1.3$, and $2.0 \mathrm{~cm})$ from the tube surface.

The thermocouples were $550 \mathrm{~cm}$ in total length including lead wires, with a reference junction connection positioned at $275 \mathrm{~cm}$ along each thermocouple. Each thermocouple consisted of $275 \mathrm{~cm}$ of type $\mathrm{E}$ chromel-constantan thermocouple wire, which was connected to $275 \mathrm{~cm}$ of silver-plated copper lead wire. Type $\mathbf{E}$ thermocouples were chosen because they were ideally suited for low-temperature measurements due to their high Seebeck coefficient $\left(0.058 \mathrm{mV} /{ }^{\circ} \mathrm{C}\right)$, and also because of their low thermal conductivity and resistance to corrosion, even in atmospheres with a high moisture content. The Seebeck coefficient for type E couples is greater than all other common thermocouples, making them useful for detecting very small changes in temperature.

Conventional welded bead junctions were constructed by stripping $1 \mathrm{~cm}$ of the overbraid and Tefion from each wire, crossing the exposed wires, and arc welding the bare wires together. The exposed junction was then sealed with "Krylon Crystal Clear" protective spray coating.

A temperature reference junction for each thermocouple was constructed by attaching 275-cmlong, 28-gauge, silver-plated, Teflon-coated copper lead wire. The junction between the thermocouple and copper wires was silver soldered and sealed with shrink tubing. An additional 224.3-cm-long copper lead was soldered to the stainless steel overbraid of the thermocouple and was used as a $60-\mathrm{Hz}$ electrical noise guard for the couple.

A Neslab model RTE-8 refrigerated circulating bath served as a zero temperature reference for each thermocouple. The reference connections formed between the copper lead and thermocouple wire for each couple were placed about 6 in. $(15 \mathrm{~cm})$ deep within the circulating water-alcohol bath. The top 
of the bath was covered with a piece of foam insulation $1 \mathrm{in.}(2.5 \mathrm{~cm})$ thick. The bath was maintained at $0^{\circ} \mathrm{C}$ with the temperature of the bath monitored with a Hewlett-Packard quartz thermometer.

Three pairs of small access ports were installed through the two Plexiglas tubes and vacuum region in order to insert a thermocouple probe for traversing along a diameter and to inject fluid for flow visualization and velocity measurements. The ports were constructed of plastic tubing and "Swagelok" tubing connectors; at the outer end a rubber plug-type seal was held captive by the nut. The thermocouple probe and a hypodermic needle could be passed through the seal without causing any leaks. The thermocouple probe was another bead-type thermocouple that, with its Teflon insulation, was sturdy enough to be used directly.

For a heater, the Plexiglas tube was fitted at the bottom with a 3-in. $(7.6 \mathrm{~cm})$ diameter, 5-in. $(13 \mathrm{~cm})$ long cylinder of copper with an inside diameter equal to that of the Plexiglas tube. The copper cylinder was sealed at the bottom with a $0.5-i n .(1.3 \mathrm{~cm})$ thick copper cap, and it was wrapped with an electrical heating tape around its outside surface, making it the heat source for the system. To minimize heat loss, the copper cylinder was enclosed within a 1.8-in. $(4.5 \mathrm{~cm})$ thick cylinder of gypsum-fiber insulation, which was also wrapped with 2 in. of Fiberglas insulation, and was closed at the bottom with 3- to 4 -in. (7 to $10 \mathrm{~cm}$ ) thick Fiberglas insulation as shown schematically in Fig. 3.1.

A Solar constant voltage regulator provided ac power to a Superior Electric variable transformer that governed the electromotive force to the heating tape. The voltage across the tape was measured with a Hewlett-Packard $3456 \mathrm{~A}$ digital voltmeter. Current was determined by measuring the voltage across a shunt, a precision resistor, and directly with a Keithley 177 digital multimeter. Four type $\mathrm{E}$ thermocouples measured heater surface temperatures.

The copper cooler was an axisymmetric configuration with a small central circular tube forming a jet that impinged on the end plate also, as shown in Fig. 3.1. This end plate filled the inside of the test section, thereby serving as its upper boundary. The region around and above the cooler was insulated with fiber glass to a diameter of about $9 \mathrm{in}$. $(23 \mathrm{~cm})$. An alcohol-water solution, cooled to near $0^{\circ} \mathrm{C}$ by the Neslab refrigerated bath, flowed through this cooler and then through a Gilmont variable area flowmeter ("rotameter"), size 13. Circulation was accomplished by a Manostat "Varistaltic" pump, A-series. Coolant temperatures were measured at the inlet and outlet with type $E$ thermocouples from the same batch as the internal thermocouples.

Data acquisition was accomplished with a Hewlett-Packard system. The copper leads to each thermocouple were connected to a Hewlett-Packard 3495A scanner; the scanner was controlled by a Hewlett-Packard 9830A computer. Millivolt readings from each thermocouple were made by a HewlettPackard 3456A digital voltmeter, which passed the readings to the $9830 \mathrm{~A}$ computer. Time was measured with a Hewlett-Packard 59309A digital clock. Data were printed on a Hewlett-Packard model 9866B printer and displayed with a Hewlett-Packard 9862A calculator plotter.

\subsection{Fluid}

In order to have the potential of conducting measurements at Rayleigh numbers in the low range from 50 to $10^{4}$, the test fluid was formed by adding polyvinyl alcohol to increase the viscosity of tap water. A $6 \mathrm{wt} \%$ solution increased the viscosity to about $150 \mathrm{lbm} / \mathrm{ft} \mathrm{hr}(64 \mathrm{cp})$ at room temperature. Trace amounts of Thymol-blue were also added for later flow visualization (Baker, 1966). This solution was then titrated to its acid-base color change point, where it had a light yellow-brown color, by adding dilute solutions of acids or caustic sodas as necessary to adjust the pH. Then injection of a very dilute solution of $\mathrm{NaOH}$ or electrically charging a small platinum wire in the fluid could be applied to change the pH locally, giving a blue color, to trace the fluid motion. 
Viscosity of the solution was measured at $25^{\circ} \mathrm{C}$ with a Brooks viscosimeter at several different rotation speeds. There was no significant variation in viscosity with strain rate, so it was concluded that the fluid could be considered Newtonian in this range. Temperature dependence of viscosity was taken to be the same as for a comparable fluid, VINOL V-350 (Geary, 1984).

Thermal conductivity was measured over a range from $10^{\circ}-60^{\circ} \mathrm{C}$ by the Dynatech Corp., Cambridge, Massachusetts (Brzezinski, 1984), by the guarded comparative technique in a horizontal cell heated from above. Specific gravity of VINOL V-350 was provided by Air Products Co., Allentown, Pennsylvania (Geary, 1984); it was within about $1 \%$ of that of pure water. Estimated fluid properties are provided in Table 3.1 .

\subsection{Thermocouple Calibration}

Before calibration all thermocouples were placed in an oven and heat-treated for 72 hours: 24 hours at $100^{\circ} \mathrm{C}, 24$ hours at $150^{\circ} \mathrm{C}$, and 24 hours again at $100^{\circ} \mathrm{C}$.

All thermocouples were calibrated at the same time by using the Hewlett-Packard data acquisition system described earlier. The same Neslab model RTE-8 refrigerated circulating bath served as a zero temperature reference for each thermocouple.

The thermocouple junctions were placed in a Rosemount controlled, refrigerated, circulating silicone oil bath. The oil bath temperature was measured to within $0.001^{\circ} \mathrm{C}$ of a degree with a Rosemount model 162CE platinum resistance thermometer and bridge circuit, whose calibration is traceable to the National Bureau of Standards. Ten calibration temperature points were made between $0^{\circ}$ and $90^{\circ} \mathrm{C}$. Millivolt readings for each thermocouple were made with the data acquisition system at each of the 10 fixed oil bath temperatures.

Millivolt readings for each thermocouple were obtained at each of the 10 calibration temperatures, and the data were analyzed to produce a calibration curve for each thermocouple. Least-squares fits were performed on a Hewlett-Packard model 9836 computer. The calibration data for each thermocouple were entered, and third- through eighth-order fits were performed, producing coefficients that satisfy the general equation $y=a_{0}+a_{1} x \ldots+a_{n} x^{n}$, where $n$ is the degree of the desired polynomial. The F-ratio statistic, the ratio of the regression sum of squares to the residual sum of squares, was used as a guide to how well the data fit an nth degree polynomial. The greater the F-ratio, the better the fit. An analysis of the F-ratios and calibrations for each thermocouple indicated that a sixth-order fit had the greatest order of accuracy for all the thermocouples. Therefore, a sixth-order polynomial was used to construct the final calibration curve for each thermocouple.

In order to measure the degree of accuracy obtained with the sixth-order fit, a cross check for each thermocouple was performed. A Hewlett-Packard 9830A computer calculated the temperatures corresponding to the millivolt calibration data using the sixth-order polynomial coefficients for each thermocouple. The difference between the calculated and calibration temperatures for each thermocouple was found for all 10 readings. Most of the calculated temperatures were within $0.03^{\circ} \mathrm{C}$ of the calibration temperatures, with the greatest deviation being only $0.06^{\circ} \mathrm{C}$. The larger deviations occurred only at the elevated temperatures, with the best agreement being in the same range of temperatures that the experiment was operated $\left(20^{\circ}-60^{\circ} \mathrm{C}\right)$. 


\section{TABLE 3.1. ESTIMATED FLUID PROPERTIES}

Thermal Conductivity, k (Brzezinski, 1984)

Temperature, ${ }^{\circ} \mathrm{C}$

$\mathbf{k}, \mathrm{W} / \mathbf{m ~ k}$
10

0.470
21

0.499
22

0.461
42

0.520
59

0.492

Viscosity, $\mu$

Measurements at $25^{\circ} \mathrm{C}$

$\begin{array}{lcccc}\text { Spindle } & \text { I } & \text { I } & \text { II } & \text { II } \\ \text { Speed } & 60 & 30 & 60 & 30 \\ \mu, \text { cp } & 70.0 & 64.0 & 63.5 & 62.0\end{array}$

Comparable fluid, VINOL V-350 (Geary, 1984)

$\begin{array}{lll} & 4 \mathrm{wt} \% & 6 \mathrm{wt} \% \\ \text { Temperature }=20^{\circ} \mathrm{C} & 65 \mathrm{cp} & 400 \mathrm{cp} \\ \text { Temperature }=65^{\circ} \mathrm{C} & 12 \mathrm{cp} & 60 \mathrm{cp}\end{array}$

Specific gravity, $\gamma$

VINOL V-350 (Geary, 1984)

$\begin{array}{lll} & \frac{4 \mathrm{wt} \%}{6 \mathrm{wt} \%} \\ \text { Temperature }=20^{\circ} \mathrm{C} & 1.0075 & 1.01^{+} \\ \text {Temperature }=70^{\circ} \mathrm{C} & 0.985 & 0.99^{+}\end{array}$

Specific Heat, cp (Taken as water) $=1 \mathrm{Btu} / \mathrm{lbm}{ }^{\circ} \mathrm{F}=4.19 \mathrm{~kJ} / \mathrm{kg}^{\circ} \mathrm{C}$

Density and Thermal Expansion, $\rho$ and $\beta \quad$ Taken as water (Kreith, 1973) 


\subsection{Experimentál Results}

For typical conditions of the experiment, expected parameters can be estimated in terms of the analysis of Section 2. At an inclination of $35^{\circ}$, fluid temperature of $100^{\circ} \mathrm{F}\left(38^{\circ} \mathrm{C}\right)$, and convected power of $\dot{E}=75$ watts, the approximate estimates are

$$
\begin{aligned}
t_{h}-t_{c} & \simeq 1.2^{\circ} \mathrm{F} \simeq 0.7^{\circ} \mathrm{C} \\
\frac{d t}{d x} & \simeq 0.2^{\circ} \mathrm{F} / \mathrm{ft} \simeq 0.4^{\circ} \mathrm{C} / \mathrm{m} \\
V & \simeq 0.6 \mathrm{in} . / \mathrm{sec} \simeq 1.5 \mathrm{~cm} / \mathrm{sec} \\
G r_{E} & \simeq 1.3 \times 10^{5} \\
\dot{E} /\left(-k A_{t} \frac{d t}{d x}\right) & \simeq 2 \times 10^{5} \\
R a_{d t / d x} & \simeq 240 \\
R e & \simeq 3.2 \\
R i & \simeq 3\left(\gg 1 / 4,{ }^{\prime \prime s t a b l e " ~}\right) \\
L_{\text {flow }} / D & \simeq 0.08 \\
L_{h t} / D & \simeq 27 .
\end{aligned}
$$

As the heating rate $\dot{E}$ is reduced, predicted $G r_{E}$ and $R e$ decrease. Since $R i$ is given by

$$
R i \simeq \frac{C_{1}}{R e_{D_{h h}}} \cdot \frac{r_{w}}{D_{h h}} \cdot \frac{\cos \alpha}{\cos \phi}
$$

the single counterflow cell would be predicted to be more stable at lower heating rates. Reducing the inclination from $35^{\circ}$ to $20^{\circ}$ reduces $R i$ by about a factor of 2 , so the cell would still forecast to be stable at this heating rate. For a vertical tube, the analysis of Section 2 predicts $R i=0$, which indicates that the hypothesized single counterflow cell would be unstable to small disturbances; thus, the simplified analysis would not be expected to be valid in that limit.

Figure 3.3 shows a velocity profile measured with the Thymol-blue tracer technique for $31^{\circ}$ inclination and input heating of about 10 watts. The photo was taken at an angle to the flow rather than directly, so it appears askew. However, one does see the expected profile: a descending plume on one side and a rising plume on the other. The Rayleigh number for this flow was estimated to be 30 , one-seventh the critical value for vertical tubes; hence it is clear that, as expected, inclined wells are more subject to natural convection than vertical wells.

Time-motion tracer studies for this flow showed that even the maximum velocities were small, of the order of $1 \mathrm{~mm} / \mathrm{sec}$. Thus, although convection did occur, it was weak. Further evidence of this weakness is provided in Fig. 3.4, which shows the disturbing effect that the small thermocouple wires had upon the flow streamlines. Occasionally this disturbance became so strong that it could break up the single cell convection pattern and produce multiple cells, each of which were only a few diameters long, quite similar to Diment's (1967) observations in actual wells. An example of such a smaller cell is shown in Fig. 3.5.

Measurements were obtained at various heating rates and tube inclinations. The maximum angle was $35^{\circ}$ from the vertical; this was also the inclination most frequently used. Preliminary measurements were conducted to determine the performance of the experimental apparatus and to identify 


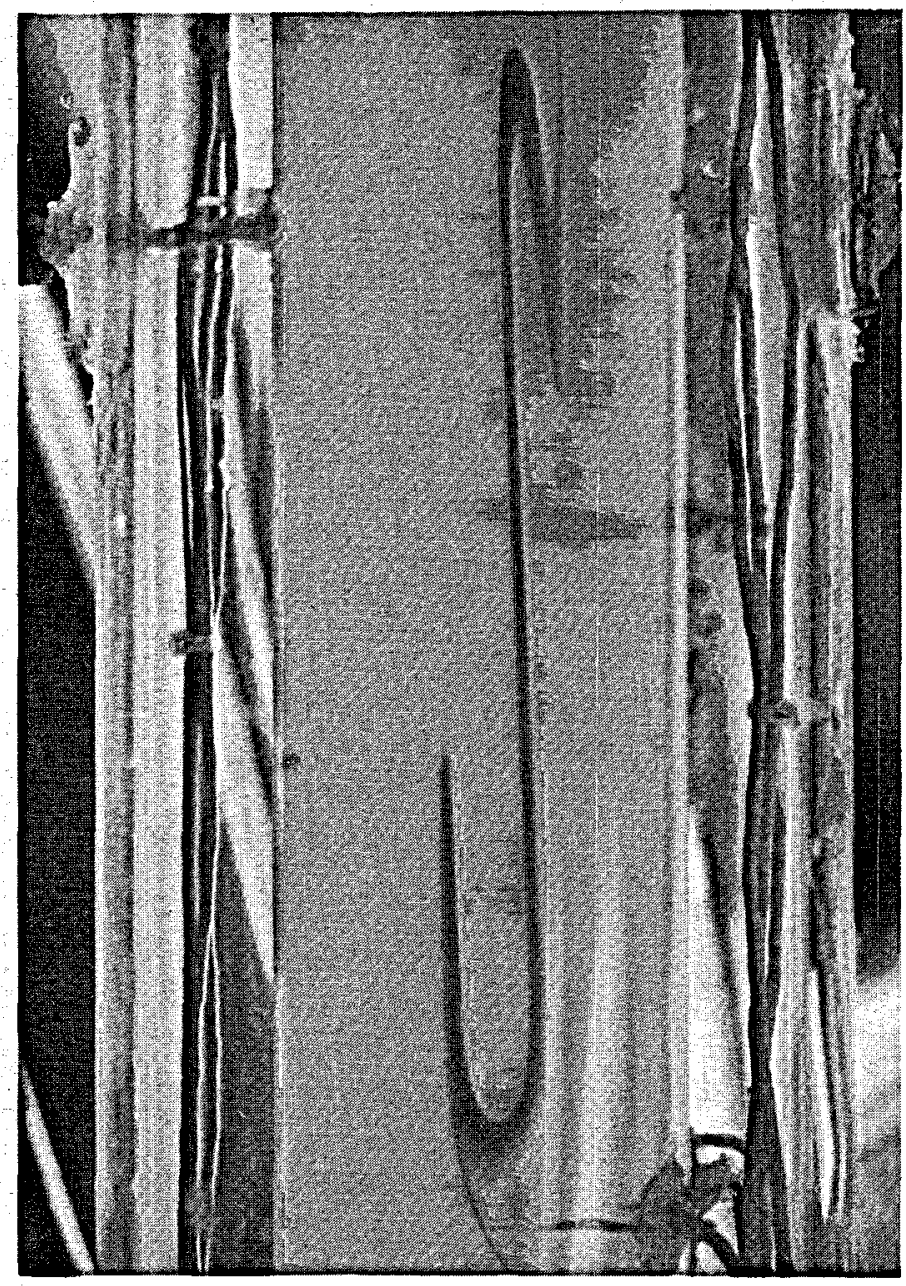

Fig. 3.3. Velocity profile with low heating rate in inclined tube, $\phi=31^{\circ}, q_{G}=10 \mathrm{~W}$.

necessary improvements. Insulation was added, the cooler was modified, and the coolant flowmeter and pump were replaced. Nine experimental runs were conducted after this process was completed; their operating conditions are listed in Table 3.2. The run on 26 and 27 June (1984), cooling from a high temperature toward ambient, was used to calibrate the heat loss through the tube wall. The most extensive data available are transient temperatures recorded via the thermocouples in the fluid. The lowest thermocouples were above the copper heating well while the top pair were slightly below the bottom of the cooler. In addition to tabular output, the data reduction system plotted the temperature distributions as $t(x)$ in the format shown in Fig. 3.6. As noted earlier, the axial arrays were immersed to $0.5 \mathrm{in}$. or $\left(r / r_{w}\right)=0.48$ or $y=1.3 \mathrm{~cm}$. Radial arrays were positioned at $\left(r / r_{w}\right)=0.17$ ("deepest"), 0.48 , and 0.85 ("wall") $\mathrm{cm}$.

An average, overall heat loss coefficient was deduced by considering the apparatus as a single thermal capacitance and a single thermal resistance dominated by the external insulation, i.e., the so-called one-lump model [or "lumped capacitance method" (Incropera and deWitt, 1981, Sec. 5.1) or "lumped single capacity system" (Kreith, 1973, Sec. 4.2)]. From the transient fluid temperature during the cooling run, a value of about $0.5 \mathrm{Btu} / \mathrm{hr} \mathrm{ft}^{2 \circ} \mathrm{F}\left(2.8 \mathrm{~W} / \mathrm{m}^{2 \circ} \mathrm{C}\right)$ was estimated.

Order-of-magnitude estimates of the convective resistance of the fluid and the conduction resistance of the insulation demonstrated that the insulation dominated; therefore, the temperature dependence of the overall thermal resistance would be small. 


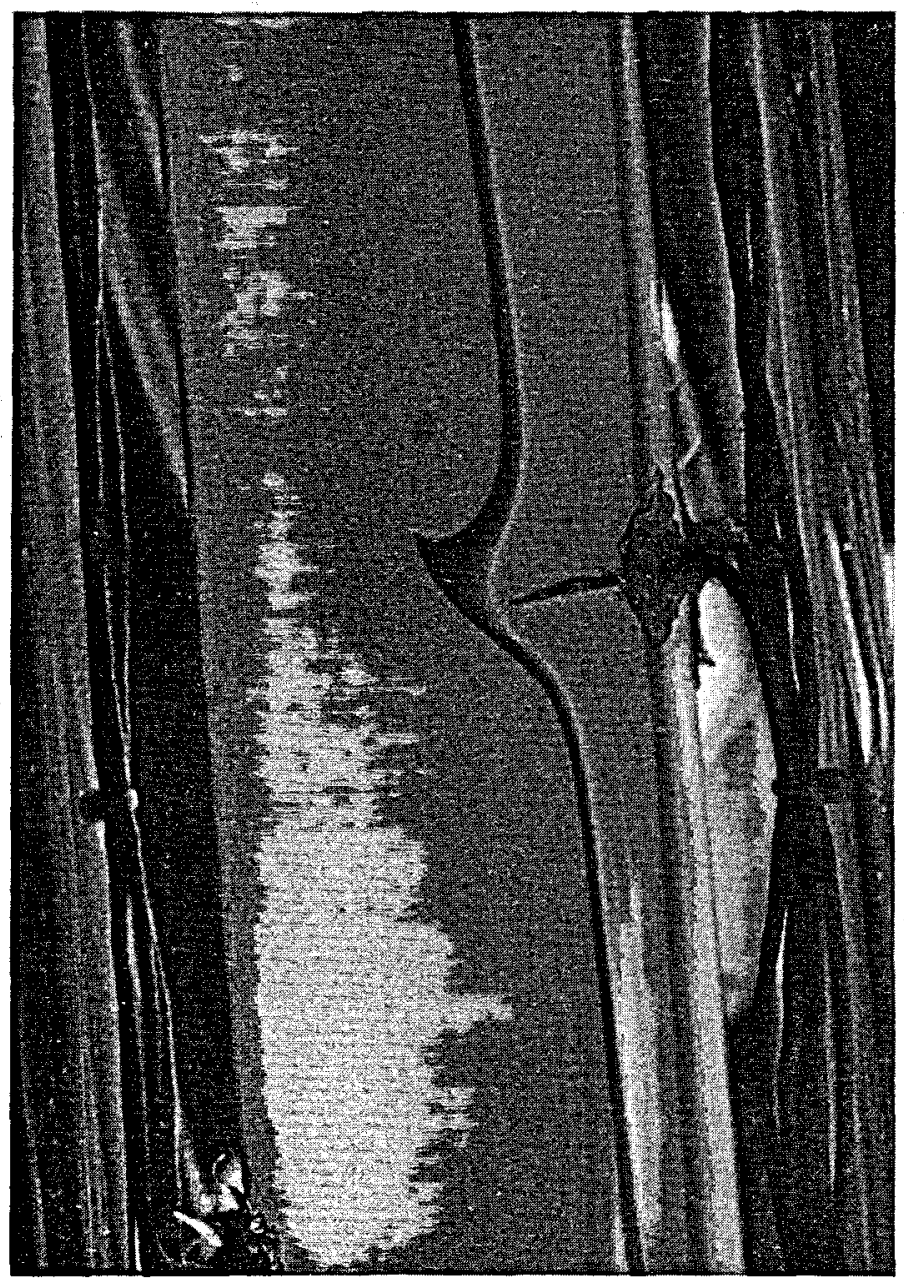

Fig. 3.4. Indication of flow disturbance by thermocouple during weak convection, $\phi=31^{\circ}$, $q_{G}=10 \mathrm{~W}$.

Typical transient response is demonstrated in Fig. 3.7. Inclination was $35^{\circ}$ and heating rate was 73 watts, the highest used. Initially, the fluid was nearly isothermal at $34^{\circ} \mathrm{C}\left(93^{\circ} \mathrm{F}\right)$. Heating started at 73 watts, and within one-half hour the temperature distribution had assumed the shape shown in the second subfigure. With the exception of minor details, this shape was maintained for the next 4 hours while the temperature level gradually increased. Eventually the power was reduced (twice) as the thermocouples in the copper heater began to indicate near-boiling temperatures.

The time constant, and therefore the rate of temperature increase, is dominated by the thermal resistance of the insulation and is slow. However, it appears that a quasi-steady temperature distribution was reached relatively quickly. Presumably this distribution corresponded to a near steady flow pattern. For this inclination $\left(35^{\circ}\right)$, the "wall" temperatures show the warm fluid to be rising along the upper side and cool fluid to be descending on the lower. There is a slight decrease in the axial direction, but near the central midplane the temperatures seem near isothermal. These observations correspond to a long, single recirculating cell along the tube. However, the thermocouple readings at the top near the cooler may indicate a small cell with circulation in the opposite direction.

Details of additional experimental runs are included later in Section 5, comparison between numerical predictions and measurements. Steady-state temperature distributions are tabulated for three illustrative runs in the Appendix. 


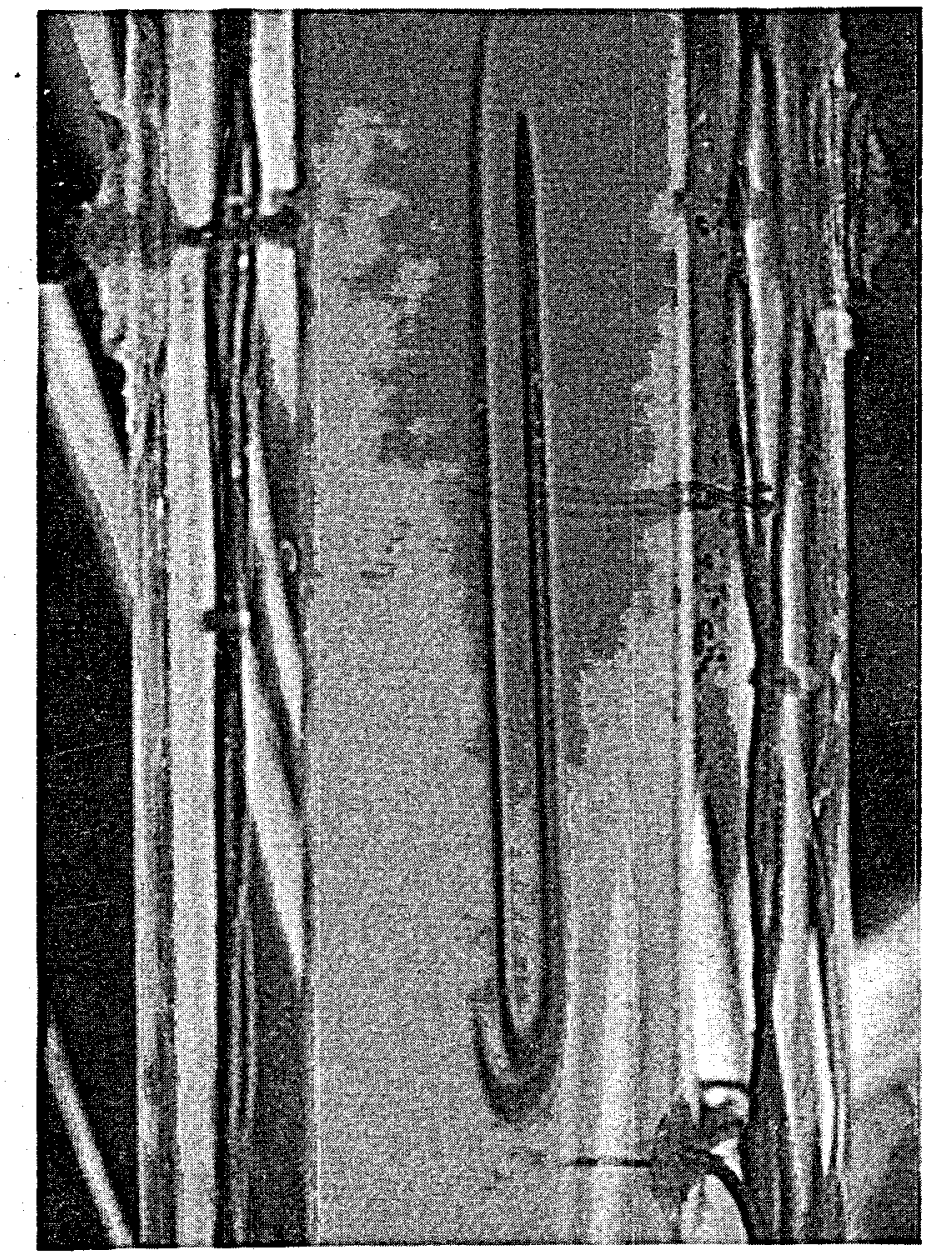

Fig. 3.5. Evidence of small convective cell typical of multicellular convection.

TABLE 3.2. LOG OF "BEST" DATA

\begin{tabular}{|c|c|c|c|c|c|}
\hline Date & $\begin{array}{l}\text { Start } \\
\text { Time }\end{array}$ & $\begin{array}{l}\text { "Stead } \\
\text { State" } \\
\text { Time }\end{array}$ & Angle & $q_{G}$ & Comments \\
\hline \multicolumn{6}{|l|}{1984} \\
\hline \multirow[t]{2}{*}{21 June } & - & 0803 & $35^{\circ}$ & $12.4 \mathrm{~W}$ & \\
\hline & 一 & 1446 & $20^{\circ}$ & $12.2 \mathrm{~W}$ & \\
\hline 22 June & 一 & 1630 & $0^{\circ}$ & $12.1 \mathrm{~W}$ & \\
\hline 26 and 27 June & 1858 & 0812 & $35^{\circ}$ & $0 \mathrm{~W}$ & Cooling \\
\hline \multirow[t]{2}{*}{27 June } & 0840 & None & $35^{\circ}$ & $73.4 \mathrm{~W}$ & Transient heating \\
\hline & 1409 & None & $35^{\circ}$ & $59.7 \mathrm{~W}$ & Transient cooling \\
\hline 27 and 28 June & 2003 & 0858 & $35^{\circ}$ & $53.0 \mathrm{~W}$ & Transient cooling \\
\hline 28 June & 1440 & 1642 & $35^{\circ}$ & $53.0 \mathrm{~W}$ & \\
\hline 28 and 29 June & 1657 & 1344 & $0^{\circ}$ & $52.9 W$ & \\
\hline
\end{tabular}




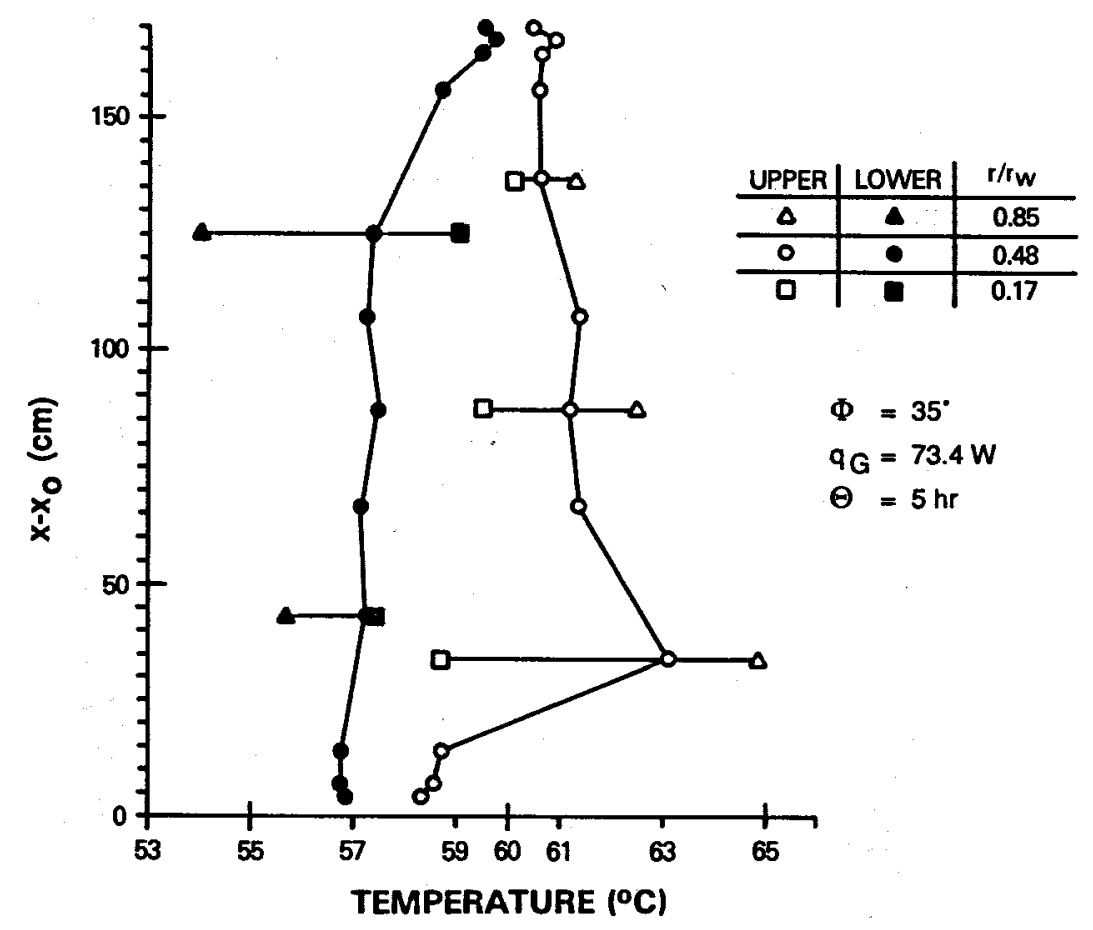

(a)

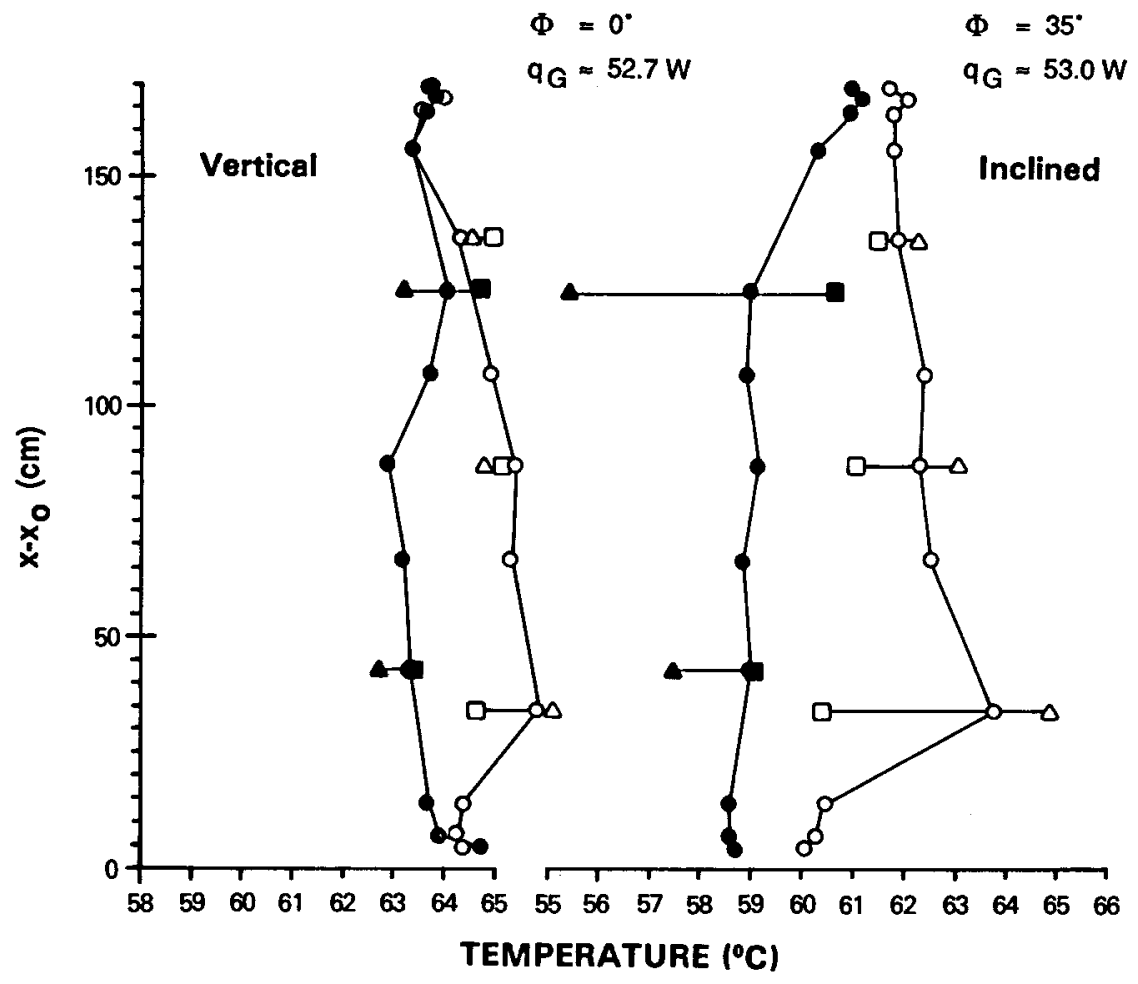

(b)

Fig. 3.6. Typical temperature distribution as plotted by data acquisition (a) during transient and (b) steady state. 


$$
\text { Inclined, } \Phi=35^{\circ}, q_{G}=73 W
$$
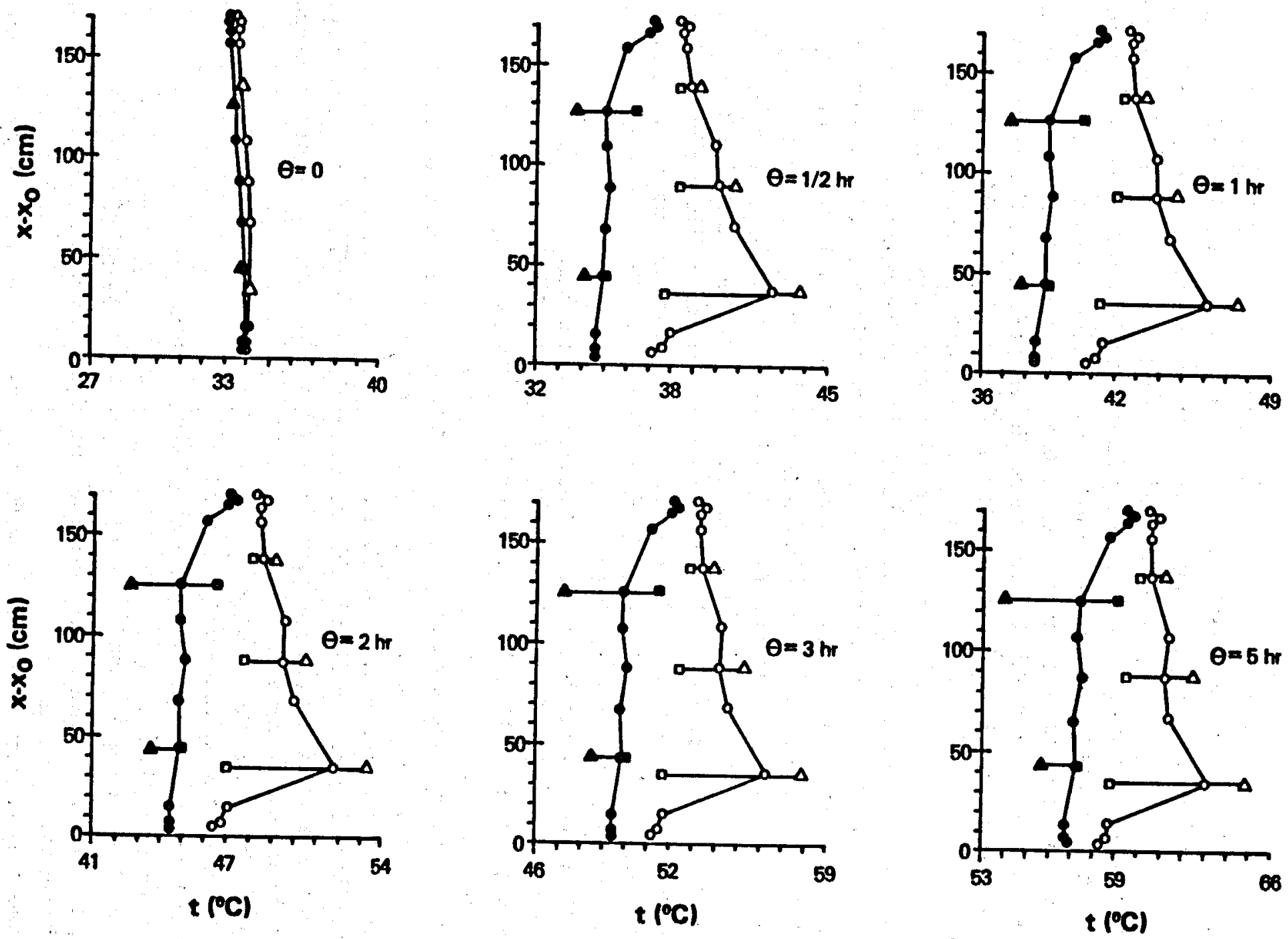

$\mathbb{8}$

Fig. 3.7. Transient response during heating run. 


\section{NUMERICAL PREDICTIONS}

\subsection{Preliminary Survey}

A variety of computer programs is available for the solution of general fluid mechanics and heattransfer problems (Johnson and Torok, 1985). The techniques, features, generality, and costs differ, so a brief study was conducted during the spring of 1985 to identify which programs might be suitable for the present work (McEligot, 1985). The search and its results are not claimed to be all-inclusive. Further, the features of the various codes continuously improve and new codes frequently appear.

The approach taken was to identify possible codes, to investigate their features, and to estimate the effort necessary to apply them to our specific problem. Handwritten forms listing their features were completed for most codes identified. Typical examples are presented in the report by McEligot (1985). Table 4.1 summarizes the results of this survey as of the summer of 1985.

The basic natural convection problem studied was laminar, transient, and (due to the tilt angle) three-dimensional in cylindrical coordinates. Since a quasi-steady state appeared to occur in the experiments while the general level of the temperature distribution was increasing with time, steady-state results were also of interest. The codes that might be feasible to apply were further considered in terms of the specific features required for such simulations, as summarized in Table 4.2. In addition, the application to the inclined tube problem was further examined in terms of the types of programming efforts that would be required plus an idea of the approximate cost for the programs deemed feasible.

As part of a seminar at Creare R\&D Co., Inc., B. R. Patel applied the FLUENT program to a comparable problem. The geometry was idealized as about 2 in. $(5 \mathrm{~cm})$ in diameter by 10 in. $(25 \mathrm{~cm})$ long to reduce the number of nodes required to describe the problem, and the angle was taken as vertical so that axisymmetric coordinates could be employed. At the time, FLUENT solved only steady-state problems, but future versions should handle transients.

A hypothetical fiuid with the following miscellaneous properties was considered:

Density $\left(\mathrm{lbm} / \mathrm{ft}^{3}\right) \simeq 20.3+0.2 T-3 \times 10^{-4} T^{2}+1 \times 10^{-7} T^{3}\left(T\right.$ in $\left.{ }^{\circ} \mathrm{R}\right)$.

Density $\left(\mathrm{kg} / \mathrm{m}^{3}\right) \simeq 325+0.36 T-1.6 \times 10^{-3} T^{2}+9.3 \times 10^{-6} T^{3}(T$ in $\mathrm{K})$.

Viscosity $\simeq 1.57 \mathrm{lbm} / \mathrm{ft} \mathrm{sec}=2340 \mathrm{cp} \simeq 2.34 \mathrm{~N} \cdot \mathrm{s} / \mathrm{m}^{2}$.

Thermal conductivity $\simeq 3.4 \mathrm{Btu} / \mathrm{hr} \mathrm{ft}{ }^{\circ} \mathrm{F} \simeq 5.9 \mathrm{~W} /\left(\mathrm{m} \cdot{ }^{\circ} \mathrm{C}\right)(10$ times water $)$.

Specific heat $\simeq 0.24 \mathrm{Btu} / \mathrm{lbm}{ }^{\circ} \mathrm{F} \simeq 1.0 \mathrm{~kJ} / \mathrm{kg}^{\circ} \mathrm{C}$ (air).

Pressure $\simeq 14.5 \mathrm{psia} \simeq 1.00 \times 10^{5} \mathrm{~N} / \mathrm{m}^{2}$.

Apparently the density represented a liquid with a large thermal coefficient of expansion (with $T$ taken in Kelvins). The values of $c_{p}, \mu$, and $k$ give $\operatorname{Pr} \simeq 400$, which is of the same order-of-magnitude as the fluid in the present experiment.

Boundary conditions were the following:

Surrounding temperature $\simeq 535^{\circ} \mathrm{R}=297 \mathrm{~K}$.

Heat flux at bottom $\simeq 8.3 \times 10^{3} \mathrm{Btu} / \mathrm{hr} \mathrm{ft}^{2}=2.62 \times 10^{4} \mathrm{~W} / \mathrm{m}^{2}$.

Temperature at top $\simeq 497^{\circ} \mathrm{R} \simeq 276 \mathrm{~K}$.

Sidewall heat-transfer coefficient $\simeq 2 \mathrm{Btu} / \mathrm{hr} \mathrm{ft}^{2}{ }^{\circ} \mathrm{F} \simeq 11 \mathrm{~W} / \mathrm{m}^{2}{ }^{\circ} \mathrm{C}$.

This external heat-transfer coefficient corresponds to natural convection in air plus radiation from a blackbody, without any insulation.

Calculations were conducted for about 400-500 iterations without convergence. The pressure "residual" (defined as normalized change in the variable on successive iterations) was still above $10 \%$ at this point. It is suspected that either there was some inconsistency in the setup or the pressure 


\begin{tabular}{|c|c|c|c|c|c|c|c|c|c|c|c|c|c|c|c|c|c|c|}
\hline . & \begin{tabular}{|l}
5 \\
\\
\\
\end{tabular} & $\begin{array}{l}8 \\
8 \\
8 \\
8 \\
8 \\
8\end{array}$ & $\begin{array}{l}E \\
\frac{5}{8} \\
\frac{5}{2}\end{array}$ & 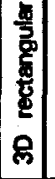 & 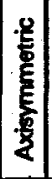 & $\begin{array}{l}\frac{8}{8} \\
\frac{5}{5} \\
\frac{5}{5} \\
8\end{array}$ & $\begin{array}{c}\dot{z} \\
8 \\
\overline{8} \\
8 \\
\stackrel{5}{2}\end{array}$ & $\begin{array}{l}\dot{z} \\
8 \\
\overline{5} \\
\frac{5}{2}\end{array}$ & $\begin{array}{c}\dot{z} \\
8 \\
8 \\
\frac{8}{2}\end{array}$ & 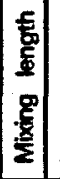 & 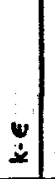 & $\begin{array}{l}\overline{8} \\
\text { है } \\
\dot{\xi}\end{array}$ & $\begin{array}{c}\frac{8}{8} \\
0 \\
\frac{8}{8} \\
\frac{8}{5} \\
5\end{array}$ & $\begin{array}{r}\text { Cost to } \\
\text { Purchase }\end{array}$ & $\begin{array}{l}0 \text { LANL } \\
\text { Lease }\end{array}$ & 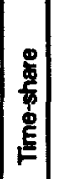 & $\begin{array}{l}\text { Learning } \\
\text { time }\end{array}$ & $\begin{array}{l}\text { Other/ } \\
\text { Comments }\end{array}$ \\
\hline CAVEAT-3D & $\mathbf{P}$ & $P$ & $Y$ & $Y$ & & $\mathbf{Y}$ & $\mathbf{Y}$ & & & & & & c & Free to & LANL & & $?$ & $\begin{array}{l}\text { Inviscid, supersonic } \\
\sim \text { June, } 1985\end{array}$ \\
\hline FASTWAKE & $\mathbf{r}$ & $\mathbf{Y}$ & 20 & L & $x$ & $x$ & $Y$ & v & $v$ & & & $Y$ & 1 & In house Gou & uld Newport & & $?$ & $\begin{array}{l}\text { 3DWake, could } \\
\text { extend }\end{array}$ \\
\hline FDAP 2.0 & $Y$ & $?$ & $Y$ & $\mathbf{Y}$ & $?$ & $?$ & $\mathbf{Y}$ & $\mathbf{Y}$ & $\mathbf{Y}$ & $Y$ & & & $\mathbf{Y}$ & $\$ 40 K$ & $\$ 15 \dot{K} / r$ & $\mathbf{Y}$ & $\begin{array}{l}1-2 \text { days } \\
\text { (Salesman) } \\
1-2 \text { mon. } \\
\text { (Engineer) }\end{array}$ & $\begin{array}{l}\text { Finite element } \\
\text { Expensive solution? }\end{array}$ \\
\hline FLUENT & $r$ & $Y$ & Dec & $\mathbf{Y}$ & $\mathbf{Y}$ & $Y$ & $Y$ & $\mathbf{Y}$ & $P$ & $Y$ & $\mathbf{Y}$ & 85 & $\gamma$ & & $\begin{array}{l}20 \mathrm{~K}+ \\
11 \mathrm{~K} / \mathrm{mo}\end{array}$ & $Y$ & $\begin{array}{l}\text { Couple } \\
\text { days? }\end{array}$ & $\begin{array}{l}\text { Transient } \\
\sim \text { Dec..1985 }\end{array}$ \\
\hline HYDR-3D & $?$ & $Y$ & $y$ & $Y$ & $P$ & $Y$ & $y$ & $Y$ & $P$ & $?$ & & & $Y$ & $\$ 35 K$ & & & & \\
\hline$K-F X \quad(3 D)$ & $\gamma$ & $r$ & $r$ & $\mathbf{Y}$ & & $Y$ & $\mathbf{Y}$ & v & $v$ & $x ?$ & $x ?$ & $x ?$ & $\mathbf{P}$ & Free & & & $?$ & Viscous terms deleted \\
\hline KIVA & P & $\mathbf{P}$ & $Y$ & $Y$ & $L$ & $\mathbf{L}$ & $\mathbf{Y}$ & $x$ & $x$ & & & $x$ & c & Free & & & $?$ & $\begin{array}{l}\text { Rectangular grid, } \\
\text { reacting flows }\end{array}$ \\
\hline PHOENICS & & $x$ & $Y$ & $Y$ & $Y$ & $\gamma$ & $Y$ & $Y$ & $p$ & $Y$ & $Y$ & & $\mathbf{Y}$ & $\begin{array}{l}\$ 72 K+ \\
\$ 18 K\end{array}$ & $\begin{array}{l}\$ 24 K / y+ \\
\$ 6 K / y r\end{array}$ & $\mathbf{r}$ & $\begin{array}{l}\text { Three day } \\
\text { course? }\end{array}$ & $\begin{array}{l}\text { Equ solver binary, } \\
\text { Setup = Fortran }\end{array}$ \\
\hline RPM & $P$ & $P$ & $Y$ & & $Y$ & $\mathbf{P}$ & $\gamma$ & $x$ & $x$ & & $\mathbf{Y}$ & & $\mathbf{Y}$ & $\sim \varepsilon 500$ & & & ? & Like KIVA \\
\hline SOLA & $\gamma$ & $P$ & $Y$ & $?$ & $Y$ & $?$ & & $?$ & & & & & & Free & & & $?$ & $\begin{array}{l}\text { Various extensions } \\
\text { also available }\end{array}$ \\
\hline SOLA-3D & $Y$ & - & $P$ & $Y ?$ & & $Y$ & & & & $x$ & $x$ & $x$ & 1 & Not released & & & & $\begin{array}{l}\text { Undocumented, in } \\
\text { process. No energy } \\
\text { eqn. }\end{array}$ \\
\hline SOLA-PTS & $r \mid$ & $Y$ & $\gamma$ & $\mathbf{Y}$ & $x$ & $x$ & $Y$ & $Y$ & $\mathbf{Y}$ & & $\gamma$ & $\sim \beta$ & $\beta, \mu$ & Free & & & $?$ & $\begin{array}{l}\text { Circ tube modeled } \\
\text { as square }\end{array}$ \\
\hline TEACH & $Y$ & $Y$ & $x$ & $x$ & $Y$ & $x$ & $\mathbf{Y}$ & 7 & $?$ & $Y$ & $\gamma$ & $\mathbf{P}$ & $\mathbf{Y}$ & Free, in ha & & & & $\begin{array}{l}\text { Weak documentation, } \\
\text { but widely used }\end{array}$ \\
\hline TEAM & $y$ & $\mathbf{P}$ & & & $Y$ & & $Y$ & & & $y$ & $y$ & $Y$ & $\mathbf{Y}$ & $\sim \_500$ & & & $\begin{array}{l}\text { Couple } \\
\text { woeks }\end{array}$ & $\begin{array}{l}\text { Still evolving, } \\
\text { others ovailable }\end{array}$ \\
\hline TEMPEST & $Y$ & $\mathbf{L}$ & $\mathbf{Y}$ & $\mathbf{Y}$ & $\mathbf{Y}$ & $Y$ & $Y$ & $\mathbf{Y}$ & $Y$ & & $Y$ & $x$ & $\mu, \mathbf{k}$ & Free & & & $\begin{array}{l}\text { Days to } \\
\text { weeks }\end{array}$ & $\begin{array}{l}\text { No foreign } \\
\text { transfer }\end{array}$ \\
\hline
\end{tabular}

Key: $Y=$ Yes, $X=$ No,$P=$ Probably, $L=$ Limited, $V=$ Vertical,$I=$ incompressible, $C=$ Compressible, $. ?=$ ? 
TABLE 4.2. FEATURES OF CODES RELATED TO NATURAL CONVECTION IN INCLINED TUBES

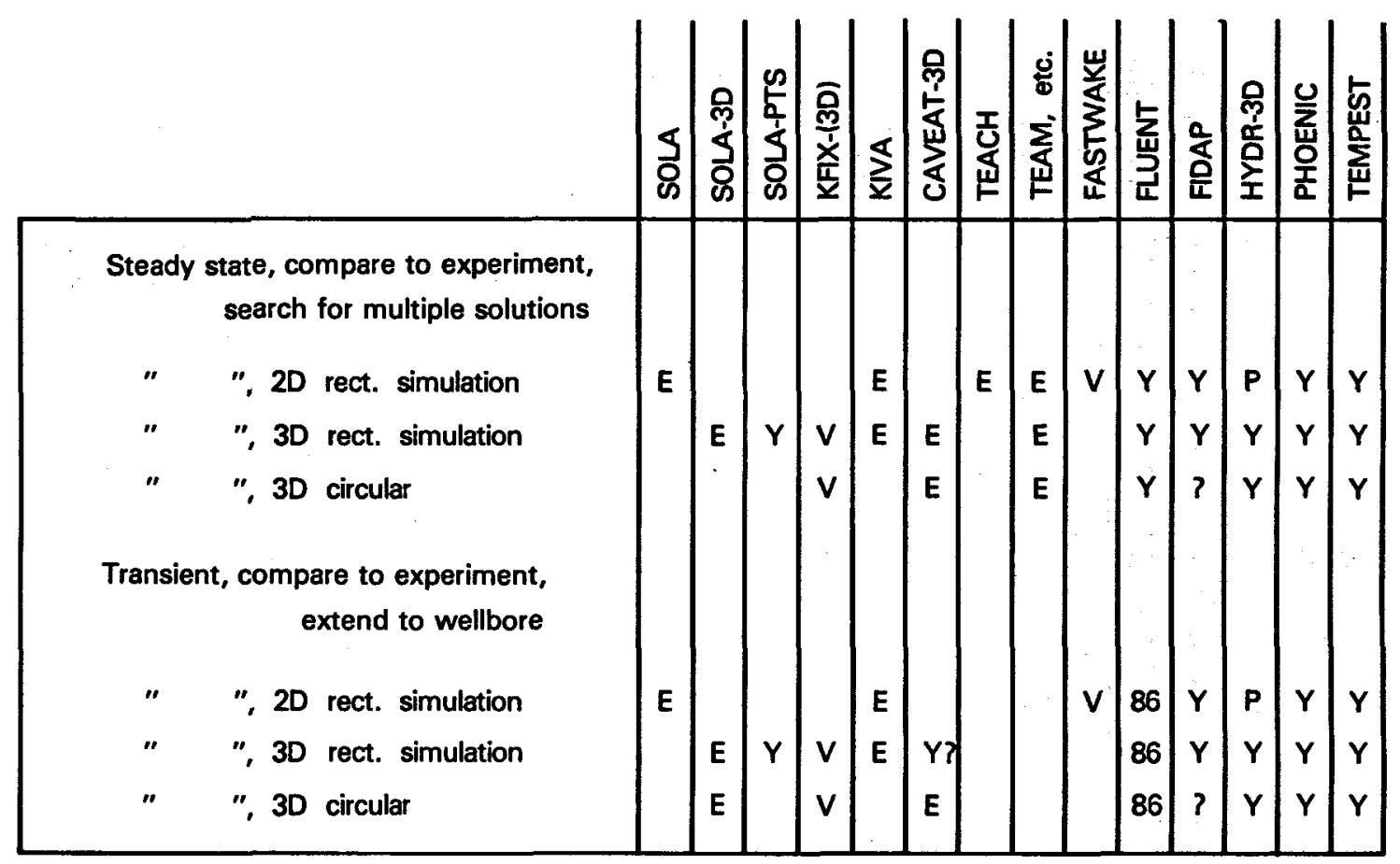

$Y=$ Yes, $P=$ Probably, $V=$ Vertical,$E=$ Needs extension for natural convection, $?=$ Maybe 
was alternating between two levels on successive iterations (only the absolute value of the change was printed on the terminal screen).

The resulting distributions were plausible (see approximate sketch, Fig. 4.1). A toroidal vortex formed at the bottom near the heater. It was about one-half to one diameter in vertical extent. The top was filled with a long counter-rotating vortex. Isotherms showed slight curvature across the tube with the highest temperatures concentrated in the bottom half of the torus at the bottom. The upper four-fifths was below the ambient temperature.

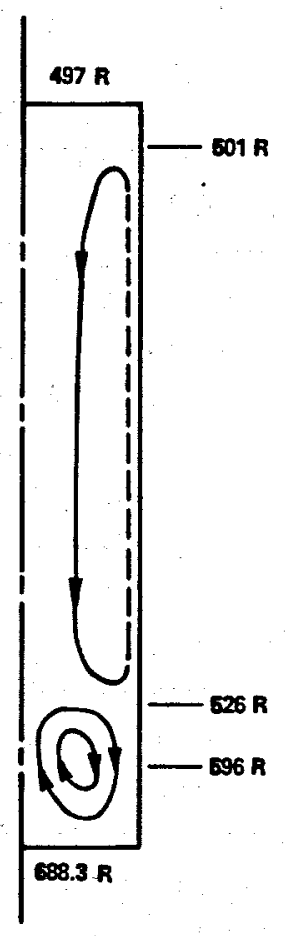

Fig. 4.1. Sketch of isotherms predicted by FLUENT code with vertical, axisymmetric constraints.

Approximate run times on a VAX 11/780 minicomputer without floating point accelerator were estimated as 2 milliseconds per node per governing equation per iteration. For a coarse grid of $20 \times 10 \times 8$ for the three-dimensional inclined geometry, expected run time would be about $8 \times 10^{3}$ seconds or 2.2 hours per case (this may be an optimistic estimate). Patel estimated that for Creare to run 10 cases on a consulting basis, it would require about $\$ 1000$ in personnel time plus about $\$ 600$ computer time per steady-state case for a 2000 -node field and 500 iterations/solution. Since the early solutions would provide reasonable first estimates for the other cases, it is expected that computer time would be reduced for the later solutions.

At first it was decided that, due to the limited time and money available for the project, SOLA-PTS would be employed and a square representation of the tube cross section would be tolerated despite the differences observed in thermosiphon experiments with various cross sections (Lockwood and Martin, 1964). Steps to obtain permission from the Nuclear Regulatory Commission, the sponsor of the code development, were initiated. However, in discussions with T. Daniel Butler and colleagues of the Fluid Dynamics Group at the Los Alamos National Laboratory (LANL), another possible general purpose fluids program was identified-TEMPEST (Trent et al., 1983). It appeared to have the features desired, 
and the authors were extremely cooperative in making a version available for the CDC 7600 at LANL. TEMPEST was subsequently chosen and applied to the problem.

\subsection{Code Description}

TEMPEST (Transient Energy, Momentum, and Pressure Equation Solution in Three dimensions) was developed by Battelle Pacific Northwest Laboratory (PNL) using the Computer Center at LANL. It is a transient, three-dimensional, finite-difference hydrothermal code designed to analyze a broad range of coupled fluid dynamic and heat-transfer systems. The initial objective of the development program was to develop a state-of-the-art computer code that could be used for design analysis of component thermal hydraulics for liquid metal, fast breeder reactors.

TEMPEST provides finite-difference solutions to the equations governing mass, momentum, and energy conservation for incompressible flows with small density variations (Boussinesq approximation). Analyses may be conducted in either cylindrical or Cartesian coordinate systems. The finite-difference approach for the fluid-flow solution is similar to the Los Alamos SMAC method (Amsden and Harlow, 1970) whereby the momentum and energy equations are solved explicitly, and the continuity/pressure solution is obtained implicitly. Although the TEMPEST technical approach is based on standard techniques, it contains the unique feature of fully coupled hydrodynamic and solid material heat diffusion solutions. The energy equation is treated using an implicit procedure. The code can be used to solve heat-conduction problems, although it is not as geometrically general as other codes designed especially for this purpose (Edwards, 1972).

The numerical basis and user input for the code are described by Trent et al. (1983). For code assessment and validation, predictions have been compared with experimental data, analytical solutions, and predictions of other codes in a separate report by Eyler et al. (1983).

One constraint on the use of the code is that it is considered to fall within the Applied Technology regulations of the U.S. Department of Energy. Therefore, further distribution of the PNL reports on it or the data therein to third parties related to foreign interests should be coordinated with the Deputy Assistant Secretary for Breeder Reactor Programs, Department of Energy. However, presentation of predictions generated with the code and qualitative description of its general features are allowable in the open literature (Eyler, 1985).

One objective of the TEMPEST code development effort was to provide a user-oriented hydrothermal analysis tool that is capable of resolving a wide range of hydrothermal flow problems. To satisfy this objective, TEMPEST was developed with several basic features. These include

- fully three-dimensional with one- and two-dimensional capabilities included, with circular or rectangular coordinates;

- time-dependent, coupled heat-transfer and fluid dynamics;

- capability for steady-state heat transfer only;

- capability to predict spatial- and time-varying turbulent effects on transport processes over a wide range of flow conditions and geometry; and

- self-contained FORTRAN code operational on a CDC-7600 computer but modifiable to run on other computers with minimal effort.

In addition to these basic features, particular emphasis was placed on

- single-phase flow and geometries typical of conditions in fast breeder reactor designs;

- ease of use through input specification and the consequent elimination of the need for internal coding changes;

- minimization of computation time; and 
- validation of numerics and modeled physics.

Development of the TEMPEST computer code under these general guidelines resulted in a finitedifference code with rather extensive capabilities. These are summarized by categories as follows:

- Modeling Capabilities

full three-dimensional with one- or two-dimensional options,

time-dependent with transient approach to steady state,

turbulence models ( $k-\epsilon$ model),

Cartesian or cylindrical coordinates,

heat diffusion in solid regions,

full implicit solution to the thermal energy equation and all scalar equations,

direct solution for thermal steady state,

multiple flow regions (may be connected through conduction heat transfer),

arbitrary orientation of solution coordinate system (with respect to gravity),

variable grid spacing along all or any coordinate direction(8),

use of specified or precomputed flow regions,

internal heat generation (20 time-dependent tables possible on a node-by-node or material-

by-material basis),

50 different material types,

inflow/outflow boundaries specified or computed,

time-dependent flow and thermal boundary condition tables (20 tables possible),

variable materials properties (thermal conductivity and viscosity),

single-cell width or zero-width wall logic,

drag coefficient correlations for each direction of each cell (98 different coefficient types avail-

able for input specification),

film coefficient for each direction of each cell,

partial material properties table built in,

wind shear, and

planetary Coriolis effects.

- Program Control

hydrodynamics only,

solids beat transfer only,

decoupled hydrodynamics (no buoyancy effects),

fully coupled hydrodynamics and heat transfer (Boussinesq approximation),

inviscid hydrodynamics,

variable eddy transport coefficients (e.g., two-equation turbulence model),

steady-state thermal solution,

ability to obtain steady-state thermal solution at each hydrodynamic time step,

internal wave stability control,

automatic time-stepping and stability control,

restart at any filed time, and

computation in either the U.S. Customary System of engineering units or the International System (SI) of units.

- I/O Control

input debug output and control (limited),

internal bookkeeping debug output options,

cell-type/material-type maps, 
intermediate output including heat-transfer connectors, cell continuity, density, thermal conductivity, molecular viscosity, eddy viscosity, turbulence quantities, heat flux map, numerical stability map, and heat generation, all primary variables with either $\mathrm{R}-\mathrm{Z}, \mathrm{R}-\mathrm{X}$, or Z-X arrays on output page, ability to specify print/file time, choice of either the engineering or SI system of units for input data supplied for the same run, partial skip of printing, result and execution time monitoring, and postprocessing graphics (including contours, vectors, and line plots).

Limitations of the code are as follows:

- Flow is incompressible only.

- Computational cell structure must be in rows/columns/tiers.

- Only Cartesian or cylindrical coordinates are allowed (regions cannot have mixed coordinates).

- Hydrodynamic solution is explicit in time - no direct solution for steady state.

- Pressure boundary conditions are not available.

- Curved boundaries (except circular) must be "stair-stepped."

The TEMPEST code simulates flow and thermal fields subject to the following assumptions and/or restrictions:

- The fiuid is single phase and incompressible (insofar as sonic effects are not considered).

- Body forces other than gravity are not considered. Forces resulting from accelerating reference frame are included.

- The fluid is Newtonian (for laminar situations, Navier-Stokes equations apply).

- The turbulent flow conservation equations are time averaged, and Reynolds stresses are incorporated through appropriate eddy viscosity models.

- Viscous dissipation is eliminated.

- The Boussinesq approximation holds.

Although TEMPEST is a reasonably easy code to use, it contains a number of operational modes that must be fully understood by the user. In addition, the user should be somewhat familiar with computational fluid mechanics and heat transfer to ensure that the code is not misused and that the accuracy of the results is properly assessed. Grid configuration is a particularly important aspect of the code usage, and it is essential that the user generally understand how the solution time step and accuracy may be affected by a poorly chosen grid. Certain convergence criteria can be important aspects of solution accuracy. For instance, a fairly large continuity error might be tolerated for certain thermally decoupled flows, whereas the error criterion might need to be quite small for certain buoyancy-induced flows.

For low-speed flows that involve small density variations (i.e., $\Delta \rho / \rho<<1$ ), the well-known Boussinesq approximation is valid. This approximation is commonly used in natural-convection simulations involving either liquids or gases. While the approximation is consistent with the accuracy of other approximations required for numerical simulation, its validity is questionable if density changes considered are large compared to local fluid density. Whereas most simulations involving liquid systems are within the valid range of this approximation, care should be exercised in gaseous systems, where temporal and spatial temperature changes may be large. The obvious reason for invoking the Boussinesq approximation in TEMPEST is that some simplification of the governing equations is possible by treating density as constant in all terms except the body force terms of the momentum equations.

The premise of "simple problem correctness" was the program author's foundation of TEMPEST assessment and validation philosophy. The approach used to support the premise was twofold. The 
first step was to verify coding. The second step was to validate the modeled physics. These two steps, however, are not completely independent.

There are numerous approaches to verification of coding logic. The basic approach that was used in the TEMPEST development is summarized as follows:

- Critical coding has been double-checked by cognizant personnel who did not do the programming; however, it is not economically practical to check the entire program in this manner.

- Code logic has been extensively exercised to ensure that input, setup, and other bookkeeping phases work correctly.

- Printing of intermediate computation debugging output has been made available by input command for hand checking.

Validating modeled physics is a more involved process. TEMPEST predictions have variously been compared to analytical results, results predicted by other codes, and experimental data (Eyler et al., 1983). Each case has provided incremental support to conclusions concerning the correctness and accuracy of TEMPEST predictions.

There are a number of analytical solutions available in technical journals and textbooks, which are readily available for code validation. Most of these, however, are analytical conduction heat-transfer solutions. Analytical solutions for hydrodynamics are more limited. Several, such as the laminar plane channel, pipe, and duct flow, have been used.

There is a wealth of information published in technical literature regarding computed results, which have been compared with experimental data. These results are invaluable because they are most often simple, separate effects simulations, and both code results and data are already compared. It is also useful to obtain and use other computer codes to run side-by-side simulations of identical problems. This has been done using TEACH (Gosman and Pun, 1973). This code has considerably less capability than does TEMPEST, but TEMPEST can simulate problems within the capabilities of the TEACH code. In this respect TEACH was very valuable in assessing the TEMPEST turbulence model.

Comparison of predicted results with experimental data is, perhaps, the best test of modeled physics. Data for separate effects and small-scale experiments are readily available in open literature. While data for large-scale experiments are less available, sufficient large-scale data were available to test the more pertinent aspects of numerically modeled flows.

Conduction heat-transfer tests are reported in Section 3.0 of the report by Eyler et al. (1983). One-, two-, and three-dimensional transient and steady-state tests have been completed in both Cartesian and cylindrical geometries using various initial and boundary conditions. These tests indicated that the thermal solution algorithm works properly in its various user-selectable modes and that accurate temperatures are predicted. Extensive laminar flow simulation tests are presented in Section 4.0 of their report. Results were variously compared with data and with analytical and computed results. Both isothermal and nonisothermal results have been assessed along with various code operational modes. These results have led to the conclusion that the basic finite differencing and solution algorithms for hydrodynamics are correct.

Turbulent flow model testing results are presented in their Section 5.0. Solution algorithms for the two-equation $\boldsymbol{k}-\epsilon$ model have been confirmed as working correctly. Basic physics of turbulent flows inherent to the $k-\epsilon$ modeling assumptions, such as free shear decay, shear production, etc., have been tested and compared with data and other results. Applied boundary conditions for the turbulence transport equations have been extensively checked and confirmed to be working correctly within limits of assumptions applied.

All of the testing results, when considered in totality, represent extensive assessment and validation of the TEMPEST code. They satisfy the objective of the code validation: to demonstrate that the 
coding logic is working correctly, that the physics are modeled properly in the code, and that the code operates as advertised. The code authors note that additional validation could and will be done as the code is used for more application-oriented analyses of large-scale and actual operating systems. The present study of diabatic natural convection in inclined tubes should provide some further testing and comparison with experimental results.

\subsection{Idealized Geometry}

In order to allow for most features of the experimental apparatus in an idealized manner, a threedimensional, circular coordinate system was chosen with multiple regions. However, to reduce computer time and storage requirements, a very coarse grid was selected. Including dummy nodes required by the calculation technique, the grid consisted of 6 nodes in the radial direction and 12 axially. The circumferential direction was represented by 8 nodes on $45^{\circ}$ planes plus cyclical (or repeating) nodes at each end, for a total of 10 . Thus, the three-dimensional geometry was modeled by 720 nodes overall. Spacing was variable in the radial and axial directions and uniform circumferentially.

Most calculations were conducted with one of two configurations sketched in Fig. 4.2. Initial efforts employed the model of Fig. 4.2(a), which corresponds more closely to the features of the apparatus. The second version, Fig. 4.2(b), evolved in the testing of the code; it was employed for the predictions developed for comparison to the steady or quasi-steady experiments. The electrical resistance heating was modeled by volumetric energy generation sources in appropriate cells since the code does not include direct provision for a specified wall heat flux as a boundary condition. In these sketches, the following symbols are employed for the cells:

$$
\begin{aligned}
& \mathbf{A}=\text { adiabatic, } \\
& \mathbf{C u}=\text { copper, } \\
& \mathbf{D}=\text { dummy, } \\
& \mathbf{G}=\text { fluid cells with internal energy generation, } \\
& \mathbf{I}=\text { insulation, } \\
& \mathrm{T}=\text { specified temperature (cooler), and } \\
& \infty \quad=\text { specified environmental temperature. }
\end{aligned}
$$

Cells without a symbol represent liquid.

Dimensions $\Delta r$ and $\Delta z$ shown are typical values usually used to simulate the experimental apparatus. The variable spacing was applied to concentrate nodes near the cooler end where the largest temperature gradients were expected. The large aspect ratios $\Delta L / D$ of the axial spacing along most of the tube probably prevent identifying cellular structures that could occur at some inclination angles and heating rates. These dimensions and the material properties were modified for convenience in some of the test cases.

\subsection{Test Cases}

In addition to the verification studies conducted by Eyler et al. (1983), a few tests of the TEMPEST code were applied for limiting situations related to the geometry of the inclined natural convection experiment. The general features of the experimental apparatus were approximated by the numerical grid specified, then quantities were adjusted to represent simple idealized cases for which closed-form solutions are available. Unfortunately, this approach only exercised the thermal aspects of the problem, since a closed-form solution for natural convection in a tubular enclosure is not known to the authors. [By modifying the dimensions and boundary conditions considerably, one might simulate 


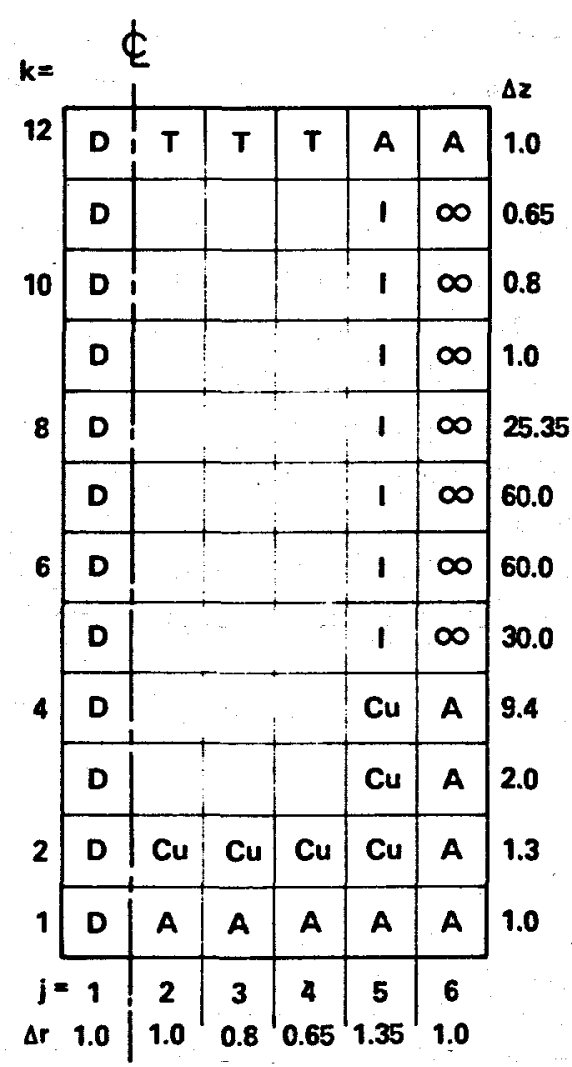

a. EARLY REPRESENTATION

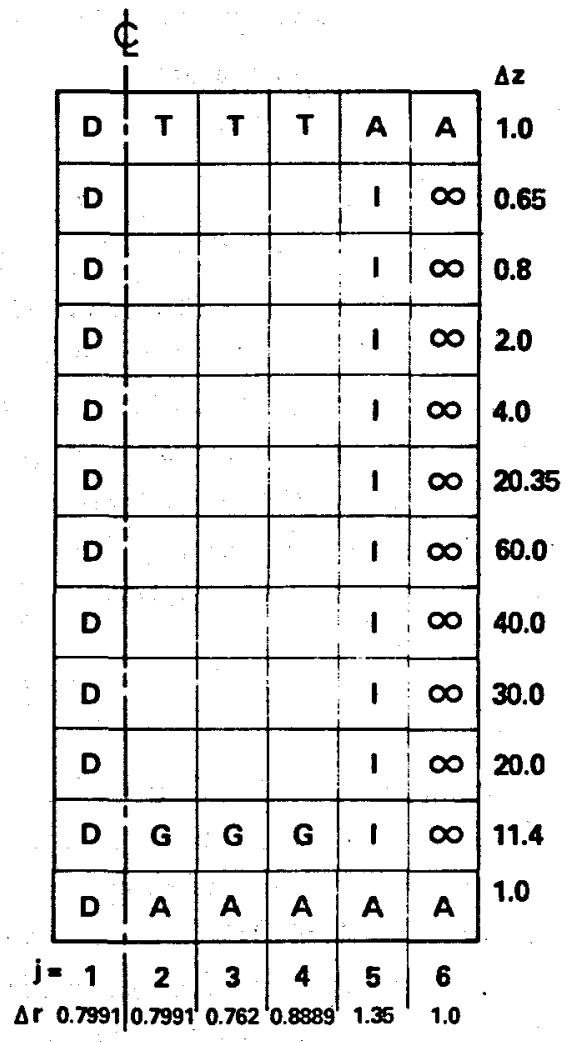

b. LATER MODEL

Fig. 4.2. Typical configurations of computational cells (sizes in $\mathrm{cm}$ ). See text for explanation of symbols.

natural convection from a vertical plate (Ostrach, 1953) or stability of a layer heated from below, but these approaches were not attempted.]

It is recognized that the grid is so coarse that the flow field is likely grid-dependent, possibly missing details such as corner eddies. However, since the flow is considered to be laminar in the range studied, the heat transfer perpendicular to the streamlines is by molecular conduction. These test cases provide some measure of the accuracy of that aspect of the predictions with the grid employed. Further, they examine whether there are any surprises revealed in these simple limiting cases.

In the following discussion, control card options (in capital letters) and cell types are presented in the terminology of the code (Trent et al., 1983) in order to assist the reader attempting to use the code.

4.4.1. Steady, One-Dimensional Conduction. In order to test application of the TEMPEST code to the simplest situation for which a closed-form solution exists, while still relating to the features of our experiment, the input was adjusted to approach a steady axial heat flow by conduction. For this situation a predictable linear temperature distribution

$$
\frac{\partial t}{\partial z}=\frac{-q}{k A_{c \varepsilon}}=\text { constant }
$$

would be expected except in the vicinity of the circumferential heater at the lower end.

Initial attempts were conducted by adjusting the outside wall heat-transfer coefficients and the thermal conductivity of the wall insulation to very low values, $0.01 \mathrm{Btu} / \mathrm{hr} \mathrm{ft}^{2}{ }^{\circ} \mathrm{F}\left(0.06 \mathrm{~W} / \mathrm{m}^{2}{ }^{\circ} \mathrm{C}\right)$ and 
$0.0001 \mathrm{Btu} / \mathrm{hr} \mathrm{ft}{ }^{\circ} \mathrm{F}\left(0.0002 \mathrm{~W} / \mathrm{m}{ }^{\circ} \mathrm{C}\right)$, respectively. Later the nodes representing wall insulation were made adiabatic nodes, cell type 50. Two equivalent approaches were employed using options on the control cards:

a) SEAL and VFIX;

b) single step from V $=0$ then VFIX and TESS (Thermal Energy Steady State).

In both cases, options HEAT, UNCP, and BESQ (and CYLN) were utilized. Approach (a) was used most often. Thus, the main variation of the input was LITMAX on the SEAL card, the maximum number of iterations of the steady-state energy equation. Solution is by an alternating-direction, linesuccessive-over-relaxation approach (Trent et al., 1983, pp. 3.32 and 4.29).

In the initial arrangement, convergence toward the proper linear temperature profile was very slow. The default value of 20 iterations was raised to 100 , then 500 , without approaching the proper shape or magnitude. The solution appeared as one would expect a transient to develop, propagating from the ends along the axis, although the code does not calculate the transient (storage) terms with options SEAL or TESS.

After consultation with L.L. Eyler of PNL, a number of additional variations were attempted with the adiabatic wall:

a) uniform spacing in axial direction;

b) uniform but different spacing in each direction;

c) equal thermal conductivities;

d) removal of control HEAT (did not calculate energy equation);

e) removal or control PACE and force of "large" time step.

Slight variations in the results were observed, but no fundamental difference nor substantial improvement appeared. Numbers of nodes and general geometry were kept fixed; consequently, maximum cell aspect ratios were about 15 to 20 , depending on the computer run.

At PNL, Eyler conducted test cases as well. Using heating boundary conditions at the bottom end, instead of the bottom sides, he found fair success for a circular geometry of aspect ratio 20. Uniform grids $10 \times 20$ (2D) and $10 \times 20 \times 10$ (3D) were tested, and the steady-state energy balance check was within $0.3 \%$ by 50 iterations. However, using input geometries comparable to ours, he still found slow convergence while varying miscellaneous control parameters.

As pointed out by Frankel (1950) and Roache (1976), when alternating direction methods are applied to elliptic problems, the iteration number can be considered analogous to the time step in a parabolic equation. However, it appears that the side wall heating, combined with cells of large aspect ratios, may require more iterations than one would normally expect. Accordingly, it was decided to model the experimental configuration via an end heating condition rather than the more realistic copper heater. It is possible that a direct solution for the $r-z$ plane would be more effective for the small number of nodes involved, but neither sufficient time nor the source code was available at the time.

4.4.2. Transient Approach to Steady-State, Pure Conduction. Calculations were conducted to test the transient solution to the energy equation with configurations comparable to the experimental apparatus. Approximations to test both axial and radial transport as near one-dimensional situations were utilized.

4.1.2.a. Axial, One-Dimensional Transport. In order to check predictions of pure axial conduction along a cylinder, the insulation nodes along the tube wall were replaced by adiabatic nodes (type 50) and uniform spacing was employed with $\Delta r=1 \mathrm{~cm}$ and $\Delta z=15 \mathrm{~cm}$. Cells at $k=2$ and $j=2,3$, and 4 were denoted as cells with internal energy generation at $8.8 \mathrm{Btu} / \mathrm{in}^{3} \mathrm{hr}$. Temperatures at the top $(j=2$ to $4, k=12)$ were held at $75^{\circ} \mathrm{F}\left(23.9^{\circ} \mathrm{C}\right)$, which was taken as the initial temperature as well. The full three-dimensional, circular problem was solved. 
Options UNCP and VFIX were used to constrain velocities to the initial values, $V=0$. Fluid and copper properties were taken to be the same with $\alpha=3.56 \mathrm{ft}^{2} / \mathrm{hr}\left(0.331 \mathrm{~m}^{2} / \mathrm{hr}\right)$. The limiting time step for an explicit solution of the energy equation would have been of the order

$$
\Delta \theta \leq \frac{1}{2} \frac{(\Delta r)^{2}}{\alpha} \simeq 1.5 \times 10^{-4} \mathrm{hr} \simeq 0.5 \mathrm{~s} .
$$

However, a fixed time step of $0.1 \mathrm{hr}$ was employed. It was expected that the temperature distribution would be close to the steady-state value when the Fourier number (or nondimensional time), $F_{0}=\alpha \theta / L^{2}$, is of the order of 2 . For a $150-\mathrm{cm}$ length, this value corresponds to about 14 simulated hours or 140 time steps. Central processor time on the CDC 7600 was about 30 seconds for 200 time steps.

The transient response is depicted in Fig. 4.3. The three-dimensional calculations yielded the expected one-dimensional results. Behavior at short times appears reasonable, with the temperature profile near the source increasing energy with the approximate shape expected for the sudden imposition of a constant heat fiux at an interface (Incropera and deWitt, 1981). The steady-state result would be a linear profile $t(z)$ with the slope given by

$$
\frac{d t}{d z}=-\frac{q^{\prime \prime}}{k} \simeq 34 \frac{{ }^{\circ} \mathrm{F}}{\mathrm{ft}} \simeq 62 \frac{{ }^{\circ} \mathrm{C}}{\mathrm{m}}
$$

The predictions for $\theta=20$ hours are in close agreement.

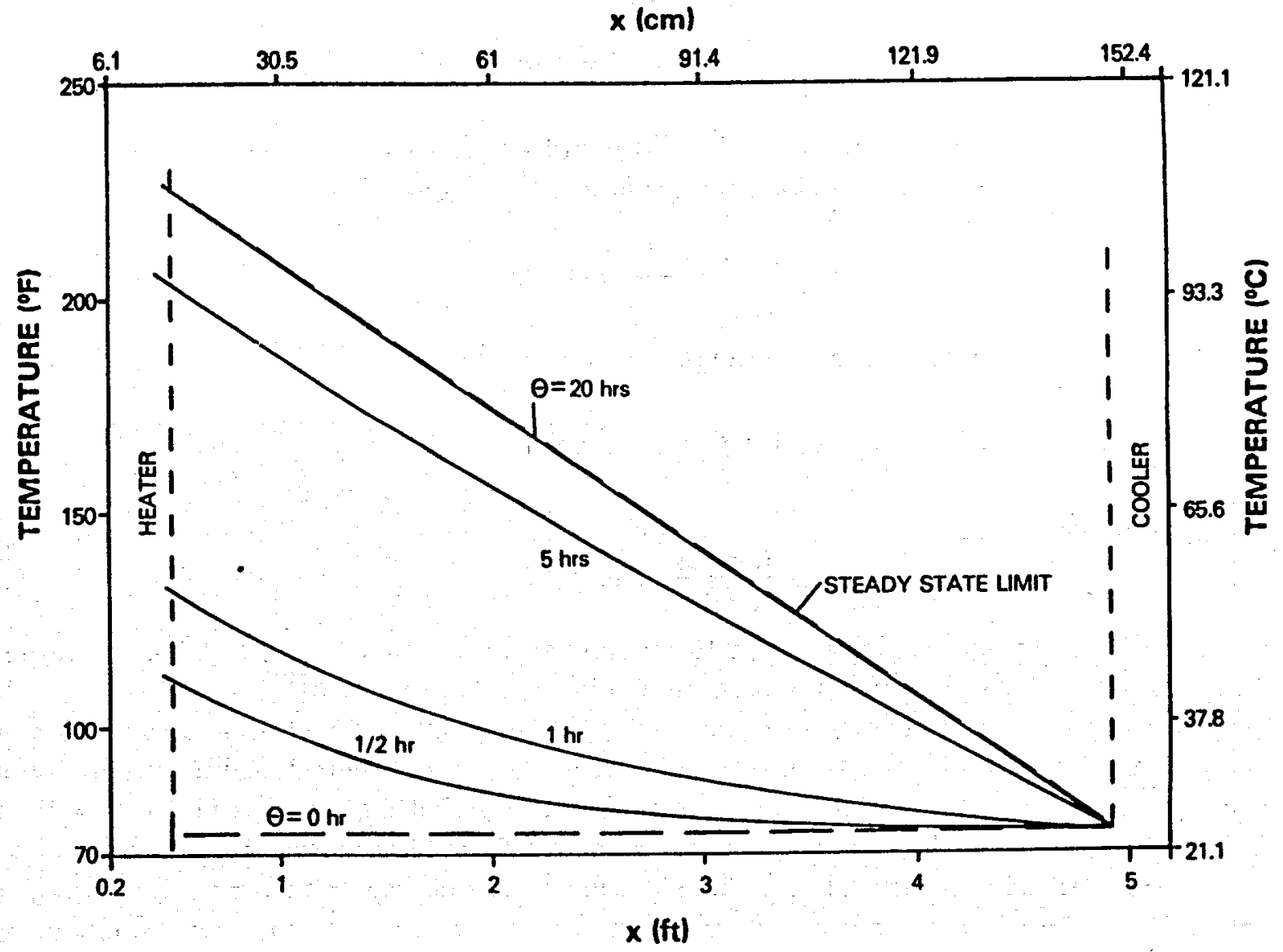

Fig. 4.3. Transient, approximately one-dimensional conduction in axial direction. 
Calculations with a time step shorter by a factor of $10(\Delta \theta=0.01 \mathrm{hr})$ gave a slightly different response for early times. For example, at a monitored node at $\mathrm{k}=7$, predictions at $\theta=0.1 \mathrm{hr}$ were $75.035^{\circ} \mathrm{F}\left(23.908^{\circ} \mathrm{C}\right)$ instead of $75.096^{\circ} \mathrm{F}\left(23.942^{\circ} \mathrm{C}\right)$ and at $\theta=0.5 \mathrm{hr}, 79.460^{\circ} \mathrm{F}\left(26.367^{\circ} \mathrm{C}\right)$ versus $79.505^{\circ} \mathrm{F}\left(26.392^{\circ} \mathrm{C}\right)$.

While the transient calculation showed the temperature profile approaching steady state within $10 \%$ by 5 hours or 50 time steps, a calculation applying the TESS option to give a direct steady-state estimate hardly changed from the initial condition after 50 iterations. The heater nodes had only reached $84.3^{\circ} \mathrm{F}\left(29.1^{\circ} \mathrm{C}\right)$ rather than the steady-state result of about $230^{\circ} \mathrm{F}\left(110^{\circ} \mathrm{C}\right)$. This difficulty corresponds to that mentioned earlier.

4.1.2.b. Radial, One-Dimensional Transport. Transient predictions were conducted for a circular rod with a step change in surrounding temperature. By using the approximate aspect ratio of the experiment and zero energy generation rate, the thermal response at early times in the lower part of the tube should become essentially one-dimensional with significant variation only in the radial direction. Graphical predictions for this case are presented in most introductory heat-transfer texts (Incropera and deWitt, 1981).

Zero fluid velocity was enforced by applying options UNCP and VFIX. Axial spacing was the same as for simulation of the experiment, while the radial spacing was set as $\Delta r=0.7,0.8,0.8$, and $0.7 \mathrm{~cm}$ for cells 2 through 5 (fluid plus insulation). Fluid and insulation properties were taken to be identical:

$$
\begin{aligned}
k & =0.29 \mathrm{Btu} / \mathrm{hr} \mathrm{ft}^{\circ} \mathrm{F}=0.50 \mathrm{~W} / \mathrm{m}^{\circ} \mathrm{C} \\
\rho & =62.0 \mathrm{lbm} / \mathrm{ft}^{3}=993 \mathrm{~kg} / \mathrm{m}^{3} \\
c_{p} & =0.998 \mathrm{Btu} / 1 \mathrm{bm}{ }^{\circ} \mathrm{F}=4.18 \mathrm{~kJ} / \mathrm{kg}^{\circ} \mathrm{C}
\end{aligned}
$$

giving $\alpha \simeq 0.0047 \mathrm{ft}^{2} / \mathrm{hr}\left(4.4 \times 10^{-4} \mathrm{~m}^{2} / \mathrm{hr}\right)$. The external heat-transfer coefficient was chosen as 2.946 $\mathrm{Btu} / \mathrm{hr} \mathrm{ft}^{2}{ }^{\circ} \mathrm{F}\left(16.73 \mathrm{~W} / \mathrm{m}^{2}{ }^{\circ} \mathrm{C}\right)$. Therefore, the reciprocal Biot number was

$$
B i^{-1}=\frac{k}{\mathrm{hr}_{\mathrm{w}}}=1.00 .
$$

For $B i=1$, the centerline response for the range

$$
0.4 \leq F o=\frac{\alpha \theta}{r_{w}^{2}} \leq 4
$$

can be approximated as

$$
\frac{t_{c}-t_{\infty}}{t_{i}-t_{\infty}} \simeq a e^{-b F_{0}},
$$

which is plotted on Fig. 4.4 [e.g., see Fig. 4-10 by Holman (1976)]. For $r / r_{w} \lesssim 0.35$, the response should be within $5 \%$ of the centerline temperature (Holman, 1976, Fig. 4-13).

Three-dimensional calculations were conducted with $\Delta \theta=0.2 \mathrm{hr}$ for 40 time steps or 8 hours. Examination of the predictions shows axisymmetry along the tube. Conduction was essentially onedimensional in the lower part at early times and for the full period for $z<4 \mathrm{ft}(1.3 \mathrm{~m})$. With the CDC 7600, calculation time was $1.06 \mathrm{cpu}$ seconds or about 0.08 milliseconds/(cell $\cdot \Delta \theta)$.

Results are presented on Fig. 4.4 as well. The square symbols represent temperatures at $j=2$ and $k=3$ or $\left(r / r_{w}\right)=0.117$ and $z=0.70 \mathrm{ft}(0.23 \mathrm{~m})$, near the centerline at the lower, adiabatic end. Agreement is good throughout. The round symbols are for $j=3$ and $k=7$, or $\left(r / r_{w}\right)=0.367$ and $z=5.63 \mathrm{ft}(1.72 \mathrm{~m})$ near the upper end, which was held at a constant temperature; agreement is good 


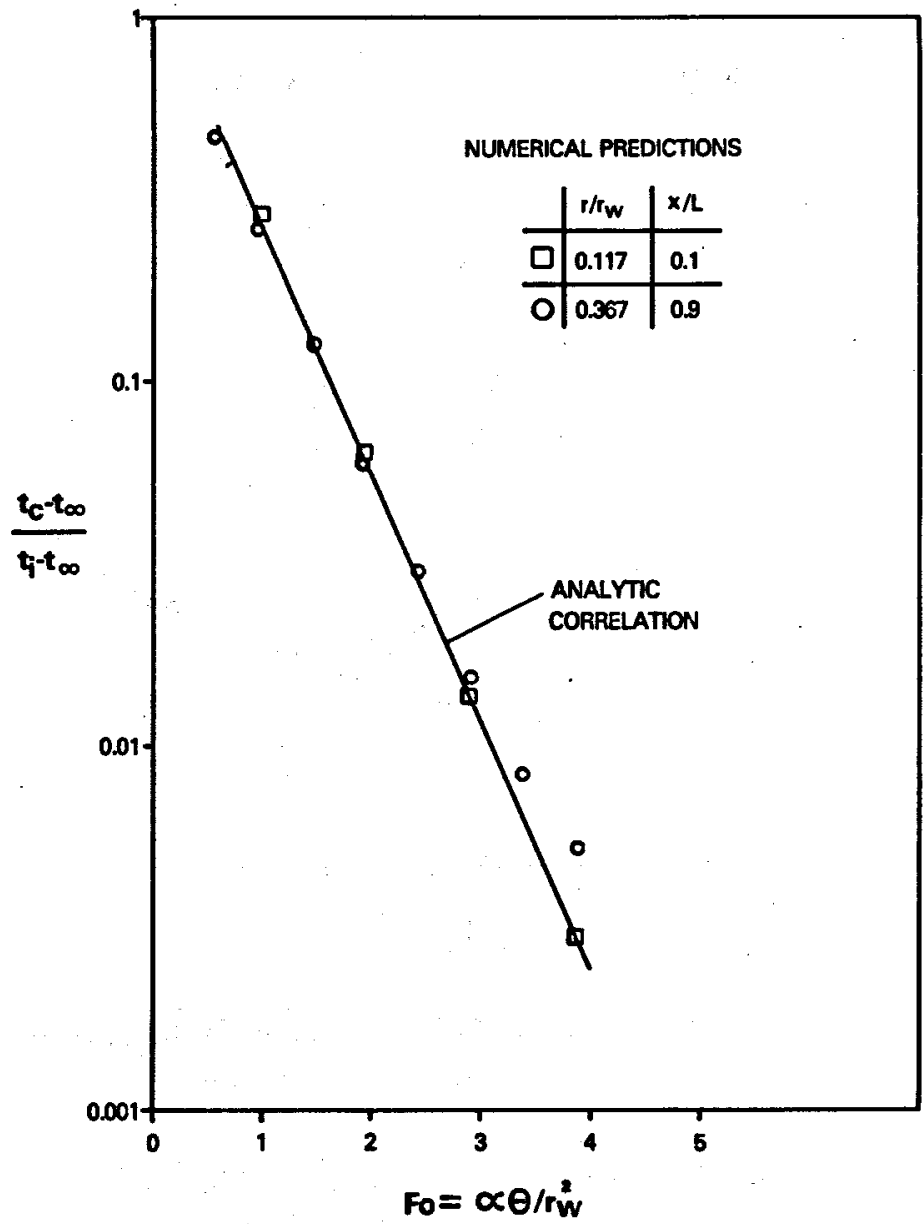

Fig. 4.4. Transient, approximately one-dimensional conduction in the radial direction.

at low nondimensional times, but for $F o>2$ the one-dimensional approximation is no longer valid at this location.

4.4.2.c. Fin Solution. The capabilities of the code were also compared to predictions from steadystate, extended surface ("fin") theory (Incropera and deWitt, 1981). The key assumption of the theory is that the temperature is isothermal throughout the cross section at any instant. This situation occurs when the Biot number is low, e.g., $B i<0.1$ or so. Then, for a specified base temperature and an adiabatic tip, the axial temperature distribution is predicted to be

$$
\frac{t-t_{\infty}}{t_{0}-t_{\infty}}=\frac{\cosh m(L-z)}{\cosh m L}=\frac{\cosh \{m L(1-z / L)\}}{\cosh m L}
$$

where $m=\sqrt{h P /\left(k A_{c s}\right)}$.

Input parameters were adjusted to approximate this situation. Insulation and fluid properties were taken as

$$
\begin{aligned}
k & =2.9 \mathrm{Btu} / \mathrm{hr} \mathrm{ft}^{\circ} \mathrm{F}=5.0 \mathrm{~W} / \mathrm{m}^{\circ} \mathrm{C} \\
\rho & =62.0 \mathrm{lbm} / \mathrm{ft}^{3}=993 \mathrm{~kg} / \mathrm{m}^{3} \\
c_{p} & =0.998 \mathrm{Btu} / \mathrm{lbm}{ }^{\circ} \mathrm{F}=4.18 \mathrm{~kJ} / \mathrm{kg}^{\circ} \mathrm{C} \\
\alpha & =0.047 \mathrm{ft}^{2} / \mathrm{hr}=0.0044 \mathrm{~m}^{2} / \mathrm{hr}
\end{aligned}
$$




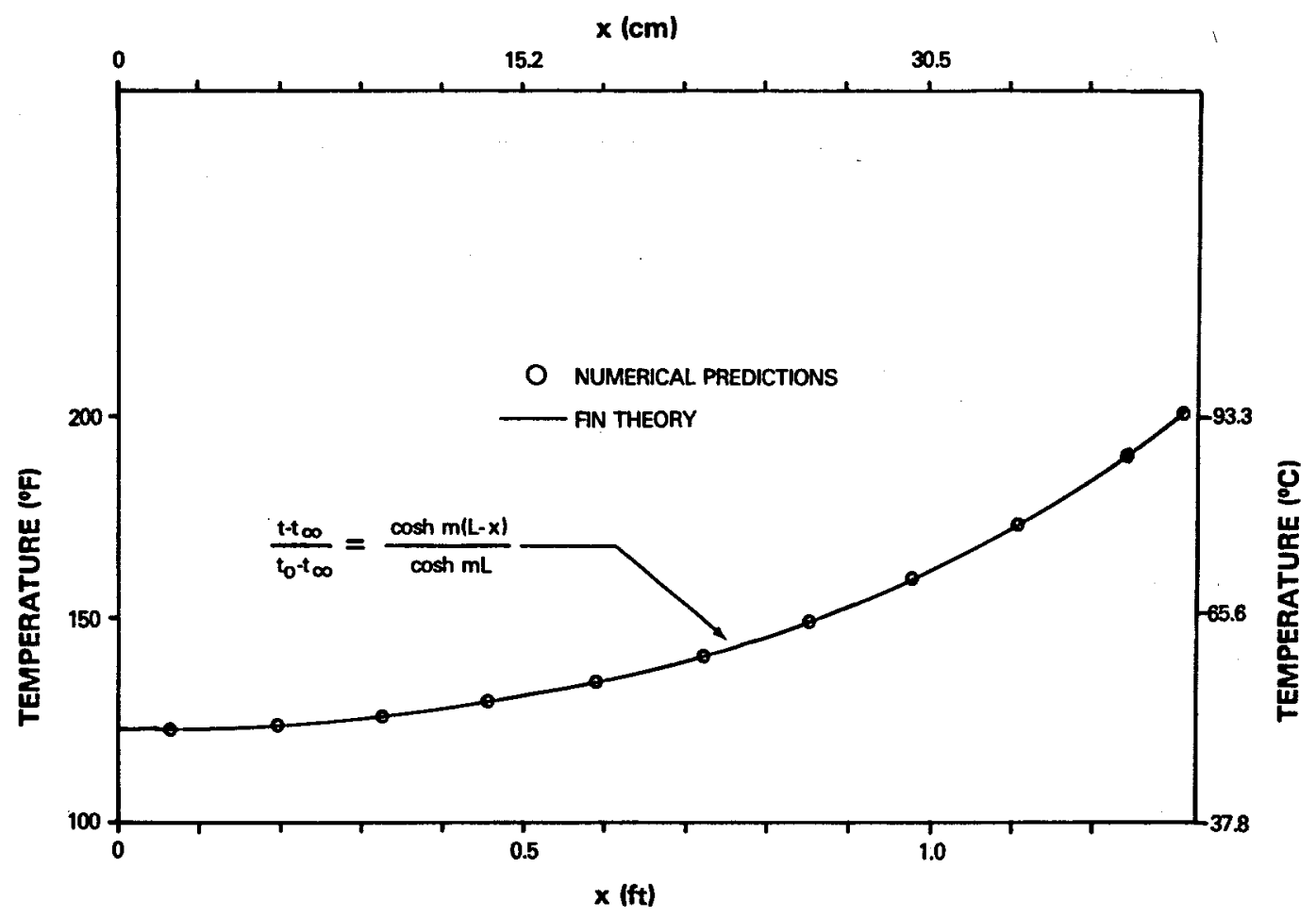

Fig. 4.5. Test of TEMPEST predictions versus extended surface (fin) theory.

with an external heat-transfer coefficient,

$$
h=0.5 \mathrm{Btu} / \mathrm{hr} \mathrm{ft}^{2}{ }^{\circ} \mathrm{F}=2.84 \mathrm{~W} / \mathrm{m}^{2}{ }^{\circ} \mathrm{C} .
$$

Radial cells were distributed as in the simulation of the experiment, giving $r_{w}=0.125 \mathrm{ft}(3.8 \mathrm{~cm})$, and uniform spacing of $\Delta z=4 \mathrm{~cm}$ was employed in the axial direction. Therefore, the Biot number was

$$
B i=\frac{h V}{k A_{s}}=\frac{h r_{w}}{2 k}=0.011
$$

which satisfies the key idealization for isothermal cross sections. Nondimensional length was

$$
m L=\sqrt{\frac{h P}{k A_{c s}}} L=\frac{2 L}{r_{w}} \sqrt{B i}=2.2,
$$

which corresponds to a fin of intermediate length.

Options UNCP and VFIX were selected to insure pure conduction. A three-dimensional calculation was conducted. A step change in top temperature was applied to provide the transient approach to steady state. The other end was kept adiabatic. Time steps of $0.4 \mathrm{hr}$ were used for 250 intervals or 100 hours to give a length-based Fourier number of

$$
F o=\frac{\alpha \theta}{L^{2}}=2.7
$$

which was believed to be long enough to approach steady state within a percent or so. Actually a monitor cell at $k=2$, near the lower end, showed steady predictions within four significant digits by about 44 hours.

Results were axisymmetric and near isothermal at each cross section (within $0.2^{\circ} \mathrm{F} \simeq 0.1^{\circ} \mathrm{C} \simeq$ $0.2 \%$ ). The axial temperature distribution is compared to the analytical solution in Fig. 4.5. Agreement is better than one would hope. 


\section{COMPARISON BETWEEN EXPERIMENTS AND PREDICTIONS}

Predictions were conducted with the TEMPEST code. A coarse grid was applied in an attempt to avoid large computer storage and long computer run times. The cell configuration selected with variable spacing has been described earlier with Fig. 4.2(b). Predictions were calculated with the constant property idealization, except for the Boussinesq approximation. The fluid temperature was usually taken as $100^{\circ} \mathrm{F}\left(\sim 38^{\circ} \mathrm{C}\right)$ to evaluate the fluid properties. Properties employed are listed in Table 5.1.

\section{TABLE 5.1. PROPERTIES EMPLOYED IN THE NUMERICAL SIMULATIONS}

$$
\begin{aligned}
& \text { Fluid (evaluated at } 100^{\circ} \mathrm{F}=37^{\circ} \mathrm{C} \text { ) } \\
& k=0.29 \mathrm{Btu} / \mathrm{hr} \mathrm{ft}{ }^{\circ} \mathrm{F}=0.50 \mathrm{~W} / \mathrm{m}^{\circ} \mathrm{C} \\
& \mathrm{cp}=0.998 \mathrm{Btu} / \mathrm{lbm}{ }^{\circ} \mathrm{F}=4.18 \mathrm{~kJ} / \mathrm{kg}^{\circ} \mathrm{C} \\
& \mu=0.0269 \mathrm{lbm} / \mathrm{ft} \mathrm{sec}=40 \mathrm{cp}=0.040 \mathrm{~N} \cdot \mathrm{s} / \mathrm{m}^{2} \\
& \rho_{0}=62.0 \mathrm{lbm} / \mathrm{ft}^{3}=993 \mathrm{~kg} / \mathrm{m}^{3} \\
& \operatorname{Pr}=334
\end{aligned}
$$

and, for buoyancy force,

$\begin{array}{llll}t & 40^{\circ} \mathrm{F}\left(4^{\circ} \mathrm{C}\right) & 100^{\circ} \mathrm{F}\left(38^{\circ} \mathrm{C}\right) & 220^{\circ} \mathrm{F}\left(104^{\circ} \mathrm{C}\right) \\ \rho(t) \mathrm{lbm} / \mathrm{ft}^{3} & 62.42 & 62.0 & 59.63 \\ \rho(t) \mathrm{kg} / \mathrm{m}^{3} & 1000.0 & 993.0 & 955.3\end{array}$

\section{Insulation}

$$
\begin{aligned}
\text { Thickness } & =0.53 \mathrm{in} . & =1.35 \mathrm{~cm} \\
k & =0.024 \mathrm{Btu} / \mathrm{hr} \mathrm{ft}^{\circ} \mathrm{F} & =0.042 \mathrm{~W} / \mathrm{m}{ }^{\circ} \mathrm{C} \\
\mathrm{P} & =4 \mathrm{lbm} / \mathrm{ft}^{3} & =64 \mathrm{~kg} / \mathrm{m}^{3} \\
\mathrm{cp} & =0.2 \mathrm{Btu} / \mathrm{lbm}{ }^{\circ} \mathrm{F} & =0.84 \mathrm{~kJ} / \mathrm{kg}^{\circ} \mathrm{C}
\end{aligned}
$$

\section{External Heat-Transfer Coefficient}

$$
h_{\infty}=6.5 \mathrm{Btu} / \mathrm{hr} \mathrm{ft}^{2}{ }^{\circ} \mathrm{F}=37 \mathrm{~W} / \mathrm{m}^{2}{ }^{\circ} \mathrm{C}
$$

\subsection{Numerical Prediction Technique - Time Scales}

Since TEMPEST solves the transient momentum equations via an explicit numerical technique, there is a large disparity between the various time scales occurring in the calculation. In attempting to handle some of the regions where large gradients were expected while using a coarse grid, some cell aspect ratios became large. For example, the ratio of the largest-to-smallest spacing was $60 / 0.65=92$. 
For insight into the time scales problem, it is convenient to consider the criteria that would apply if the problem were one-dimensional (Incropera and deWitt, 1981). For the energy equation, an explicit calculation would require a time step of

$$
\frac{\alpha \Delta \theta}{(\Delta x)^{2}} \leq \frac{1}{2} \quad \text { or } \quad \Delta \theta \leq \frac{1}{2} \frac{(\Delta x)^{2}}{\alpha} .
$$

For the materials in the experiment, the thermal diffusivities, $\alpha$, are about

$$
\begin{array}{ll}
\text { copper } & \alpha \simeq 4.28 \mathrm{ft}^{2} / \mathrm{hr}=0.398 \mathrm{~m}^{2} / \mathrm{hr} \\
\text { insulation } & \alpha \simeq 0.03 \mathrm{ft}^{2} / \mathrm{hr}=0.003 \mathrm{~m}^{2} / \mathrm{hr} \\
\text { fluid } & \alpha \simeq 0.0047 \mathrm{ft}^{2} / \mathrm{hr}=0.00044 \mathrm{~m}^{2} / \mathrm{hr}
\end{array}
$$

For the fluid, the time step could be about $0.05 \mathrm{hr} \simeq 3 \mathrm{~min} \simeq 170 \mathrm{sec}$, whereas in copper it would be limited to a much shorter time.

A comparable constraint for the momentum equation would be

$$
\Delta \theta \leq \frac{1}{2} \frac{(\Delta x)^{2}}{\nu}=\frac{1}{2} \frac{(\Delta x)^{2}}{\operatorname{Pr} \cdot \alpha}
$$

where $P_{r}$ is the Prandtl number, $c_{p} \mu / k$. For the viscous fluid of the experiment, the kinematic viscosity, $\nu$, is about $1.56 \mathrm{ft}^{2} / \mathrm{hr}\left(0.145 \mathrm{~m}^{2} / \mathrm{hr}\right)$, so $P r \simeq 330$. Thus, the maximum time step for the explicit solution of the momentum equation would be of the order of $1.5 \times 10^{-4} \mathrm{hr}$ or $0.5 \mathrm{sec}$. (For liquid metals for which the code was developed, $\operatorname{Pr} \ll 1$, so the energy equation would limit the time step if it were solved by an explicit treatment in that case.)

The Courant condition for the transient continuity equation (Roache, 1976) is

$$
\frac{V \Delta \theta}{\Delta x}<1 \quad \text { or } \quad \Delta \theta<\frac{\Delta x}{\mathrm{~V}}
$$

which is infinite at the start of a calculation. From some flow visualization results in the experiment, it is expected to be of the order of 0.6 seconds or more when approaching steady state.

An estimate of a time scale for diffusion across the tube can be taken from the solution for a step change in temperature on the surface of a cylinder (Kreith, 1973). Response to within

$$
\frac{t_{c}-t_{\infty}}{t_{w}-t_{\infty}} \simeq 0.05
$$

occurs before

$$
F o=\frac{\alpha \theta}{r_{w}^{2}} \simeq \frac{1}{2}
$$

Similarly, response to viscous disturbances to the same order would be expected for

$$
\frac{\nu \theta}{r_{w}^{2}}=\operatorname{Pr} \cdot F o \simeq \frac{1}{2} .
$$

With an explicit solution of the momentum equation, the number of time steps to approach a steady fluid-flow solution would be

$$
n=\frac{\theta}{\Delta \theta} \geq\left(\frac{r_{w}}{\Delta x_{\min }}\right)^{2}
$$


where $\Delta x_{\min }$ represents the minimum value of $\Delta r$ or $\Delta z$. On the other hand, to approach a steady thermal flow in the finid would require

$$
n=\frac{\theta}{\Delta \theta} \geq \operatorname{Pr}\left(\frac{r_{w}}{\Delta x_{\min }}\right)^{2}
$$

As an example, for a coarse mesh with $\Delta x_{\min } \simeq r_{w} / 4$ and the viscous fluid used in the experiment $(P r \simeq 330)$, these observations imply that about 16 time steps would be required for fiuid response and over 5000 for thermal! (Since the thermal distribution drives the fluid through buoyancy, it would be expected that the latter would determine the required calculation time.) With time steps of $1.5 \times 10^{-1} \mathrm{hr}$, thermal response times of about three-fourths hour are predicted.

These estimates do not include the response of the insulation, which is estimated to introduce a time constant of about 7 hours. These values agree qualitatively with the measurements of transient temperatures. As noted earlier in the discussion of experimental results, a quasi-steady distribution appeared in about one-half hour, but one-half to one day was necessary before the temperature level could be considered steady.

\subsection{Numerical Prediction Technique - Steady-State Estimate}

Calculations were conducted to obtain steady-state results for the operating conditions of four experiments. These experiments spanned the range of inclination angles and heating rates considered, $0 \leq \phi \leq 35$ and $12 \leq \dot{E} \leq 73$ watts.

Despite applying a very coarse mesh to model the experiment [as in Fig. 4.2(b)], transient calculations were relatively slow. For example, with option PACE enabled, the time step was calculated to be about $2 \times 10^{-5} \mathrm{hr}$, 805000 steps represented $0.1 \mathrm{hr}$ or 6 minutes of simulated time. The total execution time was about 460 seconds or near 8 minutes on the CDC 7600 . That is, simulated time and computer time were nearly the same. Therefore, an alternate technique of estimating the steady distributions was sought.

The TEMPEST code includes an option called TESS (Thermal Energy Steady State), which is used to achieve steady state in systems that are thermally slow in responding. When imposed, it conducts an iterative solution of the steady-state energy equation (storage term suppressed) at each time step using the most recent calculations of the velocity and pressure fields. Thus, this approach can accelerate the determination of the steady flow field if the changes from step to step are not too difficult. One key to this procedure seemed to be ensuring a reasonably well converged solution of the pressure field at each step by keeping the control parameter, PTOL, small.

The procedure that evolved was to apply the TESS option for the first 100 time steps with a limitation of 20 thermal iterations per step, and then to calculate 5000 to 20,000 steps as a simple transient. The initial condition at the first step was taken as the approximate temperature level of the experiment being simulated. However, at the first step the TESS option predicted a much different distribution.

At the first step the uniform initial temperature distribution leads to the calculation of a stagnant flow field, $V=0$. The thermal solution is then a pure conduction problem as described in Section 4.4.1, Steady, One-Dimensional Conduction. The resulting axial temperature gradient would be much larger than observed (a factor of $10^{4}-10^{5}$ according to the simple analysis), but the slow convergence of the steady-state conduction calculation inhibited an extreme value from occurring. Nevertheless, it was necessary to extend the temperature range of the properties table to avoid halting on the first step via an out-of-range diagnostic. 
In the TESS simulation at 53 watts and $35^{\circ}$, the temperatures at the monitor cells were within a few percent (in terms of $t-t_{\text {cooler}}$ ) of the steady-state results in 5 to 10 time steps. Extending the calculation to $\mathbf{1 0 0}$ time steps showed the temperatures to oscillate slightly from step to step. While the amplitude appeared to be decaying at monitor locations on the vertical centerplane, closer inspection showed temperatures at a pair of image cells on either side of the centerplane to be oscillating $180^{\circ}$ out of phase. Longitudinal and radial velocity components off the centerplane oscillated as well, but these velocities were of smaller magnitudes than those on the centerplane. These were apparently related to circumferential velocities alternating in direction; these were also small, $\pm 10^{-4} \mathrm{ft} / \mathrm{sec}\left(3 \times 10^{-5} \mathrm{~m} / \mathrm{sec}\right)$ versus $10^{-2} \mathrm{ft} / \mathrm{sec}\left(3 \times 10^{-3} \mathrm{~m} / \mathrm{sec}\right)$ for comparable longitudinal velocities.

Shifting to the simple transient after 100 TESS time steps gave a gradual approach to steady values through 5000 steps. The slight asymmetries in image points across the centerplane also decreased. From 5000 to 20,000 steps, the transient change in temperatures along the centerplane at $r / r_{w}= \pm 0.82$ was only about $1 \%$ of $t-t_{\text {cooler. }}$ Therefore, results at 5000 time steps, after 100 TESS time steps, were considered to be reasonable estimates of steady-state values.

\subsection{Effects of Heating Rate and Inclination}

Comparisons of the axial temperature profiles predicted via TEMPEST and measured with the immersed thermocouples are presented in Fig. 5.1 for steady state. Solid lines represent the predictions using the coarse grid described earlier and the circular symbols depict the data, all at $r / r_{w}=0.48$, the middle point along a radius in the fluid. For the inclined tube the higher temperatures correspond to the upper sector of the cross section where the heated fluid rises, while the lower temperatures correspond to the lower sector.

Data are not presented in this representation for the experiment at a heating rate of 73 watts since steady-state conditions were not attained. During the measurements it appeared that temperatures in the well heater were nearing the boiling temperature of water at Los Alamos elevation, $7000 \mathrm{ft}(2100 \mathrm{~m})$ MSL, so the voltage across the resistance heater was reduced twice. The final steady condition was reached with 53 watts as shown.

The vertical orientation with heating at 53 watts was set in the laboratory by rotating the tube to $0^{\circ}$ after the steady-state measurements at an angle of $35^{\circ}$ with the same setting on the variable transformer. Therefore, the initial conditions were the pre-existing velocity and temperature distributions for $35^{\circ}$.

An attempt was made to use the steady-state predictions at $35^{\circ}$ and 53 watts as the starting point for the vertical case via the READ option, which starts the calculations from a previously saved restart file. It was found later that the new environmental boundary condition, $t_{\infty}=81.3^{\circ} \mathrm{F}$ $\left(27.4^{\circ} \mathrm{C}\right)$, was not imposed by this procedure so the steady-state predictions were based on the previous condition of $t_{\infty}=71.4^{\circ} \mathrm{F}\left(21.9^{\circ} \mathrm{C}\right)$. (Presumably in setting up the input file for the calculations, the letter $r$ should have been added to column 67 of the "appropriate input card" to enforce a restart with new temperature data, and it was overlooked.) For the predictions presented for the vertical case, the initial conditions were taken as uniform temperature at $135^{\circ} \mathrm{F}\left(57.2^{\circ} \mathrm{C}\right)$ and velocities set at zero.

Agreement is remarkable despite some differences in details. It can be taken as partial confirmation of the usefulness of the TEMPEST computer code and of aspects of the simple analysis.

Along the length of the tube, the temperature variation is very slight as predicted by the simple analysis for inclined tubes. Thus, the temperature level is determined by the energy generation rate from the electrical heater, the cooler temperature at the top end and the thermal resistances to heat 


\section{TEMPERATURE $\left({ }^{\circ} \mathrm{C}\right)$}

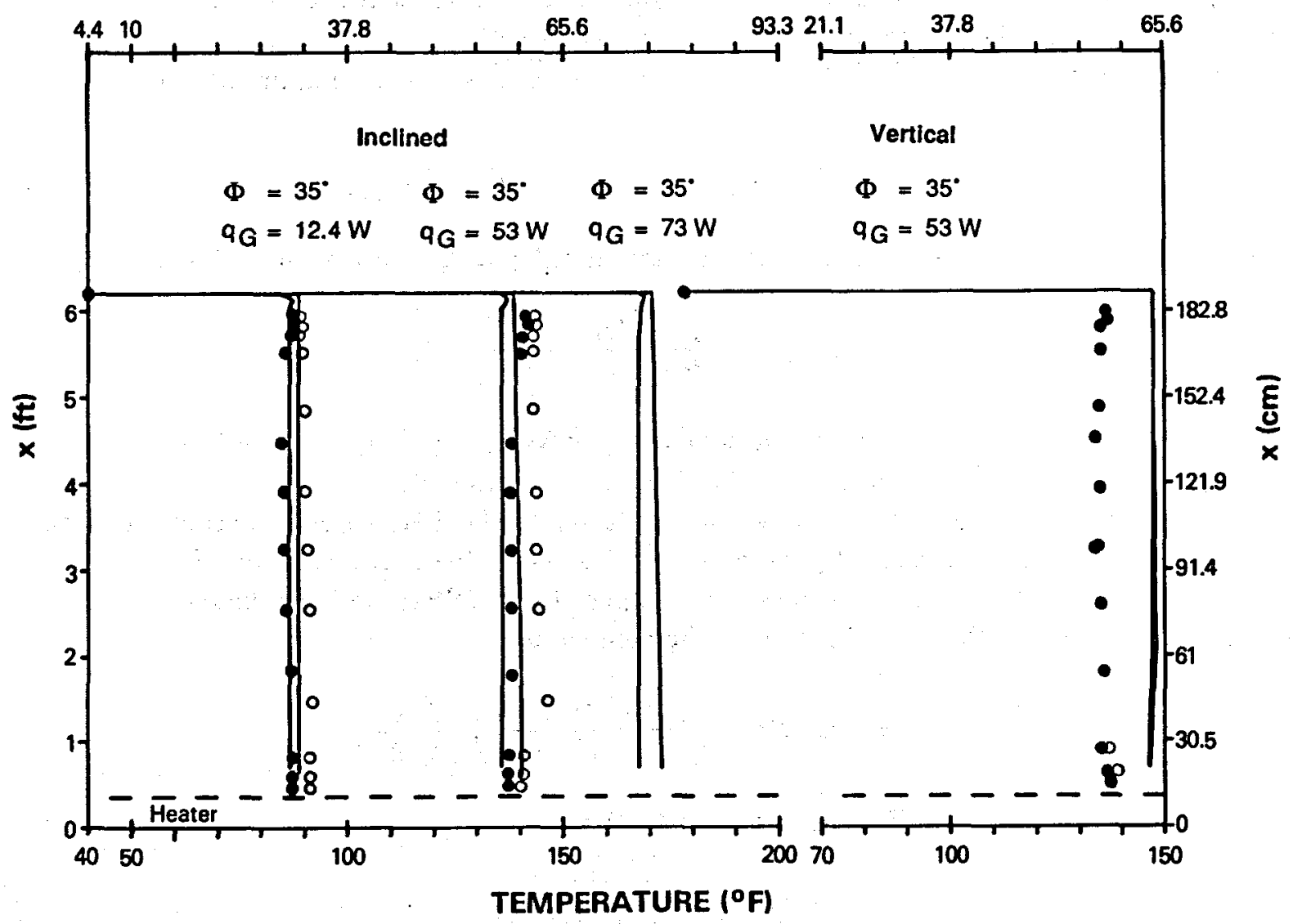

Fig. 5.1. Steady-state predictions compared with measurements.

loss through the insulation and convective heat transfer to the cooler. The cooler acts as the thermal reservoir providing the datum or reference temperature for the experiment.

Since the heat loss coefficient of the apparatus was calibrated by a cooling experiment and then was adopted for the code calculations, the prediction of the heat-transfer loss through the tube walls, vacuum jacket, and insulation can be expected to be reasonably good. In fact, if the heat transfer to the cooler were small, this radial heat loss would dominate in determining the fluid temperature level and these comparisons would not be meaningful tests of the code. This is not the situation in the present study. The heat loss through the insulation and heat transfer to the cooler are estimated to be of the same order of magnitude, ranging from $\left(q_{c} / q_{\ell}\right)=0.8$ to 1.8 for the data shown.

The approximate agreement of temperature levels demonstrates that, despite the coarse mesh, the TEMPEST prediction of the velocity and temperature distributions in the fluid provides a good estimate of the thermal resistance at the cooled upper end.

An average Nusselt number can be calculated for the cooled end as

$$
N u_{c}=\frac{h_{c} D}{k_{c}}=\frac{4 q_{c}}{\pi D k_{c}\left(t_{f}-t_{c}\right)}
$$

where $t_{f}$ could be taken as the fluid temperature in the core of the tube, extrapolated to $z=L$. Since $t(z)$ is almost isothermal at the aspect ratio of the apparatus, an average temperature would be a fair approximation for $t_{f}$. Whether $t_{c}, t_{f}$, or an intermediate (film) temperature is most useful for 
evaluating properties in correlating the data is a question for further research. In the present study the variation of $k(t)$ is slight (and uncertain) (Brzezinski, 1984).

From the numerical predictions, the average Nusselt number could be approximated as

$$
N u_{c}=\frac{q^{\prime \prime}}{\left(t_{f}-t_{c}\right)} \frac{D}{k_{c}} \simeq-\frac{t_{N}-t_{N-1}}{t_{f}-t_{c}} \frac{D}{Z_{N}-Z_{N-1}} .
$$

With the mesh employed, one could use the temperature at $j=2, k=7$ as an estimate of $t_{f}$, giving

$$
N u_{c} \simeq-\frac{t_{12}-t_{11}}{t_{7}-t_{12}} \cdot \frac{2 D}{\Delta z_{\mathrm{N}-1}} .
$$

However, the grid is too coarse for representing $\partial t / \partial z$ by $\Delta t / \Delta z$, so $N u_{c}$ was predicted via the energy balance $\left(q_{c}=q_{G}-q_{L}\right)$ as in the data reduction from the experiment.

The appropriate independent parameter for correlating the heat transfer at the cooled end would be a Rayleigh number or Grashof number, based on heat-transfer rate or temperature difference. Provided the aspect ratio, $L / D$, is long enough, one would expect the result to be independent of aspect ratio. The Rayleigh number for the enclosed end can be defined as

$$
R a_{c}=G r_{c} \cdot \operatorname{Pr}=\left(\frac{\rho^{2} g \beta D^{4}\left(q_{c}^{\prime \prime} / k\right)}{\mu^{2}}\right) \cdot\left(\frac{c_{p} \mu}{k}\right) .
$$

$G r_{c}$ relates to $G r_{E}$, defined via Eqs. (2-17) and (2-13) as

$$
\frac{G r_{c}}{G r_{E}}=\left(\frac{D}{D_{h h}}\right)^{4}=O\left(2^{4}\right)
$$

Again, the question arises concerning which temperature(s) to use in evaluating the fluid properties. In the idealized problem for the end of a tube, the known conditions would probably be a) $t_{f}$ and $t_{c}$ or b) $q_{c}^{\prime \prime}$ and $t_{f}$, plus $\rho(t)$ and $\mu(t)$ and the geometry and inclination. For the present data reduction, the properties were evaluated at two temperatures for the experimental measurements: $t_{c}$ and $t_{f} \simeq t_{\mathrm{avg}}$. Predictions were calculated with constant properties, other than in the Boussinesq approximation, with $100^{\circ} \mathrm{F} \simeq 38^{\circ} \mathrm{C}$ taken as the fluid temperature.

The measurements and predictions of $N u_{c}\left(R a_{c}\right)$ are compared in Fig. 5.2 for the three steadystate results. The solid line represents the predicted trend based on the two sets of calculations at an angle of $35^{\circ}$, while the dashed line below shows the prediction for the vertical tube based on a single calculation. Circular symbols show the data when $t_{c}$ is used to evaluate fluid properties, and squares are for $N u_{c}$ and $R a_{c}$ based on an approximate average fluid temperature. The solid symbols are for the vertical tube, and the open ones are for the angle of $35^{\circ}$.

One sees better agreement when $R a_{c}$ is based on properties evaluated in the fluid away from the cooled surface; these properties would be comparable to the freestream in an external flow. Since $R a_{c}$ (or $R a_{E}$ ) can be considered to be the driving parameter for the natural circulation, it may be reasonable to expect its value away from the surface to determine the strength of the recirculating flow field, which serves approximately as a boundary condition for the heat transfer to the end region. However, this ambiguity concerning the property evaluation and the large difference in resulting Rayleigh numbers may be an indication that the agreement of the temperature distributions is fortuitous.

While the trend of increase in $N u_{c}$ with increase in heating rate $\left(R a_{c}\right)$ is seen in both the predictions and data for the $35^{\circ}$ angle, the variation with angle differs. In the predictions $N u_{c}$ is reduced about 


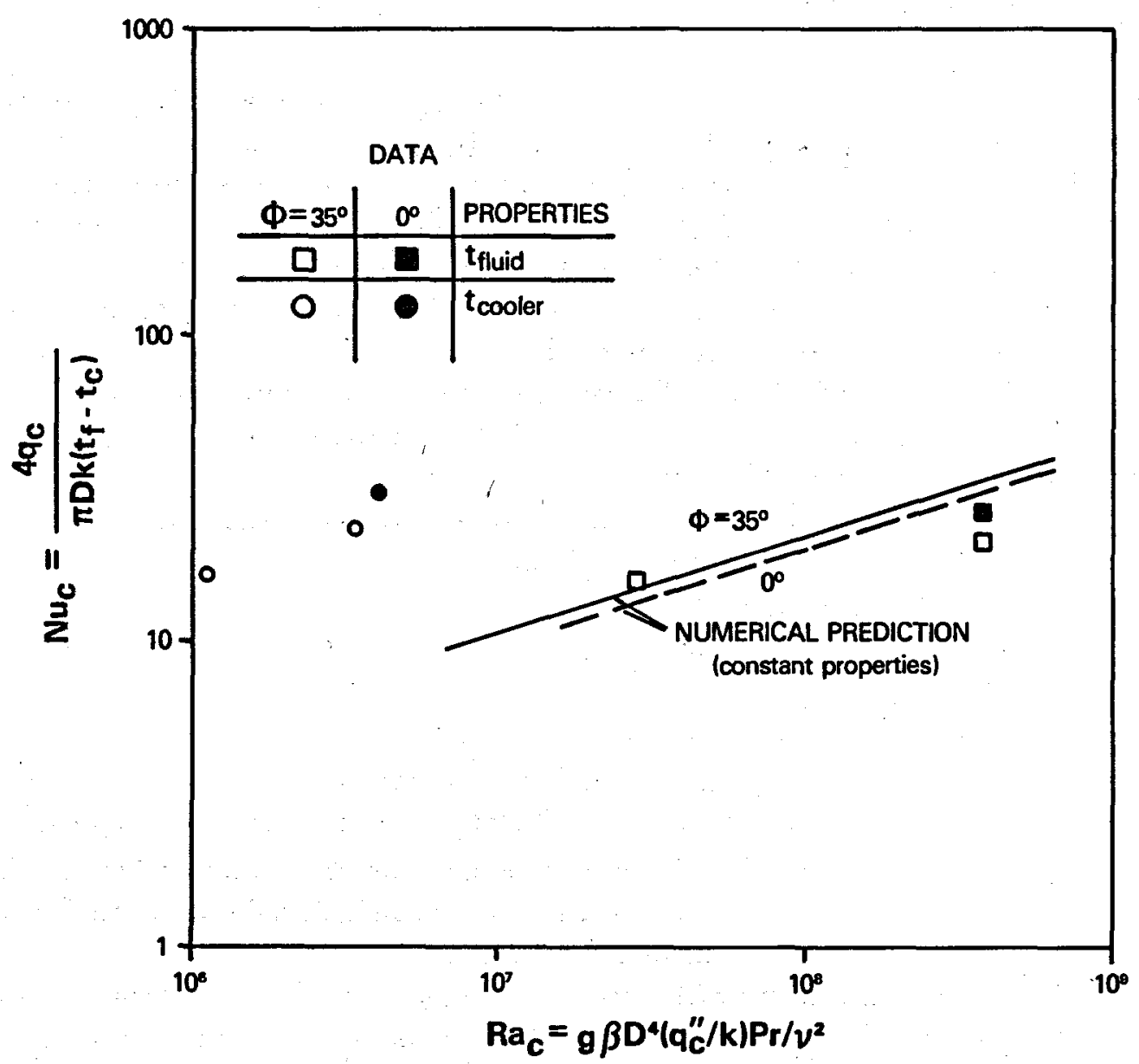

Fig. 5.2. Convective heat transfer at cooled end. Measurements compared with numerical predictions.

$10 \%$ by changing the angle from $35^{\circ}$ to vertical. On the other hand, the measurements show an increase of 15 to $20 \%$ percent. Since the calculations were for laminar flow, this observation may imply that the flow in the vertical orientation is unstable, turbulent, or involves more recirculating cells than predicted. It should be recalled that, in the simple analysis, application of Hines (1971) treatment of nonhorizontal shear layers led to

$$
R i \sim \frac{\cos (\pi / 2-\phi)}{\cos ^{3 / 2} \phi}
$$

which is zero for vertical tubes. Values less than one-fourth are believed to be unstable. This result implies that countercurrent flow consisting of a single, long cell is inherently unstable in the vertical configuration. A turbulent or unstable flow would be expected to provide better transport of thermal energy to the end surface than laminar flow and, therefore, increase the Nusselt number. Further calculations with the code, and perhaps additional experiments, are necessary to resolve these aspects of the problem. 


\section{CONCLUDING REMARKS}

Natural convection in inclined tubes with heat loss through the wall was studied analytically and numerically, and the predictions have been compared with measurements taken in a comparable experiment at the Los Alamos National Laboratory. Although the results should be considered primarily qualitative rather than quantitative, useful insight evolved. The following tasks were accomplished:

- A simple analysis was completed for natural convection with an adiabatic wall.

- Experiments were conducted in inclined and vertical tubes for a range of heating rates.

- General purpose flow codes were surveyed.

- The TEMPEST code from Battelle Pacific Northwest Laboratory was selected.

- TEMPEST predictions were tested versus limiting analyses and the range of data available for heating rate and inclination angle.

The simple analysis for long, inclined, adiabatic tubes predicted that, under the idealizations imposed, the effects of increasing the heating rate $\dot{E}$ are

- to increase the induced flow rate as $\sqrt{\dot{E}}$,

- to increase $\left(t_{h}-t_{c}\right)$ as $\sqrt{\dot{E}}$, and

- to leave $d t / d x$ constant.

Consequently, away from ends, the Rayleigh number based on streamwise temperature gradient is predicted to be a function of geometry and inclination only, varying as $1 / \cos \phi$. The stability of the hypothesized countercurrent flow, consisting of a single, long cellular pattern, was represented in terms of a Richardson number; this number is a function of inclination and varies as $1 / \sqrt{\dot{E}}$. Small values indicate potential instability, so increasing the heating rate or reducing the angle toward the vertical tends to make the single cell unstable to small disturbances.

TEMPEST is a versatile, transient hydrothermal computer program. Since it solves the momentum equations by explicit techniques, it can require considerable computer time to approach steady state in thermal problems at high Prandtl numbers. Options are included that can accelerate the approach to steady state in some conditions.

It can be concluded that the TEMPEST code is a promising approach to solution of the threedimensional natural circulation and heat transfer that is induced in an inclined circular tube heated at the bottom and cooled both at the top and through the tube wall. The full three-dimensional code was tested by comparison with the following limiting analyses:

- steady, one-dimensional, axial conduction (slow convergence in some configurations);

- transient approach to steady state with one-dimensional axial conduction;

- transient, one-dimensional radial conduction; and

- transient approach to one-dimensional fin (extended surface) solution.

The results for the latter three cases were reasonable for the coarse grid used and were as expected.

Predictions were conducted for comparison with four experiments over a range of heating rates from 12 to 73 watts and inclination angles from vertical to $35^{\circ}$. Laminar flow of a constant property fluid was assumed under the Boussinesq approximation, and a coarse grid with variable spacing was employed to reduce storage and computer time. Even so, central processing time with a CDC 7600 was of the same order of magnitude as the simulated time in transient calculations.

In general, the axial spacing was too large to resolve details of multiple small-scale flow cells that may occur in unstable situations. Comparison with experiments showed good agreement of temperatures for the limiting inclination of $35^{\circ}$ and slightly poorer agreement for the other limit, a vertical tube. Trends of temperature and Nusselt number with heating rate or Rayleigh number were reasonable, but the variation of (cooled) end Nusselt number with inclination was opposite to that observed 
in the experiment. Further study is needed to understand this latter observation, but the measured increase in Nusselt number was consistent with simple stability theory coupled with the predictions of a simple analysis.

\section{RECOMMENDATIONS FOR FURTHER WORK}

There are a number of aspects of this study where further work would be warranted. Some are

- extending the numerical predictions to account for property variation with temperature, particularly viscosity;

- conducting more detailed examination and comparison of the four situations studied plus additional intermediate cases;

- testing the transient behavior with comparison to initial transients in the experiments;

- investigating vertical and near-vertical situations in more detail, searching for temporal instabilities and multiple solutions;

- developing alternate calculation techniques to accommodate potential multicellular flow patterns;

- examining predieted flow patterns in end regions with finer grids; and

- obtaining additional data for near-vertical conditions.

\section{ACKNOWLEDGMENTS}

George Zyvoloski of Los Alamos National Laboratory provided the support necessary to use the Laboratory's CDC 7600; Loren Eyler of Battelle Pacific Northwest Laboratory made the TEMPEST code available and provided guidance in its use. Withont their help, these predictions could not have proceeded as far as they did. We are extremely grateful to both. Numerical predictions were conducted under subcontract 9-X85-R6899-1 from Los Alamos National Laboratory to Gould Ocean Systems Division, Middletown, Rhode Island. 


\section{REFERENCES}

Abdulmeguid, A. M., and D. B. Spalding, 1979. J. Fluid Mech., 04, pp. 383-400.

Al-Arabi, M., and Y. K. Salman, 1980. Int. J. Heat Mass Transfer, 23, pp. 45-51.

Amsden, A. A., and F. H. Harlow, 1970. J. Comput. Phys., 6, pp. 322-325.

Baker, D. J., 1966. J. Fluid Mech., 26, pp. 573-575.

Batchelor, G. K., 1954. Q. Appl. Math., 12, pp. 209-233.

Bejan, A., and A. N. Rossie, 1981. J. Heat Transfer, 103, pp. 108-113.

Benard, H., 1900. Rev. Gen. Sci. Pures Appl., 11, pp. 1261-1271.

Brzezinski, A. J., 1984. Dynatech Company letter LOS-1 of 10 July 1984.

Buchberg, H., I. Catton, and D. K. Edwards, 1976. J. Heat Transfer, 88, pp. 182-188.

Catton, I., 1978. Proc., 6th Int. Heat Thansfer Conf., Toronto, 2, pp. 13-31.

Catton, I., and D. K. Edwards, 1967. J. Heat Transfer, 89, pp. 295-299.

Charlson, G. S., and R. L. Sani, 1970 Int. J. Heat Mass Transfer, 13, pp. 1479-1496.

Charlson, G. S., and R. L. Sani, 1971. Int. J. Heat Mass Transfer, 14, pp. 2157-2160.

Cheng, K. C., and S. W. Hong, 1972a. Appl. Sci. Res., 27, pp. 19-38.

Cheng, K. C., and S. W. Hong, 1972b. Sol. Energy, 13, pp. 363-371.

Chung, K. C., and L. M. Trefethen, 1982. Int. J. Heat Mass Transfer, 25, pp. 277-284.

Combarnous, M., 1978. Natural convection in porous media and geothermal systems. Proc., 6th Int. Heat Transfer Conf., Toronto.

Diment, W. H., 1967. Geophysics, 32, pp. 720-726.

Donaldson, I. G., 1961. Aust. J. Phys., 14, pp. 529-539.

Donaldson, I. G., 1968. Proc., 3rd Australasian Conf. Hydraulics and Fluid Mech., pp. 200-204.

Donaldson, I. G., 1970. Geothermics - Spec. Issue 2, pp. 649-654.

Edwards, A. L., 1972. Technical report UCRL-14754 (Rev. 3).

Edwards, D. K., 1969. J. Heat Transfer, 81, pp. 145-150.

Edwards, D. K., and I. Catton, 1969. Int. J. Heat Mass Transfer, 12, pp. 23-30.

Einarsson, T., 1942. Rit. Visind. Isl., 26, pp. 1-92 (in German).

el Sherbiny, S. M., G. D. Raithby, and K. G. T. Hollands, 1982. J. Heat Transfer, 104, pp. 96-102.

Eyler, L. L., 1985. Personal communication, Battelle Pacific Northwest Laboratory. 
Eyler, L. L., D. S. Trent, and M. J. Budden, 1983. Battelle Pacific Northwest Laboratory technical report PNL-4348 Vol. II, UC 79T.

Frankel, S. P., 1950. Math. Tables Aids Comp., IV, pp. 65-75.

Geary, M., 1984. Personal communication, Air Products Company.

Gosman, A. D., and W. M. Pun, 1973. Lecture notes for course entitled "Calculation of recirculating flows." Report HTS/74/2, Mechanical Engineering Department, Imperial College, London.

Gretener, P. E., 1967. Geophysics, 32, pp. 727-738.

Hales, A. L., 1937. R. Astrophys. Soc. Geophys. Suppl., 4, pp. 122-131.

Hartnett, J. P., and W. E. Welsh, 1957. Trans. ASME., 79, pp. 1551-1557.

Hartnett, J. P., W. E. Welsh, and F. W. Larsen, 1959. Chem. Eng. Prog., Symp. Ser., Nucl. Eng., 55, p. 85.

Hasegawa, S., K. Nishikawa, and K. Yamagata, 1963. Bull. Japan Soc. Mech. Eng., 6, pp. 230-250.

Hazel, P., 1972. J. Fluid Mech., 51, p. 39.

Heitz, W. L., and J. W. Westwater, 1971. J. Heat Transfer, 93, pp. 188-196.

Hess, S. L., 1959. Introduction to Theoretical Meteorology. New York: Holt, Rinehart, and Winston.

Hines, C. O., 1971. Q. J. R. Meteorol. Soc., 97, pp. 429-439.

Holman, J. P., 1976. Heat Transfer. New York: McGraw-Hill.

Incropera, F. P., and D. P. deWitt, 1981. Fundamentals of Heat Transfer. New York: Wiley.

Japiske, D., 1973. Adv. Heat Transfer, 8, pp. 1-111.

Johnson, A. E., and D. Torok, 1985. Comput. Mech. Eng., pp. $41-45$ (July 1985).

Jones, G. F., 1986. J. Sol. Energy Sci. Eng., 108, pp. 163-171.

Kays, W. M., and A. LLondon, 1964. Compact Heat Exchangers, 2nd ed. New York: McGraw-Hill.

Kimura, S., and A. Bejan, 1980a. Int. J. Heat Mass Transfer, 23, pp. 1117-1126.

Kimura, S., and A. Bejan, 1980b. Wärme and Stoffübertragung, 14, pp. 269-280.

Kreith, F., 1973. Principles of Heat Transfer, 3rd ed. Scranton: Intext.

Krige, L. J., 1939. Proc.. R. Soc. London, 173A, pp. 450-474.

Leslie, F. M., 1959. J. Fluid Mech., 7, p. 115.

Lighthill, M. J., 1953. Q. J. Mech. Appl. Math., 6, pp. 398-439.

Lockwood, F. C., and B. W. Martin, 1964. J. Mech. Eng. Sci., 6, pp. 379-393.

Martin, B. W., 1959. Proc., Inst. Mech. Eng., 173, pp. 761-778.

McEligot, D. M., 1985. Gould, Inc., technical report OSD-771-HYDRO-CR-85-06. 
McEligot, D. M., M. F. Taylor, and F. Durst, 1977. Int. J. Heat Mass Transfer, 20, pp. 475-486.

Mertol, A., W. Place, T. Webster, and R. Greif, 1981. Sol. Energy, 27, pp. 367-386.

Murphy, H. D., 1984. Personal communication, Los Alamos National Laboratory.

Olson, J. M., and F. Rosenberger, 1979. J. Fluid Mech., 92, pp. 609-629 and 631-642.

Ostrach, S., 1953. NACA report 1111.

Ostrach, S., 1982. Proc., 7th Int. Heat Transfer Conf., München.

Ostrach, S., and P. R. Thornton, 1958. Trans., ASME, 80, p. 363.

Ostroumov, G. A., 1952. NACA technical memorandum 1407 (1958).

Ozoe, H., T. Shibata, and S. W. Churchill, 1981. Int. J. Heat Mass Transfer, 24, pp. 727-737.

Roache, P. J., 1976. Computational Fluid Dynamics. Albuquerque: Hermosa.

Rosten, H. I., D. B. Spalding, and D. G. Tatchell, 1983. Proc., Srd Int. Conf. Eng. Software, pp. 639. 655 .

Rowley, J. C., and R. S. Carden, 1982. Los Alamos National Laboratory report LA-9512-HDR.

Schlichting, H., 1968. Boundary Layer Theory. New York: McGraw-Hill.

Shah, R. K., and A. L. London, 1978. Laminar flow forced convection in ducts, Adv. Heat Transfer, Supplement 1. New York: Academic Press.

Smith, M. C., G. J. Nunz, and G. M. Ponder, 1983. Los Alamos National Laboratory report LA-9780HDR.

Takata, Y., K. Iwashige, K. Fukuda, and S. Hasegawa, 1984. Int. J. Heat Mass Transfer, 27, pp. 747754.

Trefethen, L. M., 1970. Proc., 4th Int. Heat Transfer Conf., Paper NC 2.12, Versailles.

Trent, D. S., L. L. Eyler, and M. J. Budden, 1983. Battelle Pacific Northwest Laboratory technical report PNL-4348, Vol I, UC-79T, Rev. 1.

Verhoeven, J. D., 1969. Phys. Fluids, 12, pp. 1733-1740.

Zvirin, Y., A. Shitzer, and G. Grossman, 1977. Int. J. Heat Mass Transfer, 20, pp. 997-999. 


\section{APPENDIX}

\section{MEASURED STEADY-STATE TEMPERATURE DISTRIBUTIONS}


TABLE A.1. STEADY-STATE TEMPERATURES, LOW POWER, INCLINED

$$
\begin{array}{lll}
\text { Date: } 21 \text { June } 1984 & \text { Time: } 0803 \text { Angle }=35^{\circ}, \text { Power }=12.4 \mathrm{~W} \\
\text { SCAN } 150 & \text { Disk } 1 & \text { Voltage }=19.76 \mathrm{~V} \quad t_{\infty}=25.73^{\circ} \mathrm{C}=78.3^{\circ} \mathrm{F} \\
Q_{c}=1.1 \mathrm{ml} / \mathrm{s} & t_{c, \text { in }}=2.72^{\circ} \mathrm{C}=36.9^{\circ} \mathrm{F}, \quad t_{c, \text { out }}=4.13^{\circ} \mathrm{C}=39.4^{\circ} \mathrm{F}
\end{array}
$$

\begin{tabular}{|c|c|c|c|c|c|c|c|c|}
\hline \multirow[b]{2}{*}{$\begin{array}{r}z_{\exp } \\
\text { (cm) }\end{array}$} & \multirow[b]{2}{*}{$\stackrel{\mathrm{z}}{(\mathrm{cm})}$} & \multirow[b]{2}{*}{$\begin{array}{l}\mathrm{z} \\
\text { (ft) }\end{array}$} & \multicolumn{3}{|c|}{ Left $=$ upper $\left({ }^{\circ} \mathrm{C} /{ }^{\circ} \mathrm{F}\right)$} & \multicolumn{3}{|c|}{ Right $=$ lower $\left({ }^{\circ} \mathrm{C} /{ }^{\circ} \mathrm{F}\right)$} \\
\hline & & & $r / r_{w}=0.85$ & 0.48 & 0.17 & 0.17 & 0.48 & 0.85 \\
\hline 4.0 & 15.4 & 0.505 & - & $32.6 / 90.7$ & - & - & $30.7 / 87.3$ & - \\
\hline 6.9 & 18.3 & 0.600 & - & $32.8 / 91.0$ & - & - & $30.8 / 87.4$ & - \\
\hline 13.8 & 25.2 & 0.827 & - & $32.9 / 91.2$ & - & - & $30.7 / 87.3$ & - \\
\hline 33.9 & 45.3 & 1.486 & $33.6 / 92.5$ & $33.5 / 92.3$ & $32.7 / 90.9$ & - & - & - \\
\hline 43.0 & 54.4 & 1.785 & - & - & - & $30.7 / 87.3$ & $30.6 / 87.0$ & $30.3 / 86.5$ \\
\hline 66.4 & 77.8 & 2.552 & - & $33.1 / 91.6$ & - & - & $30.4 / 86.7$ & - \\
\hline 87.1 & 98.5 & 3.232 & $32.8 / 91.0$ & $32.8 / 91.0$ & $32.4 / 90.3$ & - & $30.3 / 86.5$ & - \\
\hline 107.4 & 118.8 & 3.898 & - & $32.6 / 90.7$ & - & - & $30.0 / 86.0$ & - \\
\hline 125.0 & 136.4 & 4.475 & - & - & - & $30.7 / 87.3$ & $29.7 / 85.5$ & $29.1 / 84.4$ \\
\hline 136.4 & 147.8 & 4.849 & $32.3 / 90.1$ & $32.3 / 90.1$ & $32.2 / 90.0$ & - & - & - \\
\hline 156.1 & 167.5 & 5.495 & - & $32.1 / 89.8$ & - & - & $30.0 / 86.0$ & - \\
\hline 163.9 & 175.3 & 5.751 & - & $32.1 / 89.8$ & - & - & $30.8 / 87.4$ & \\
\hline 167.1 & 178.5 & 5.856 & - & $32.3 / 90.1$ & - & - & $31.0 / 87.8$ & - \\
\hline 169.6 & 181.0 & 5.938 & - & $32.0 / 89.6$ & - & - & $30.8 / 87.4$ & - \\
\hline
\end{tabular}


TABLE A.2. STEADY-STATE TEMPERATURES, MODERATE POWER, INCLINED

Date: 28 June 1984 Time: 0858 Angle $=35^{\circ}$, Power $=53.04 \mathrm{~W}$

SCAN 92 Disk 2 Voltage $=41.63 \mathrm{~V} \quad t_{\infty}=21.91^{\circ} \mathrm{C}=71.4^{\circ} \mathrm{F}$

$t_{c, \text { in }}=1.72^{\circ} \mathrm{C}=35.0^{\circ} \mathrm{F}, \quad t_{c, \text { out }}=4.48^{\circ} \mathrm{C}=40.1^{\circ} \mathrm{F}$

Left $=$ upper $\left({ }^{\circ} \mathrm{C} /{ }^{\circ} \mathrm{F}\right)$

Right $=$ lower $\left({ }^{\circ} \mathrm{C} /{ }^{\circ} \mathrm{F}\right)$

\begin{tabular}{|c|c|c|c|c|c|c|c|c|}
\hline $\begin{array}{r}z_{\exp } \\
(\mathrm{cm})\end{array}$ & $(\mathrm{cm})$ & $\begin{array}{l}z \\
(f t)\end{array}$ & $r / r_{w}=0.85$ & 0.48 & 0.17 & 0.17 & 0.48 & 0.85 \\
\hline 4.0 & 15.4 & 0.505 & - & $60.1 / 140.2$ & - & - & $58.7 / 137.7$ & - \\
\hline 6.9 & 18.3 & 0.600 & $\because \quad-$ & $60.3 / 140.5$ & - & - & $58.6 / 137.5$ & - \\
\hline 13.8 & 25.2 & 0.827 & - & $60.5 / 140.9$ & - & - & $58.6 / 137.5$ & - \\
\hline 33.9 & 45.3 & 1.486 & $64.9 / 148.8$ & $63.8 / 146.8$ & $60.4 / 140.7$ & - & - & - \\
\hline 43.0 & 54.4 & 1.785 & $\therefore \quad-$ & - & - & - 59.2/138.6 & $59.0 / 138.2$ & $57.5 / 135.5$ \\
\hline 66.4 & 77.8 & 2.552 & - & $62.5 / 144.5$ & - & - & $58.9 / 138.0$ & - \\
\hline 87.1 & 98.5 & 3.232 & $63.0 / 145.4$ & $62.3 / 144.1$ & $61.1 / 142.0$ & - & $59.2 / 138.6$ & - \\
\hline 107.4 & 118.8 & 3.898 & - & $62.4 / 144.3$ & - & - & $58.9 / 138.0$ & - \\
\hline 125.0 & 136.4 & 4.475 & - & - & - & $60.7 / 141.3$ & $59.0 / 138.2$ & $55.4 / 131.7$ \\
\hline 136.4 & 147.8 & 4.849 & $62.2 / 144.0$ & $61.9 / 143.4$ & $61,6 / 142.9$ & - & - & - \\
\hline 156.1 & 167.5 & 5.495 & $\therefore-$ & $61.8 / 143.2$ & - & - & $60.3 / 140.5$ & - \\
\hline 163.9 & 175.3 & 5.751 & - & $61.8 / 143.2$ & - & - & $61.0 / 141.8$ & 一 \\
\hline 167.1 & 178.5 & 5.856 & - & $62.1 / 143.8$ & - & - & $61.2 / 142.2$ & - \\
\hline 169.6 & 181.0 & 5.938 & - & $61.7 / 143.1$ & - & - & $61.0 / 141.8$ & - \\
\hline
\end{tabular}


TABLE A.3. STEADY-STATE TEMPERATURES, MODERATE POWER, VERTICAL

Date: 29 June 1984 Time: 1344 Angle $=0^{\circ}$ (vertical), Power $=52.9 \mathrm{~W}$

SCAN 111 Disk $2 \quad$ Voltage $=41.57 \mathrm{~V} \quad t_{\infty}=27.39^{\circ} \mathrm{C}=81.3^{\circ} \mathrm{F}$

$t_{c, \text { in }}=1.94^{\circ} \mathrm{C}=35.5^{\circ} \mathrm{F}, \quad t_{c, \text { out }}=3.61^{\circ} \mathrm{C}=38.5^{\circ} \mathrm{F}$

\begin{tabular}{rrr}
$\begin{array}{r}\text { Zexp } \\
(\mathbf{c m})\end{array}$ & $\begin{array}{c}z \\
(\mathrm{~cm})\end{array}$ & $\begin{array}{c}z \\
(\mathrm{ft})\end{array}$ \\
\hline & & \\
4.0 & 15.4 & 0.505 \\
6.9 & 18.3 & 0.600 \\
13.8 & 25.2 & 0.827 \\
33.9 & 45.3 & 1.486 \\
43.0 & 54.4 & 1.785 \\
66.4 & 77.8 & 2.552 \\
87.1 & 98.5 & 3.232 \\
107.4 & 118.8 & 3.898 \\
125.0 & 136.4 & 4.475 \\
136.4 & 147.8 & 4.849 \\
156.1 & 167.5 & 5.495 \\
163.9 & 175.3 & 5.751 \\
167.1 & 178.5 & 5.856 \\
169.6 & 181.0 & 5.938
\end{tabular}$$
r / r_{w}=0.85
$$

Left $=$ upper $\left({ }^{\circ} \mathrm{C} /{ }^{\circ} \mathrm{F}\right)$

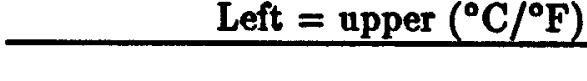

0.48

0.17

-

59.3/138.7

-

$56 . \overline{1} / 133.5$

-

$55.8 / 132.4$

-

-

-
$58.3 / 136.9$

$58.2 / 136.8$

$58.3 / 136.9$

$59.9 / 139.8$

57.7/135.9

$57.6 / 135.7$

$57.1 / 134.8$

$-$

$57.2 / 135.0$

$57.2 / 135.0$

$57.4 / 135.3$

$58.0 / 136.4$

57.8/136.0

-
$\overline{-}$
$59.4 / 138.9$
-
$\overline{-}$
$58.5 / 137.3$
-
$\overline{-}$
$58.6 / 137.5$
-
-
-

\begin{tabular}{ccc}
\hline & & \\
0.17 & 0.48 & 0.85 \\
- & $58.4 / 137.1$ & - \\
- & $59.5 / 139.1$ & - \\
- & $\mathbf{5 7 . 3 / 1 3 5 . 1}$ & - \\
- & - & - \\
$\mathbf{5 8 . 2 / 1 3 6 . 8}$ & $\mathbf{5 7 . 7 / 1 3 5 . 9}$ & $\mathbf{5 5 . 9 / 1 3 2 . 6}$ \\
- & $\mathbf{5 7 . 4 / 1 3 5 . 4}$ & - \\
- & $\mathbf{5 6 . 9 / 1 3 4 . 4}$ & - \\
- & $\mathbf{5 7 . 4 / 1 3 5 . 3}$ & - \\
$\mathbf{5 8 . 7 / 1 3 7 . 7}$ & $\mathbf{5 6 . 9 / 1 3 4 . 4}$ & $\mathbf{5 5 . 7 / 1 3 2 . 3}$ \\
- & - & - \\
- & $\mathbf{5 7 . 4 / 1 3 5 . 3}$ & - \\
- & $\mathbf{5 7 . 8 / 1 3 6 . 0}$ & - \\
- & $\mathbf{5 7 . 9 / 1 3 6 . 2}$ & - \\
- & $\mathbf{5 7 . 9 / 1 3 6 . 2}$ & -
\end{tabular}

Right $=$ lower $\left({ }^{\circ} \mathrm{C} /{ }^{\circ} \mathrm{F}\right)$ 
This report has been reproduced directly from

the best available copy.

Avallable w DOE and DOE contractors from

the Office of Scientific and Toctnical Information P.0. Box 62

Oit Ridge, TN 37831

prices aveilable from

(615) 576-8401, FTS 626-8401

Availuble to the public from

the National Technical Information Service

U.S. Department of Commerce

S285 Port Royal RA.

Springfield, VA 22161

Micsofiche A0I

NTtS

Page Range Price Code

Nits

Page Range Price Code

co1-02s

$\infty 1-025$
$026-050$

051-075

076-100

$101-125$

$A 02$

151-175 A0s

176-200

201-225

226-250

251-275

AO9

A10

AOS

106

$276-300$

A11
A12
A13

Pange

301-325 A14

326-350

351-375

A15

$376-400 \quad A 17$

$\begin{array}{ll}401-425 & A 18 \\ 426-450 & A 19\end{array}$

- Contect NTIS for a price quote. 


\section{UJ NUI S BCROFIIS \\ Coliti}

